\title{
IRRIGATION ASSESSMENT VIA REMOTE SENSING AND LAND SURFACE MODEL DATA
}


Examining committee:

Prof. dr. ing. W. Verhoef

Prof. dr. J.C.J. Kwadijk

Prof. dr. L. Jia

Prof. dr. W.G.M. Bastiaanssen

Prof. dr. J.A. Sobrino
University of Twente, ITC

University of Twente, CTW/Deltares CAS/Alterra

Technische Univ. Delft

Univ. Valencia

ITC dissertation number 259

ITC, P.O. Box 217, 7500 AA Enschede, The Netherlands

ISBN 978-90-365-3791-9

DOI: $10.3990 / 1.9789036537919$

Cover designed by Mireia Romaguera Albentosa

Printed by ITC Printing Department

Copyright (c) 2014 by Mireia Romaguera Albentosa

1日- FACULTY OF GEO-INFORMATION SCIENCE AND EARTH OBSERVATION 


\title{
IRRIGATION ASSESSMENT VIA REMOTE SENSING AND LAND SURFACE MODEL DATA
}

\author{
DISSERTATION
}

\section{to obtain}

the degree of doctor at the University of Twente, on the authority of the rector magnificus, prof.dr. H. Brinksma, on account of the decision of the graduation committee, to be publicly defended

on Wednesday $12^{\text {th }}$ November 2014 at 14:45 hrs

Mireia Romaguera Albentosa

born on $26^{\text {th }}$ April 1979

in Valencia (Spain) 
This thesis is approved by

Prof. dr. Z. Su, supervisor

Prof. dr. ir. A. Y. Hoekstra, supervisor

Dr. ir. M. S. Salama, co-supervisor

Dr. M. S. Krol, co-supervisor 


\section{Acknowledgements}

Doing a PhD with two promoters and two supervisors from different disciplines is a challenging experience. Bob and Suhyb (from ITC), Arjen and Maarten (from CTW), thank you. From you I have learned to look at my research from multiple perspectives. I really appreciate your confidence in my way of working and your support and feedback during our scientific discussions. I would also like to thank you Bob, for your kindness and help since we first met in 2004 .

Other relevant people that have contributed to my research are Joris and Wim from ITC. Thanks for our talks about technical and scientific issues which inspired me and gave me new ideas. Also thanks to Xuelong for providing me the data needed for my application chapter. And Mesfin from CTW, thank you for helping me with issues about the green and blue water concepts, data and literature.

I would like to thank the PhD community at the Water Resources department at ITC, with whom I have shared and enjoyed the Water PhD Workshops and many other social activities like the international cooking sessions. Amongst them, Enrico, Mustafa, Yijian, Ying, Chandra, Xuelong, Tina, Donghai, Shaoning and the temporary visitors Rafa, Nuria, Ana Andreu and Ana Cano, thanks for your friendship and support.

I would also like to thank my colleagues at the Water Engineering and Management group at CTW faculty, especially for the nice moments shared, including the private dancing sessions. Amongst them, Blanca, Mehmet, Marcela, Nico, Freek, Guoping, Erika, Maite, Markus and Joep S.

Probably music was the most important extra-academic activity during my years in Enschede. Here is where I started playing drums, composed music and enjoyed playing with two bands. Thanks a lot for the fun I had in Ken Lee with Özgün, Mustafa, Enrico and Yiannis, and later on in Swafflers with Juantxo, Enrico and Joep. I also followed the local scene and during quite a lot of time was part of the 'Rimon' crew as a photographer. Thank you Gerard, Diego, Rimon, Joey and Jochem for your really nice musical vibes. Besides, if there is somebody that from the beginning pushed and believed in my 
melancholic music creations (even remixing them), those were the guys from HaaH and Symptoms of Reality, thanks a lot for your support.

'Mens sana in corpore sano'. With that quotation I'd like to thank Linda and her zumba lessons and all endorphins generated, to which I can say I am addicted since I started dancing five years ago. Also many thanks to the 'Catch up' club for giving me the opportunity to learn a bit more about juggling. I really enjoyed juggling and playing with pois, the unicycle and the slackline. N.B. enjoying does not mean mastering the discipline, just for clarification.

Ivo and Blanca are my paranymphs, and it could not be better since they are two of my best good friends, full of good energy and positivism, always supporting me in my scientific and artistic projects. When I think about it, I smile and feel lucky for having them around.

Last but not least, I want to thank my friends in Valencia, especially to Ivan, Raquel and Estela for the nice (music) experiences and passions that we share; to my brother Enric because he is an inexhaustible source of inspiration to find and bring out the artistic spirit that lies inside me; to my parents Enric and Dora for the way they raised me, their support from the distance and their experienced points of view; and to Juantxo for being so confident in me, for his day by day support and for all the fun we have together.

All in all, thank you everybody for the support, the friendship, the music and all the nice experiences we share. 
Table of Contents

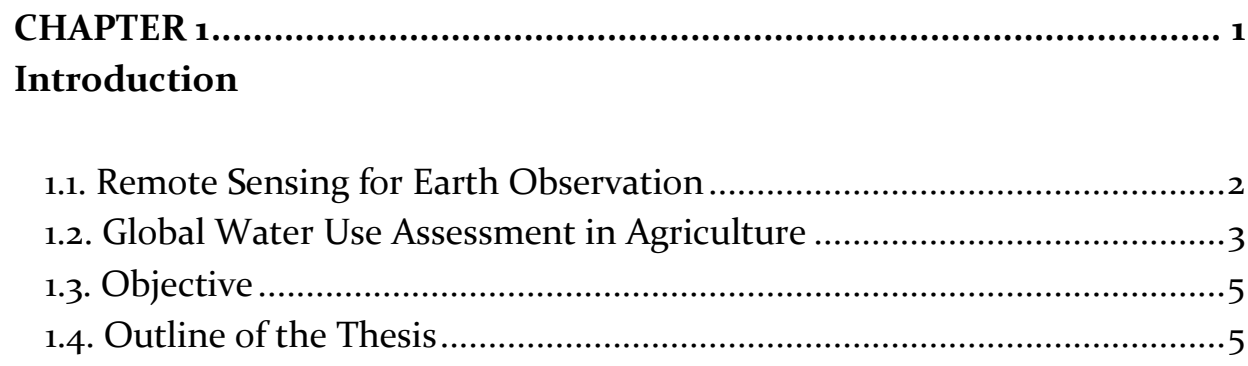

CHAPTER 2 ..........................................................................................9

Potential of Using Remote Sensing Techniques for Global Assessment of Water Footprint of Crops

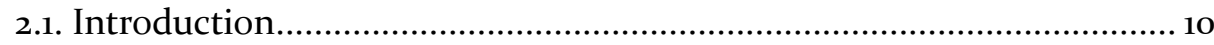

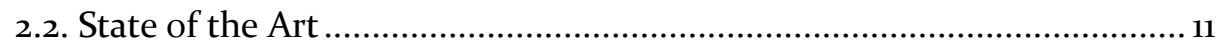

2.2.1. Water Footprint of Crops .......................................................... 11

2.2.2. Irrigation Mapping ............................................................. 14

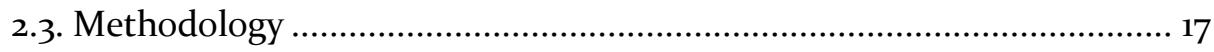

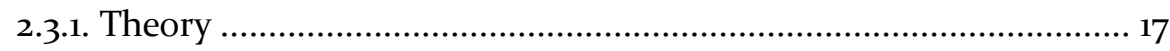

2.3.2. Global EO Products...................................................................... 19

2.3.3. Estimation of Evapotranspiration from Remote Sensing Data.......22

2.3.4. Land Use from Remote Sensing Data.........................................23

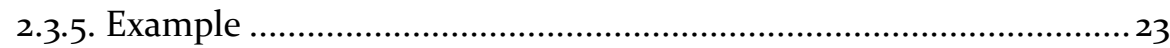

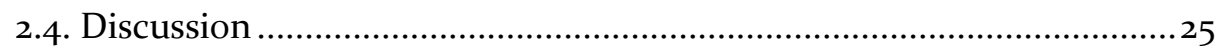

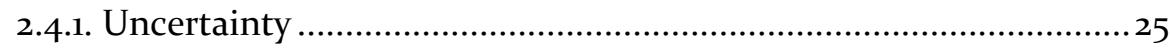

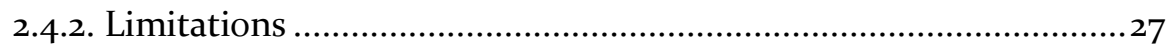

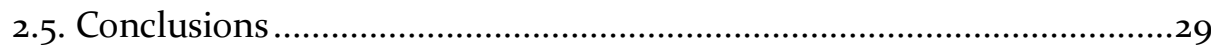

CHAPTER 3 ..................................................................................31

A First Approach to Separate Green and Blue Water Evapotranspiration Using Remote Sensing Based Soil Moisture Products and GLDAS Hydrological data

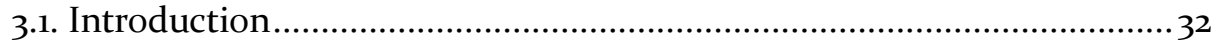

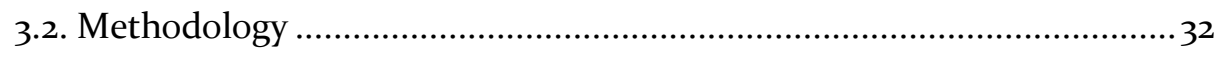

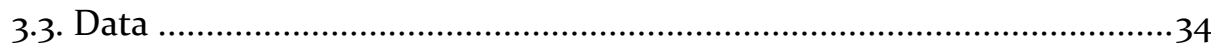




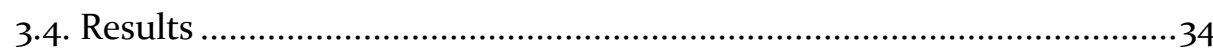

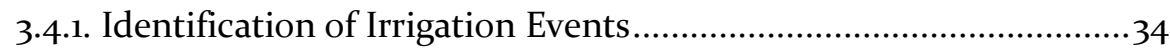

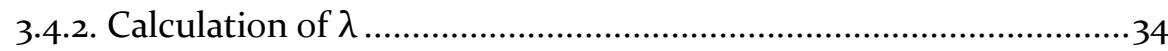

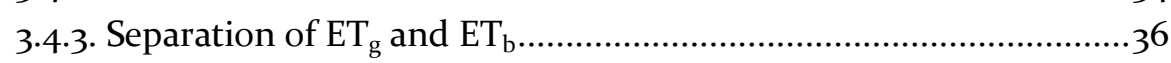

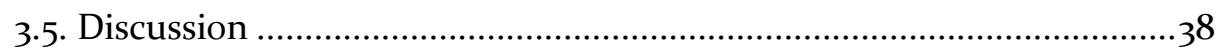

3.6. Conclusions ....................................................................................

CHAPTER 4 ............................................................................................41

Determining Irrigated Areas and Quantifying Blue Water Use in

Europe Using Remote Sensing Meteosat Second Generation (MSG)

Products and Global Land Data Assimilation System (GLDAS) data

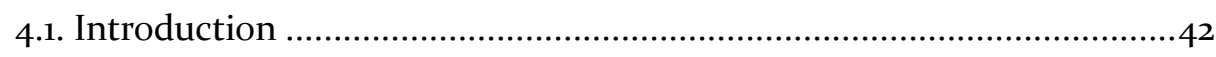

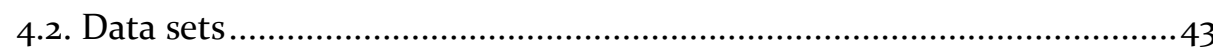

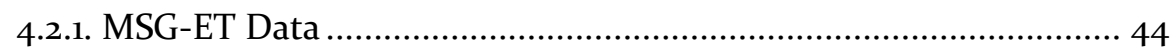

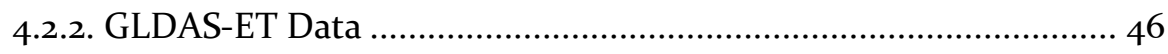

4.2.3. GlobCover Land Cover Map …......................................................47

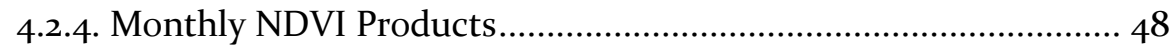

4.2.5. MSG Viewing Zenith Angle ........................................................ 48

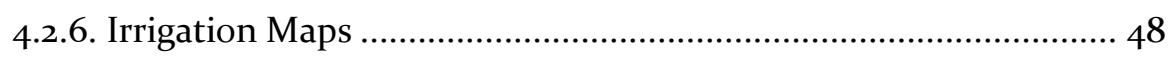

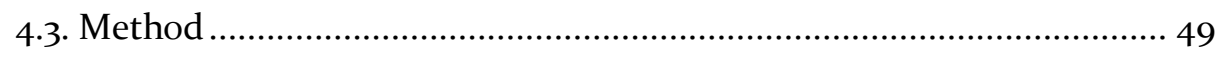

4.3.1. Overview …….......................................................................... 49

4.3.2. Classification map ..................................................................

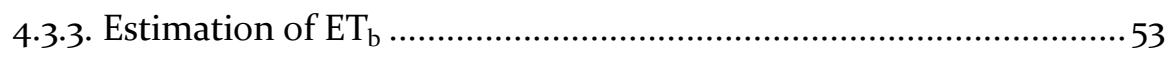

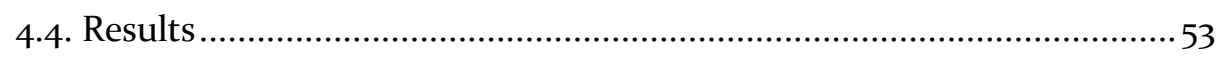

4.4.1. Classification Map …….......................................................... 53

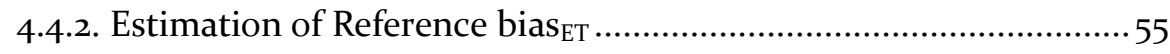

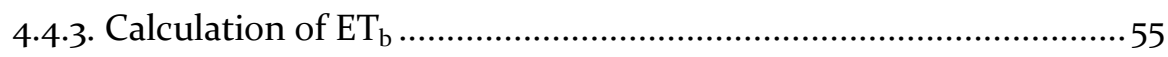

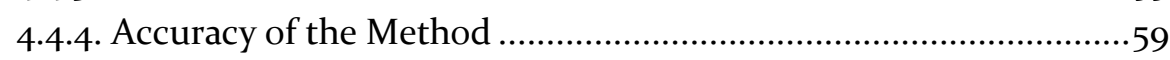

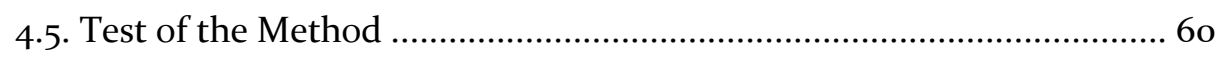

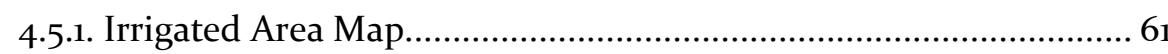

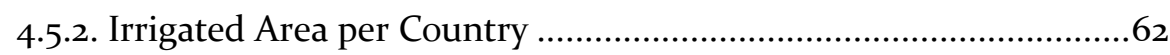

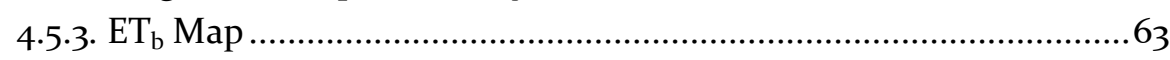

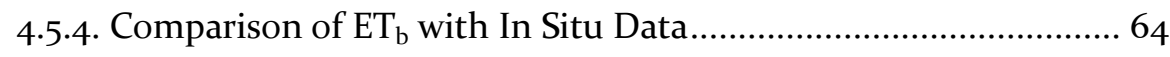

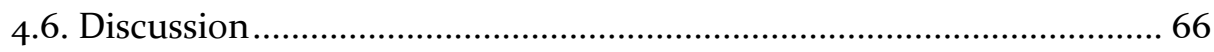

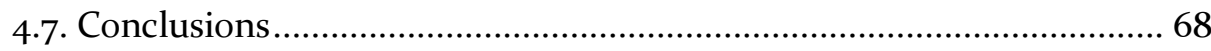

iv 


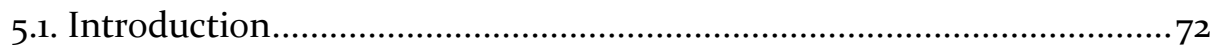

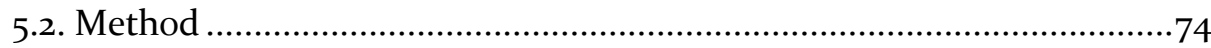

5.2.1. Selection of Parameters for the Classification ...................................74

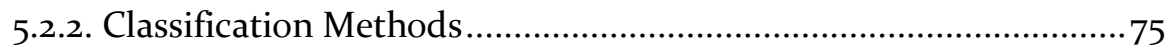

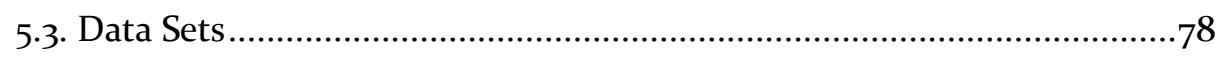

5.3.1. Evapotranspiration and Cover Type Data ........................................79

5.3.2. Data for the Classification................................................................ 81

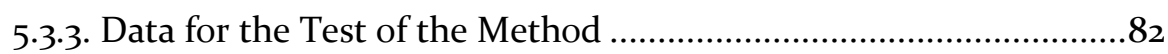

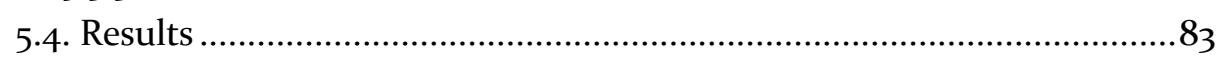

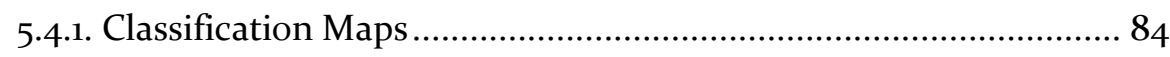

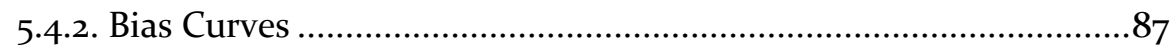

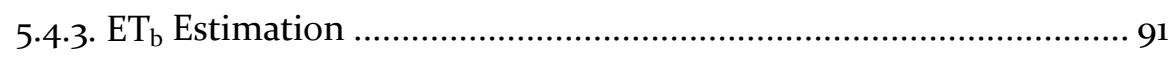

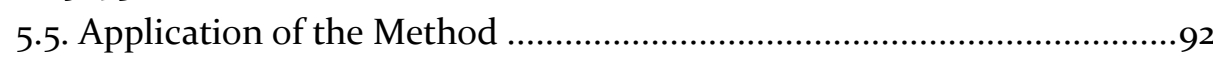

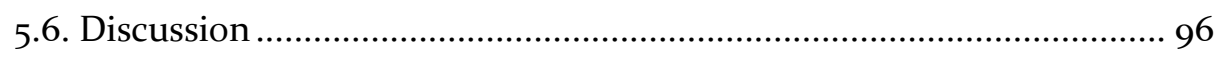

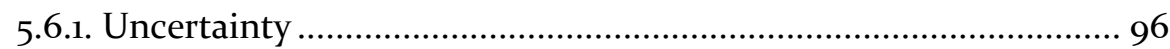

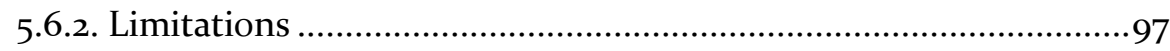

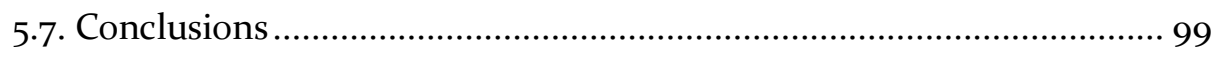

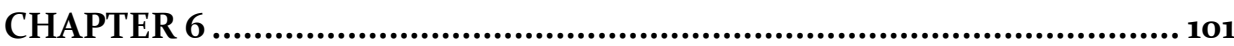

Monthly Blue Water Evapotranspiration in Irrigated Agriculture. Study cases of Ethiopia and Sichuan Province of China

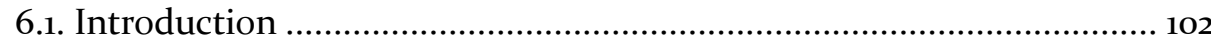

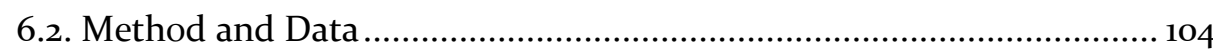

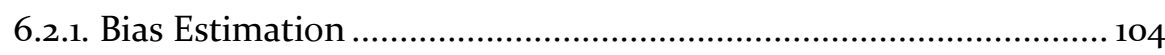

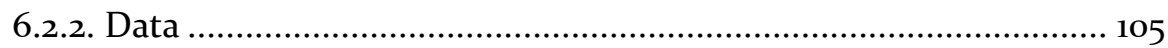

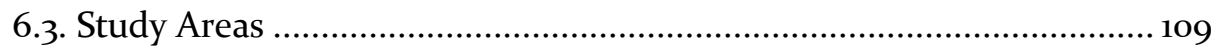

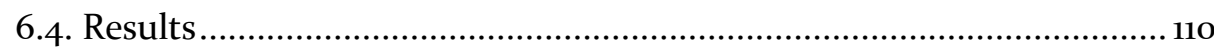

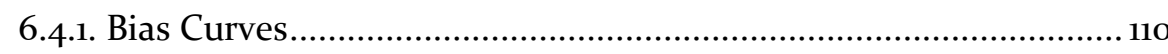

6.4.2. Monthly $\mathrm{ET}_{\mathrm{b}}$ and Source of Irrigation............................................111

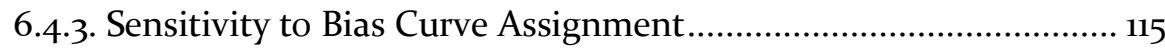

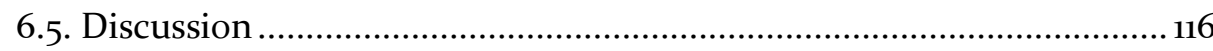

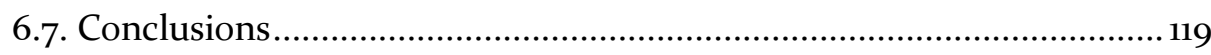


CHAPTER 7 .

.121

Conclusions and Future Outlook

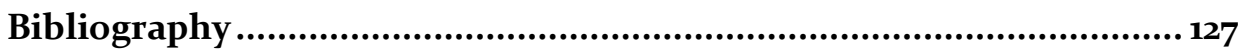

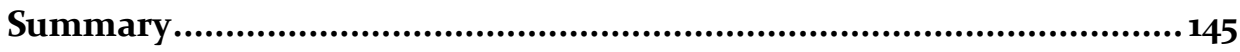

Samenvatting...................................................................................149

About the Author ................................................................................. 153

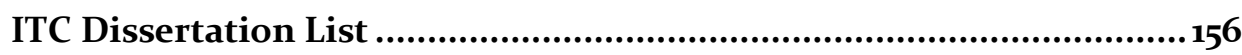




\section{Chapter 1}

\section{Introduction}

In 2011 the Horn of Africa was affected by a drought where 13 million people suffered of food insecurity (Ledwith, 2011). The failure of the October to December 2010 "short" rains and delayed arrival of the April to June 2011 "long" rains caused crop failures across Somalia, Ethiopia and Kenya. The event could be forecasted by the Famine Early Warning System Network (FEWS NET), although the warnings before and during the drought were not enough to avert the food crisis, mainly due to political issues (Funk, 2011).

FEWS NET uses remote sensing data and statistical forecasts to provide early warnings of potential droughts in East Africa, Afghanistan, and Central America (Funk, 2009). Remotely sensed vegetation indices and precipitation estimates are used in the system, while a Water Requirements Satisfaction Index (WRSI) model is employed to gauge crop conditions. The information is also combined with socio-economic analyses.

Precipitation is modelled from infrared information from Meteosat 7 geostationary data, the Special Sensor Microwave/Imager (SSM/I) and the Advanced Microwave Sounding Unit (AMSU). Normalized Difference Vegetation Index (NDVI) estimates are taken from the Moderate Resolution Imaging Spectroradiometer (MODIS).

This amongst other initiatives reflects the considerable interest in developing East African drought monitoring systems based on remotely sensed and model-derived analyses (Anderson et al., 2012). In situ networks are not sufficient to provide spatially distributed drought information in real time. Therefore remote sensing techniques and data are crucial in food security applications, for forecasting, monitoring and supporting socio-economic decision making. 
In this thesis the use of remote sensing techniques in the field of water management will be explored, focusing in the quantification of irrigation water use at global scale.

\subsection{Remote Sensing for Earth Observation}

The use of remote sensing for Earth observation and monitoring begun in the early 1960's with the launch of the Television Infrared Observation Satellite (TIROS) series of meteorological satellites. Since then, numerous satellites have provided valuable information about the Earth surface, from a local to global scale, with revisiting times of 15 minutes to weeks, and with multiple spectral characteristics that allow observing the physical processes in the atmosphere, at the sea and land surfaces.

In this context, enormous efforts and research have been undertaken in order to design the remotely sensed sensors to satisfy the science and application needs. Global observations are currently ensured with geostationary and polar orbit satellites like the series of the European Meteosat first and second generation, MetOp, Soil Moisture Ocean Salinity (SMOS), the American Geostationary Operational Environmental Satellites (GOES), Earth Observation Satellite (EOS) Terra/Aqua, the Japanese MTSAT, the Indian INSAT and the Canadian RADARSAT among many others.

In the field of water cycle and agriculture, the improvement and continuity of the remote sensing data are ensured based on the future missions scheduled for the following years. The European Space Agency is implementing the Sentinel mission (Berger et al., 2012), whose aim is to establish operational supply of Earth observation data. Sentinel-1 mission is a radar based mission for land and ocean monitoring and was launched in April 2014. The Sentinel-2 will provide high resolution optical imagery for land monitoring (vegetation, soil and water cover, inland waterways and coastal areas) and is scheduled for the end of the year 2014. Moreover, the National Aeronautics and Space Administration (NASA) plans the launch of the Soil Moisture Active Passive (SMAP) mission (Entekhabi et al., 2010) in late 2014. SMAP includes a radiometer and a synthetic aperture radar operating at L-band and will make global measurements of soil moisture present at the Earth's land surface and distinguish frozen from thawed land surfaces. This will improve estimates of water, energy, and carbon transfers between the land and the atmosphere. 
The international satellite mission Global Precipitation Measurement (GPM) launched in February 2014 will provide rain and snow measurements worldwide at a temporal resolution of three hours. Other relevant future missions are the Gravity Recovery and Climate Experiment Follow-On (GRACE-FO) to estimate the water storage term, scheduled in the year 2017, and the Eumetsat Polar System Second Generation (EPS- SG), currently in development phase and scheduled for the year 2020.

\subsection{Global Water Use Assessment in Agriculture}

The assessment of water use is crucial in a changing environment where water is an essential but scarce resource. From a water management perspective, an accurate evaluation of the irrigation water used in agriculture is of high importance. The latest data of water withdrawal for irrigation published at the AQUASTAT database (FAO, 2014a) showed a wide range of values, reporting for example percentages of o.6, 60 and $85 \%$ of total national water withdrawals in The Netherlands, Spain and United Republic of Tanzania respectively.

Crop water use, or evapotranspiration (ET) has traditionally been separated into its 'blue' and 'green' components, depending on the source of water supply; that is irrigation and precipitation respectively. In this context, a relevant indicator, the Water Footprint (WF) of a crop was introduced by Hoekstra (2003) and defined as the volume of water consumed for its production.

Early studies in the literature estimated blue and/or green water use at country, continental or global levels (Postel et al., 1996; Seckler et al., 1998; Rockstrom et al., 1999; Shiklomanov and Rodda, 2003). Later, global estimates of consumptive water use for a number of crops per country were obtained by Hoekstra and Hung (2002), Chapagain and Hoekstra (2004) and Hoekstra and Chapagain $(2007,2008)$, although there was no separation of the blue and green components.

At a global scale and higher spatial resolution, different studies have tackled this issue: Alcamo et al. (2007) estimated blue water withdrawal and Döll and Siebert (2002) the irrigation water requirements. More recently, a few studies have separated global water consumption for crop production into green and 
blue water at spatial resolutions of 30 and 5 arc minutes, such as the works of Rost et al. (2008), Siebert and Döll (2008, 2010), Liu et al. (2009), Liu and Yang (2010), Hanasaki et al. (2010), Fader et al. (2011), Mekonnen and Hoekstra (2011) and Pfister et al. (2011).

The aforementioned approaches used hydrological models with the objective of estimating evapotranspiration from croplands per crop type, distinguishing between blue and green ET. However, the input used and the type of output produced, differed. The results were presented at spatial resolutions of country scale, 5, and 30 arc minutes and covered different time periods. The inputs of the methods were national statistics, reports, climatic databases and crop-related maps. The spatial and temporal resolutions of the source data were coarse in some cases, especially where extracted from statistical databases, implying in some cases the use of disaggregation techniques.

Bearing this in mind, remote sensing techniques may improve on the estimates of blue and green water use since they provide global coverage, varied temporal and spatial resolution and broad spectral information. This allows characterizing the physical processes and monitoring crops in appropriate space and time scales.

Moreover, in recent years, several studies have approached the problem of global irrigation mapping, using national statistical data as input (Siebert et al., 2005; Siebert et al., 2006) or making use of multispectral and temporal remote sensing data to perform classifications and obtain irrigated areas (Ozdogan and Gutman, 2008; Thenkabail et al., 2009a). These methods provide information about areas equipped for irrigation, about crop dominance and irrigation source, and about existence or absence of irrigation, but none of the methods quantifies the actual amount of water received by the crops through irrigation, or blue water.

Therefore, it seems fruitful to explore the potential of remote sensing techniques and data to evaluate crop water use at different spatial and temporal scales, focusing on the retrieval of the extent and quantity of irrigation at global scale. 


\subsection{Objective}

The overall objective of this thesis is to explore the use of remote sensing techniques and data to retrieve global water use in agriculture, focusing on the blue component of the evapotranspiration $\left(E_{\mathrm{b}}\right)$. More precisely, specific objectives are: a) to analyse the state of the art in blue and green global water use and irrigation estimation, and identify the potential of using remote sensing data, b) to develop methods for $\mathrm{ET}_{\mathrm{b}}$ estimation using remote sensing data and c) to apply the method to time series of data and identify the potential use from a water management perspective.

\subsection{Outline of the Thesis}

Figure 1.1 shows the outline of the thesis, starting from the analysis of existing approaches and data sets, followed by the development of new methods and ending with their application.
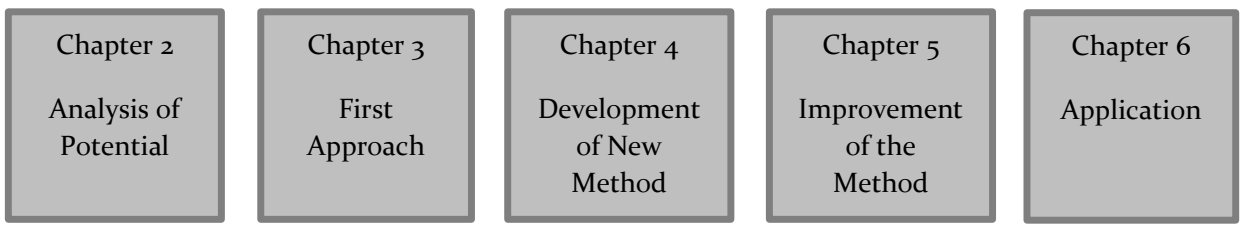

Figure 1.1. Scheme of the contents of the chapters of this thesis.

Bearing in mind that the general objective of this work is the assessment of global water use of crops by means of remote sensing, as a starting point Chapter 2 analyses the concept of Water Footprint (WF) and the key parameters needed for its estimation. This chapter discusses the potential of using remote sensing based data in this field, by reviewing the existing methods and data and identifying the limitations and opportunities for improvement. Specific attention is paid to the estimation of irrigation and a mass balance approach is proposed by providing detailed information about the involved hydrological parameters obtained via remote sensing techniques. In this context, crop evapotranspiration due to precipitation and irrigation respectively, i.e. green and blue evapotranspiration, are separated using a simplified approach. The content of this chapter serves as a motivation of the whole thesis, since it describes the state of the art for WF estimation, identifies new research lines and provides preliminary tools and data sources for the development. However, the need of an improved 
approach for irrigation estimation and ET separation is also indicated taking into account the uncertainty of the inputs used and the particularities of the assumptions considered.

Chapter 3 tackles the separation of ET in its green and blue components by using an approach based on anomalies of soil moisture (SM). This new approach combines the remote sensing Advanced Microwave Scanning Radiometer-EOS (AMSR-E) soil moisture products with other hydrological parameters simulated by a land surface model and included in the Global Land Data Assimilation System (GLDAS). Daily irrigation events are identified when positive SM anomalies are found and precipitation values are below a threshold. Monthly $\mathrm{ET}_{\mathrm{b}}$ is obtained by using the calculated daily irrigation values and the ET depletion time. This chapter presents a first approach for $\mathrm{ET}_{\mathrm{b}}$ estimation using remote sensing data, and is still open to improvement.

The core of this thesis starts in Chapter 4 where an innovative method for determining irrigated areas and $\mathrm{ET}_{\mathrm{b}}$ retrieval is proposed, developed and tested. $\mathrm{ET}_{\mathrm{b}}$ is obtained by calculating (at a resolution of around $5 \mathrm{~km}$ ) the difference between the ET estimate from remote sensing and the simulated ET from a land surface model. This difference is interpreted as the irrigation term and is corrected with a reference bias, reflecting structural differences in the estimation methods and primary data used. The remote sensing based ET are the ones provided by the Land Surface Analysis Satellite Applications Facility (LSA-SAF) which are estimated from the Meteosat Second Generation satellite. The simulated data are obtained from the GLDAS, estimated with the Noah model. A classification map of the study area (Europe) is generated using as a proxy the NDVI and the viewing angle of the remote sensing sensor, and a bias is obtained per class.

Chapter 5 investigates on the improvement of the method proposed in Chapter 4. This is done by enhancing the classification scheme in two aspects. First, a new set of parameters is selected for the classification, which better accounts for the different hydrometeorological conditions. These are evapotranspiration, NDVI and a climate index based on precipitation and net radiation. Second, the performance of three classifiers is explored and evaluated in terms of the classifications and the bias curves generated. This constitutes a more robust approach avoiding relatively arbitrary thresholds 
used in the original classification method. The $\mathrm{ET}_{\mathrm{b}}$ outputs are obtained using the improved methodology in the regions of Europe and Africa and compared with existing literature.

Chapter 6 includes the application of the proposed and improved method to time series of data. It shows the possibility to exploit the method and data for monitoring irrigation practices in time using remote sensing techniques. Monthly $\mathrm{ET}_{\mathrm{b}}$ values are obtained in two case studies: the Horn of Africa (period 2010-2012) and Sichuan province of China (period 2001-2010). Moreover, $\mathrm{ET}_{\mathrm{b}}$ is divided into the sources of irrigation water by using the Global Irrigated Area Map (GIAM), i.e. surface water, groundwater and conjunctive use. The analysis of the temporal evolution of the total $\mathrm{ET}_{\mathrm{b}}$ and the relative contribution of its components showed the potential of the method and the data for monitoring irrigation practices, especially useful in periods of drought.

Finally, the conclusions chapter synthesizes the main conclusions of the different chapters and provides recommendations for further research. 


\title{
Chapter 2
}

\section{Potential of Using Remote Sensing Techniques for Global Assessment of Water Footprint of Crops $^{1}$}

\begin{abstract}
Remote sensing has long been a useful tool in global applications, since it provides physically-based, worldwide, and consistent spatial information. This chapter discusses the potential of using these techniques in the research field of water management, particularly for 'Water Footprint' (WF) studies. The WF of a crop is defined as the volume of water consumed for its production, where green and blue WF stand for rain and irrigation water usage, respectively. In this chapter evapotranspiration, precipitation, water storage, runoff and land use are identified as key variables to potentially be estimated by remote sensing and used for WF assessment. A mass water balance is proposed to calculate the volume of irrigation applied, and green and blue WF are obtained from the green and blue evapotranspiration components. The source of remote sensing data is described and a simplified example is included, which uses evapotranspiration estimates from the geostationary satellite Meteosat 9 and precipitation estimates obtained with the Climatic Prediction Center Morphing Technique (CMORPH). The combination of data in this approach brings several limitations with respect to discrepancies in spatial and temporal resolution and data availability, which are discussed in detail. This work provides new tools for global WF assessment and represents an innovative approach to global irrigation mapping, enabling the estimation of green and blue water use.
\end{abstract}

${ }^{1}$ Based on Romaguera et al. (2010) 


\subsection{Introduction}

Accurate assessment of water use is an important issue in a globally changing climate and environment, where water is becoming a scarce but essential resource. In this context, the concept 'Water Footprint' (WF) was introduced by Hoekstra (2003), and later elaborated on by Hoekstra and Chapagain (2008), as an indicator that relates human consumption to global water resources. The WF of a crop is defined as the volume of water consumed for its production, where green and blue WF stand for rain and irrigation water usage, respectively. The importance of this parameter lies in the fact that international trade in commodities creates flows of what has been called 'virtual water' (Allan, 1998; Hoekstra and Hung, 2005; Chapagain and Hoekstra, 2008), by importing and exporting goods that require water. The indicator provides valuable information for a global assessment of how water resources are used. The WF can be calculated for goods, services, a specific activity, a business, an organization, an individual or for a community.

Remote sensing has long been a useful tool in global climate studies and hydrology, since it provides physically-based, worldwide, consistent spatial information (Baret et al., 2007; Wagner and Scipal, 2000; Sobrino and Romaguera, 2004; Guanter et al., 2008; Bartholome and Belward, 2005; Joyce et al., 2004; $\mathrm{Mu}$ et al., 2007; Rodell et al., 2009; Melesse and Shih, 2002), which represents a major improvement compared to the traditional point measurements. In the last few decades, the advances in science and technology have led to an increasing series of remotely sensed systems for Earth observation and monitoring, with applications in various fields of the environmental sciences, such as agriculture, meteorology, geology, land cover dynamics, global climate studies and hydrology. Nowadays, geostationary and polar-orbiting Earth observation satellites ensure global, multitemporal and multispectral coverage of the planet.

The aim of this chapter is to discuss the potential of these techniques in the research field of water management, and in particular water footprint studies. Existing methods have calculated the WF and virtual water using data from national statistics, reports and climatic databases (Hoekstra and Hung, 2005; Liu et al., 2009; Mekonnen and Hoekstra, 2010; Siebert and Döll, 2010). However, the use of remote sensing data has not yet been exploited in this field. The spatial and temporal coverage obtained with remote sensing data 
form an improvement over traditional in situ measurements. The spatial resolution is also improved, especially compared with data based on statistics or interpolated climatic station measurements, thus facilitating monitoring of the spatial variability of parameters.

In this chapter, the potential use of remote sensing and its analysis techniques is illustrated to improve the understanding and estimation of a WF. An innovative remote sensing approach is presented for irrigation mapping, which enables the estimation of green and blue water use. However, global assessment of water footprints is outside the scope of this chapter and will be considered during follow up research. The chapter is organized in the following sections: In Section 2.2, the state of the art in WF estimations is described and how remote sensing data may improve final retrievals. The state of the art in global irrigation mapping is also incorporated in this section. A method for WF estimation is proposed in Section 2.3, where remote sensing estimates of precipitation, evapotranspiration, runoff, water storage and land use are employed. The data sources needed for this method are described in detail in this section and a simplified example is included. Finally, the approach and its limitations are discussed in Section 2.4.

\subsection{State of the Art}

\subsubsection{Water Footprint of Crops}

In recent years WFs and virtual water have been calculated for crops, goods, services, as well as on generic national levels (Hoekstra and Chapagain, 2008; Hoekstra and Hung, 2005; Hoekstra and Chapagain, 2007; Liu et al., 2009; Mekonnen and Hoekstra, 2010; Siebert and Döll, 2010).

The WF of crops forms the basis for WF estimations of crop products and derived commodities. The WF of a product is defined as the total volume of fresh water used to produce the product, summed over the various steps in the production chain (Hoekstra et al., 2009).

Blue WF stands for irrigation water usage and green WF for rain water usage. In the case of irrigation, a part of the water withdrawn from the surface or groundwater system is evaporated between the point of withdrawal and the 
field, another part infiltrates and returns to the water source (and can be reused), and the rest reaches the field; there is a part that turns into drainage flow, which may be available for reuse as well. The blue WF refers to the sum of evaporation from storage reservoirs, transport canals and evapotranspiration from the field, although many previous studies have focused on the physical processes that happen in the field.

The main inputs for green and blue WF estimation are shown in Figure 2.1 and include crop evapotranspiration, area and volume of irrigation, water storage, runoff, crop characteristics, climatic data and crop production data.
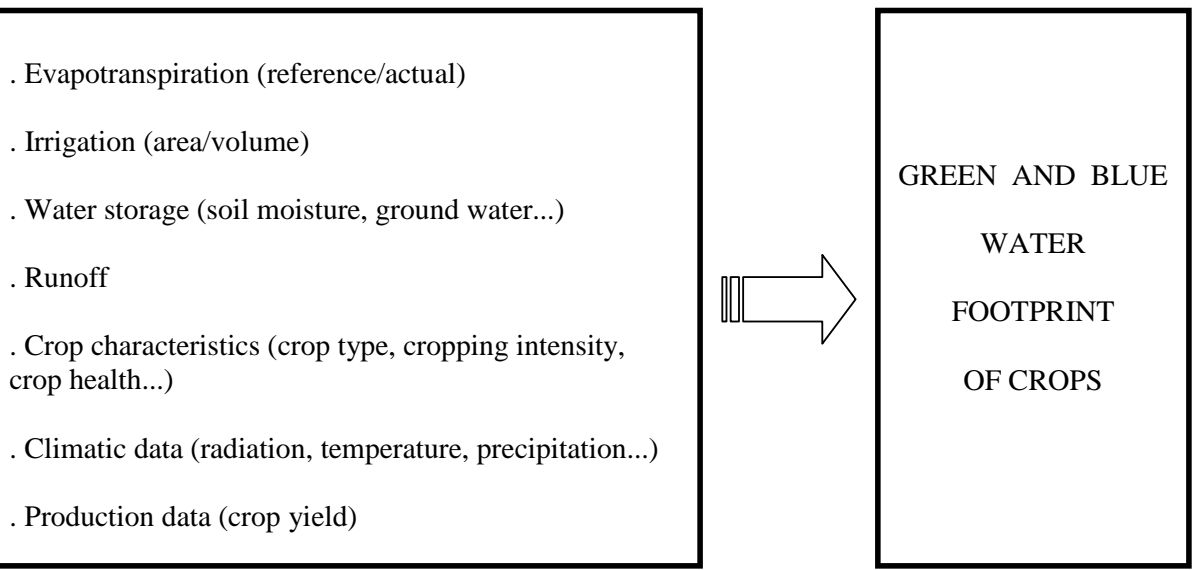

Figure 2.1. Inputs for water footprint estimation.

Hoekstra and Hung (2005) carried out a global study to calculate the WF of crops based on crop yields and crop water requirements, where the latter were estimated following Allen et al. (1998). The results were presented per country and referred to the period 1995-1999. They made use of the CropWat model (Smith, 1991; Allen et al., 1998) of the Food and Agriculture Organization

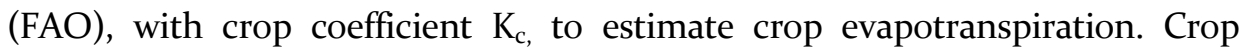
yields were obtained from the FAOSTAT database (FAO, 2005a). Climatic data were taken from FAO's climatic database ClimWat, (FAO, 2005b) and crop parameters from the CropWat package. This model assumes that crops are planted under optimal soil moisture conditions, are disease-free, well-fertilized, grown in large fields with $100 \%$ coverage and have a single cropping pattern. 
Siebert and Döll (2010) provided blue and green virtual water content in global crop production. The results are presented at a spatial resolution of 5 arc minutes (approximately $10 \mathrm{~km}$ at the equator), for 26 different crops, and refer to the period 1998-2002. Their Global Crop Water model (GCWM) is based on a soil water balance where actual evapotranspiration is calculated according to Allen et al. (1998) using the crop and stress coefficients $\left(\mathrm{K}_{\mathrm{c}}\right.$ and $\mathrm{K}_{\mathrm{s}}$ ), and irrigation at time $(t+1)$ is computed by subtracting the actual available soil water at time $t$ from the total soil water capacity. This model uses the cropping pattern and cropping season information of Portmann et al. (2010) as input, as well as climate data derived from the Climate Research Unit (CRU) of the University of East Anglia dataset (Mitchell and Jones, 2005) and crop coefficients according to Allen et al. (1998).

Liu et al. (2009) estimated blue and green water components of consumptive water use for a range of agricultural crops with a spatial resolution of 30 arc minutes (approximately $55 \mathrm{~km}$ at the equator) for the period 1998-2002. Their model simulated crop yield, total evapotranspiration and crop water productivity (Liu et al., 2007). The data sets used in this study included maps of harvested areas by Ramankutty et al. (2008) and Portmann et al. (2008). Climatic data were obtained from the CRU dataset (Mitchell and Jones, 2005), crop fertilizer application from statistical reports and soil parameters from work by Batjes (2006).

Mekonnen and Hoekstra (2010) estimated the global blue and green WF of wheat with a resolution of 5 arc minutes (approximately $10 \mathrm{~km}$ at the equator) for the period 1996-2005. In this approach, actual evapotranspiration and irrigation requirements were calculated according to Allen et al. (1998) using crop and stress coefficients $\left(\mathrm{K}_{\mathrm{c}}\right.$ and $\left.\mathrm{K}_{\mathrm{s}}\right)$. The total WF at each grid cell was estimated to be the weighted average of the WFs in a rainfed and an irrigated scenario. Weighting was based on the actual presence of irrigation. The method also derived yield data and the grey WF, which is defined as the volume of freshwater required to assimilate the load of pollutants, based on existing ambient water quality (Hoekstra et al., 2009). This work used reference evapotranspiration data from FAO (FAO, 2008a), precipitation data from CRU (Mitchell and Jones, 2005), irrigated area values from Portmann et al. (2008), and the Global Map of Irrigation Areas (GMIA) from Siebert et al. (2006). 
All the aforementioned approaches are based on the concept of evapotranspiration with the objective of estimating blue and/or green water use. However, the input used, and the type of output produced, differ. The results are presented at different spatial resolutions, namely country scale, 5, and 30 arc minutes. Different data sources are considered in the methods, such as national statistics, reports, climatic databases and crop-related maps, with different spatial and temporal resolutions. In some cases, the crops are assumed to be growing in ideal conditions, i.e., their irrigation requirement is met and growing characteristics are optimal. In addition, the results presented cover different time periods. This leads to the following limitations:

1. coarse spatial resolution of the source data, mainly where extracted from statistical databases,

2. coarse temporal resolution of the input data, which may imply the use of disaggregation techniques,

3. assumption of ideal conditions, e.g., optimum soil water conditions,

4. outputs are static, i.e., they are given for particular periods of time.

On the other hand, remote sensing techniques provide global coverage, varied temporal and spatial resolution and broad spectral information, countering these limitations. Monitoring crops in an appropriate space and time scale may, as a result, provide better estimates of blue and green water use.

In particular, five aspects have been identified which may be estimated and show improvement with the use of remote sensing techniques on a global scale: retrieval of actual evapotranspiration, quantification of precipitation, mapping of land use, estimation of surface runoff, and quantification of water storage. In addition, this chapter proposes an innovative method for quantifying the amount of irrigation, using the aforementioned parameters. In order to have an overview of existing methods, the next section discusses the state of the art in global irrigation mapping.

\subsubsection{Irrigation Mapping}

In recent years, several studies have approached the problem of global irrigation mapping, using national statistical data as input (Siebert et al., 
2005; Siebert et al., 2006) or making use of spectral and temporal remote sensing data for classification (Ozdogan and Gutman, 2008; Thenkabail et al., 2009a, b).

Siebert et al. (2005, 2006) provided a global map of areas equipped for irrigation (GMIA) with a spatial resolution of 5 arc minutes, around the year 200o. The input in this approach consisted of data from FAO reports, the United Nations, the World Bank, Ministries of Agriculture, irrigation associations, printed maps, digital datasets and the land cover data set of the United States Geological Survey (USGS) for the year 2000. This method combined sub-national statistical data with land cover information to produce output at a grid resolution. The results are given in terms of percentage of surface area equipped for irrigation. The quality of the map is assessed by taking into account the density of the statistical information available and the amount of agreement between different data sources. The map is also compared with global land cover datasets, revealing large discrepancies.

Thenkabail et al. (2008, 2009a) developed the Global Irrigated Area Map (GIAM) with 28 classes and a spatial resolution of $10 \mathrm{~km}$, around year 1999. Temporal series of remote sensing data were used in this work. Reflectance values, brightness temperatures and Normalized Difference Vegetation Index (NDVI) were obtained from the Advanced Very High Resolution Radiometer (AVHRR). NDVI estimates were acquired at a higher resolution from the Système Pour l'Observation de la Terre Vegetation (SPOT VGT) and precipitation data were obtained from the Japanese Earth Resources Satellite1 Synthetic Aperture Radar (JERS-1 SAR). A digital elevation model and a global tree cover map were used as input as well. The method is based on classification and identification techniques to establish different classes of irrigated areas and to differentiate irrigated areas from non-irrigated areas. Global ground-truth data from approximately 5,60o locations and Landsat Enhanced Thematic Mapper Plus (ETM+) mosaics were used as training data for the classification. The 28 class global map provides classes labeled based on irrigation source (surface water, groundwater or conjunctive use), intensity (single, double or continuous crop) and crop dominance. The map shows discrepancies with the map of irrigated areas produced by Siebert et al. (2005), and with national statistics from India. However, linear relations 
between the data are found with correlation coefficients of 0.94 and 0.76 (1:1 line), respectively.

Ozdogan and Gutman (2008) used Moderate Resolution Imaging Spectroradiometer (MODIS) data to produce a $500 \mathrm{~m}$ resolution irrigation map for the United States. The input data for this approach were the Nadir Bidirectional Distribution Function Adjusted Reflectance (NBAR) data acquired during 2001. In this work, a climatic moisture index was calibrated to define irrigation potential. In addition, spectral indices such as the NDVI and the greenness index were identified. The method is based on a supervised classification of the remotely sensed data and the irrigation potential. Ancillary data for training the model are Landsat images, climatic data, county based irrigated area maps, and state reports. The method provides a binary classification into irrigated and non-irrigated classes, and a fractional area estimate of each pixel identified as irrigated. The output is compared with sub-national statistics providing a rms error of $2 \%$ of the total irrigated area.

Regarding the type of inputs, the different methods obtain their data mainly from national statistics, or from remote sensing estimates such as NDVI, brightness temperatures and surface reflectance values. The methods are based on classification techniques applied to data time series.

Regarding output, the aforementioned methods provide information about areas equipped for irrigation, about crop dominance and irrigation source, and about existence or absence of irrigation. None of the methods quantify the actual amount of water received by the crops through irrigation, from here onwards called 'actual irrigation'.

The present chapter proposes an innovative approach for the retrieval of actual irrigation on a global scale. First of all, as input, the method uses water cycle components such as evapotranspiration, precipitation, surface runoff and water storage from remote sensing techniques. Secondly, a physicallybased method is applied, whereas previous studies applied classification techniques to the remote sensing data. Finally, making use of the temporal resolution of remote sensing data, this method will allow actual irrigation maps to be obtained on time scales of a month or a season, representing a physically more correct monitoring of the processes involved. This forms an 
improvement over existing methods, which provided static estimates for particular years only.

\subsection{Methodology}

\subsubsection{Theory}

The use of Earth Observation (EO) estimates of precipitation, evapotranspiration, surface runoff, and water storage is proposed to estimate actual irrigation. The mass water balance in an irrigated area $A\left[\mathrm{~L}^{2}\right]$ for time period $\mathrm{dt}$ is given by:

$$
P+I=E T+Q+\frac{d S}{d t}
$$

where $\mathrm{P}\left[\mathrm{LT}^{-1}\right]$ is precipitation, I $\left[\mathrm{LT}^{-1}\right]$ is actual irrigation, $\mathrm{ET}\left[\mathrm{LT}^{-1}\right]$ is actual evapotranspiration, $\mathrm{Q}\left[\mathrm{LT}^{-1}\right]$ is surface runoff/streamflow, and $\mathrm{S}[\mathrm{L}]$ is water storage in a vertical column (snow, canopy water storage, soil moisture and groundwater). Therefore, the retrieval of I is ensured as soon as the other parameters are estimated.

In addition, for the analysis of green and blue water use, ET is divided into a green water component $\left(\mathrm{ET}_{\mathrm{g}}\right)$, and a blue water component $\left(\mathrm{ET}_{\mathrm{b}}\right)$ :

$$
E T=E T_{g}+E T_{b}
$$

For regions with negligible runoff, $\mathrm{ET}_{\mathrm{g}}$ and $\mathrm{ET}_{\mathrm{b}}$ may be assumed to occur proportionally to the input from precipitation and irrigation, on a sufficiently long time scale. Other cases need to be analyzed with a more complex approach.

The green component in the water footprint of a crop $\left(\mathrm{WF}_{\mathrm{g}}, \mathrm{m}^{3} / \mathrm{ton}\right)$ is calculated as the green component in crop water use $\left(\mathrm{CWU}_{\mathrm{g}}, \mathrm{m}^{3} / \mathrm{ha}\right)$ divided by the crop yield (Y, ton/ha), according to Hoekstra et al. (2009). The blue component is calculated in a similar way:

$$
W F_{g}=\frac{C W U_{g}}{Y}, \quad W F_{b}=\frac{C W U_{b}}{Y}
$$


The green and blue components in crop water use are calculated by accumulation of daily evapotranspiration ( $\mathrm{mm} /$ day) over the total growing period:

$$
C W U_{g}=10 \cdot \sum_{d=1}^{l g p}\left(E T_{g}\right)_{d}, \quad C W U_{b}=10 \cdot \sum_{d=1}^{l g p}\left(E T_{b}\right)_{d}
$$

where the factor 10 is meant to convert water depths in $\mathrm{mm}$ into water volumes per land surface in $\mathrm{m}^{3} /$ ha. Summation takes place from the day of planting (day 1 ) to the day of harvesting (lgp stands for length of the growing period in days).

Figure 2.2 shows the flowchart of the input needed and the output desired for WF estimations. The first step of the proposed methodology consists of using remote sensing estimates of $\mathrm{P}, \mathrm{ET}, \mathrm{Q}$ and $\mathrm{S}$ for retrieving I by means of equation (2.1) on a global scale. The separation of croplands from other land covers and the differentiation of crops are elicited from land use maps obtained with remote sensing. Next, $\mathrm{ET}_{\mathrm{g}}$ and $\mathrm{ET}_{\mathrm{b}}$ need to be modeled and obtained from ET, P and I. The calculation of the components of the WF per crop is carried out by using equations (2.3) and (2.4). Finally, crop yields are based on statistics.

The data sources available on a global scale through remote sensing techniques are detailed in the next sections, as well as the methods employed for obtaining the different types of input. 


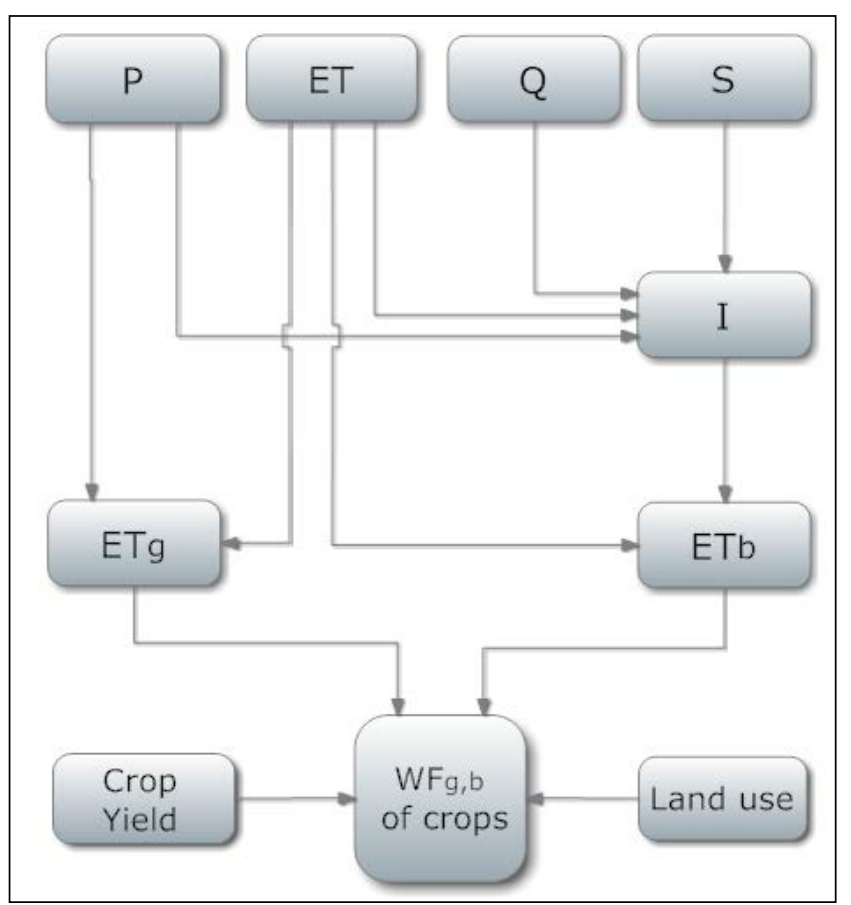

Figure 2.2. Flowchart proposed for obtaining WF of crops from remote sensing data.

\subsubsection{Global EO Products}

Table 2.1 shows an overview of the sources of data and available global EO products. The table also includes information on spatial coverage, spatial and temporal resolution, main inputs, and data availability.

EO data on global precipitation can be obtained from different sources, such as the Climatic Prediction Center (CPC) Morphing Technique (CMORPH), which produces global precipitation estimates every 30 minutes with a resolution of $8 \mathrm{~km}$ at the equator. This technique uses precipitation estimates that have been derived from low orbiting satellite microwave (MW) observations exclusively. Infrared (IR) information from geostationary satellites with a higher temporal resolution is used to retrieve cloud motion vectors. The precipitation values are then interpolated in time, based on the motion of the clouds (Joyce et al., 2004). Another source is the Precipitation Estimation from Remotely Sensed Information using Artificial Neural Networks (PERSIANN) system that uses neural network techniques to estimate 
rainfall rate at six hourly intervals for each $0.25^{\circ} \times 0.25^{\circ}$ pixel (approximately 30 $\mathrm{km}$ at the equator) of the infrared brightness temperature image provided by geostationary satellites (Hsu et al., 1997; Hsu et al., 1999).

Table 2.1. Earth observation products (incomplete) involved in equation (2.1): Source, spatial coverage, spatial and temporal resolution, main inputs and availability of data.

\begin{tabular}{|c|c|c|c|c|c|c|}
\hline $\begin{array}{c}\text { EO } \\
\text { prod. }\end{array}$ & Source & $\begin{array}{c}\text { Spatial } \\
\text { coverage }\end{array}$ & $\begin{array}{l}\text { Spatial } \\
\text { resol. }\end{array}$ & $\begin{array}{l}\text { Temp. } \\
\text { resol. }\end{array}$ & Main input & Data avail. \\
\hline \multirow{3}{*}{$\mathbf{P}$} & $\mathrm{CMORPH}^{* *}$ & Global & $\begin{array}{l}8 \mathrm{~km} \\
\text { at the } \\
\text { equator }\end{array}$ & $\begin{array}{l}30^{\prime} \\
\text { monthly }\end{array}$ & $\begin{array}{l}\text { MW } \\
\text { IR }\end{array}$ & 2002-present \\
\hline & PERSIANN & Global & $0.25^{\circ}$ & $6 \mathrm{~h}$ & IR & 2000-present \\
\hline & MPE & $\begin{array}{l}\text { Meteosat } \\
\text { disk * }\end{array}$ & $\begin{array}{l}\text { Met7:5 km } \\
\text { Met8:3 km } \\
\text { Met9:3 km } \\
\text { at nadir }\end{array}$ & $\begin{array}{l}\text { Met7: } 30^{\prime} \\
\text { Met8: } 15 \\
\text { Met9: } 15\end{array}$ & $\begin{array}{l}\text { MW } \\
\text { IR }\end{array}$ & 2000-present \\
\hline \multirow{2}{*}{ ET } & MET & $\begin{array}{l}\text { Meteosat } \\
\text { disk * }\end{array}$ & $\begin{array}{l}3 \mathrm{~km} \\
\text { at nadir }\end{array}$ & $30^{\prime}$ & $\begin{array}{l}\text { Radiation fluxes } \\
\text { LAI, FVC } \\
\text { Climatic data }\end{array}$ & $\begin{array}{l}\text { Pre-operational } \\
\text { (available) } \\
* * *\end{array}$ \\
\hline & MOD 16 & Global & $1 \mathrm{~km}$ & daily & $\begin{array}{l}\text { Land cover } \\
\text { LAI, FAPAR } \\
\text { Climatic data }\end{array}$ & $\begin{array}{l}\text { Pre-operational } \\
\text { (not available) } \\
* * *\end{array}$ \\
\hline $\mathbf{S}$ & GRACE & Global & $400 \mathrm{~km}$ & monthly & Gravity fields & 2002-present \\
\hline $\mathbf{Q}$ & GLDAS & Global & $1^{\circ}$ & $\begin{array}{l}\text { 3h } \\
\text { monthly }\end{array}$ & $\begin{array}{l}\text { Land cover } \\
\text { LAI \& soil param. } \\
\text { Skin temperature } \\
\text { Radiation fluxes } \\
\text { Climatic data }\end{array}$ & 1979-present \\
\hline
\end{tabular}

${ }^{*}$ Meteosat disk covers latitudes between $-60^{\circ}$ and $+60^{\circ}$ and longitudes between $-60^{\circ}$ to $+60^{\circ}$.

${ }^{* *}$ List of acronyms: CMORPH (Climate Prediction Center Morphing Technique), PERSIANN (Precipitation Estimation from Remotely Sensed Information using Artificial Neural Networks), MPE (Multisensor Precipitation Estimate), MET (Meteosat EvapoTranspiration), MOD 16 (MODIS product 16), GRACE (Gravity Recovery and Climate Experiment), GLDAS (Global Land Data Assimilation System), MW (Microwave), IR (Infrared), LAI (Leaf Area Index), FVC (Fraction of Vegetation Cover), FAPAR (Fraction of Absorbed Photosynthetically Active Radiation).

*** Product availability at the moment of writing this chapter. 
At a continental scale, the Multisensor Precipitation Estimate (MPE) produces precipitation estimates from Meteosat 7, 8 and 9 satellites. The data from Meteosat 7 (Met7) are generated every 30 minutes with a spatial resolution of $5 \mathrm{~km}$ at nadir. Meteosat 8 (Met8) and Meteosat 9 (Met9) data have a temporal resolution of 15 minutes and a spatial resolution of $3 \mathrm{~km}$ at nadir. The method combines passive microwave data from the Special Sensor Microwave Imager (SSM/I) and images in the Meteosat IR channel (Heinemann et al., 2002).

Remote sensing evapotranspiration data (Meteosat EvapoTranspiration, MET) are available from the Land Surface Analysis-Satellite Applications Facility (LSA-SAF) at a temporal resolution of 30 minutes, for the disk of Meteosat Second Generation (MSG) satellites, and were in a pre-operational phase at the moment of writing this chapter. The method is based on forcing a Soil-Vegetation-Atmosphere-Transfer (SVAT) scheme with relevant data (short and long-wave radiation fluxes, albedo, leaf area index (LAI), fraction of vegetation cover (FVC) and snow cover) derived from Meteosat and auxiliary data (air temperature, humidity, wind speed, atmospheric pressure, etc.) from other sources, mainly from the European Center for MediumRange Weather Forecast (ECMWF) (Gellens-Meulenberghs et al., 2007). Other products on a global scale that were in pre-operational phase and not yet available at the moment of writing this chapter are derived from MODIS on a daily basis at a $1 \mathrm{~km}$ resolution (MODIS product MOD 16). The algorithm for retrieving these products is based on the Penman-Monteith equation for computing evapotranspiration and uses MODIS land cover, Fraction of Photosynthetic Active Radiation Absorbed by the vegetation (FAPAR) and LAI, as well as global surface meteorology from the Global Modeling and Assimilation Office (GMAO) (Mu et al., 2007).

The change in water storage (the $\mathrm{dS} / \mathrm{dt}$ term) includes water storage in the vertical column, i.e., snow, canopy water storage, soil moisture and groundwater. Global data on water storage are obtained from the satellite GRACE (Gravity Recovery and Climate Experiment) at a resolution of $400 \mathrm{~km}$ on a monthly basis. The sensors measure temporal variations in the gravity field that can be used to estimate changes in terrestrial water storage (Swenson and Wahr, 2009; Rodell et al., 2009). The data are presented as equivalent height of water. 
Finally, global data on runoff are provided by the Global Land Data Assimilation System (GLDAS) (Rodell et al., 2004). The system integrates different land surface models based on satellite and ground-based observational data. In particular, the Variable Infiltration Capacity (VIC) model focuses on runoff processes and uses an infiltration curve to characterize them (Nijssen et al., 2001). These data are provided every three hours and on a monthly basis, with a spatial resolution of $1^{\circ}$ (approximately $110 \mathrm{~km}$ at the equator).

\subsubsection{Estimation of Evapotranspiration from Remote Sensing Data}

At the moment of writing this chapter, the possibility of obtaining operational ET data using remote sensing on a global scale was not widely available. Therefore, an overview of existing methods is included. Remote sensing techniques have meant an important improvement in actual evapotranspiration estimation, since they allow monitoring spatial and temporal variability beyond traditional point measurements. Many analyses have been carried out in the past decades using remote sensing data on a regional to global scale, and by applying empirical and/or physically-based methods. The one-dimensional methods, Surface Energy Balance System (SEBS) (Su, 2002) and Two-source Energy Balance (TSEB) Model (Norman et al., 1995), are physically-based surface energy balance models. Other methods make use of the spatial variability of the surface temperature and reflectance and/or vegetation index observations, such as the Surface Energy Balance (SEBAL) approach (Bastiaanssen et al., 1998a) and the Simplified Surface Energy Balance Index (S-SEBI) method (Roerink et al., 2000). Others use direct correlations between vegetation indices and evaporation (Glenn et al., 2007). Actual evapotranspiration can also be estimated using the FAO approach (Allen et al., 1998), which uses reference ET (e.g., from the PenmanMonteith method) combined with crop specific coefficients. All these approaches have been applied to sensors onboard different platforms, such as the Along-Track Scanning Radiometer (ATSR), the Advanced Spaceborne Thermal Emission and Reflection Radiometer (ASTER), AVHRR and Landsat (Anderson et al., 2007a; French et al., 2005; Jia et al., 2003; van der Kwast et al., 2009; Sobrino et al., 2007; Bastiaanssen et al., 1998b). On a global scale, the fusion of data from different sensors ensures full coverage. However, the parameters that are involved in this process should be observed at relevant scales. 


\subsubsection{Land Use from Remote Sensing Data}

Different land cover maps are available on a global scale, such as the Global Land Cover 2000 Project (GLC 2000) (Bartholome and Belward, 2005) and the MODIS yearly global product for the period 2001-2004 (Friedl et al., 2002), both at a $1 \mathrm{~km}$ resolution. The Medium Resolution Imaging Spectrometer (MERIS) GlobCover product for 2005 (ESA, 2008;Arino et al., 2007) is produced at a $300 \mathrm{~m}$ resolution. These maps are based on classification techniques and distinguish between generic land cover classes such as croplands, forests, desert areas, savannas, shrublands, etc. In order to identify different types of crops, several approaches have been proposed. For example, Zhang et al. (2008) made use of Fast Fourier Transforms on MODIS NDVI series, Blaes et al. (2005) discussed the synergy of optical and Synthetic Aperture Radar (SAR) image time series for this purpose and Rao (2008) developed a spectral library from in situ hyperspectral data to carry out classification of a remote sensing image.

\subsubsection{Example}

This section provides a simplified example, where $\mathrm{ET}_{\mathrm{g}}$ and $\mathrm{ET}_{\mathrm{b}}$ are obtained for Egypt in October 2009. In this country, the contrast between the nonirrigated desert areas and the irrigated croplands in the Nile basin is very clear.

The calculations were carried out for equation (2.1) over a period of one month. In this case, there is no runoff due to the characteristics of study area: dry conditions with low monthly precipitation in October 2009 (less than 30 $\mathrm{mm}$ ) and highly permeable soils. Furthermore, in this example, for simplicity reasons the storage term $(\mathrm{dS} / \mathrm{dt})$ is assumed to be negligible, meaning that all actual irrigation transforms into evapotranspiration. Therefore, actual irrigation is calculated according to:

$$
\left.\begin{array}{l}
P+I=E T+Q+\frac{d S}{d t} \\
Q=0 \\
\frac{d S}{d t}=0
\end{array}\right\} \rightarrow I=E T-P
$$


Precipitation data were obtained from the CPC Famine Early Warning System Network (FEWS-NET) data archive on a daily base and were aggregated to a monthly value. Pre-operational Meteosat-9 ET values were acquired from LSA-SAF with a temporal resolution of 30 minutes.

Instantaneous values of ET were integrated during the day and summed to a monthly value. Linear interpolation was used to fill in missing data. ET values were not considered if the lack of data occurred during a period of one hour or longer. In general terms, the percentage of day-time acquisitions used for the calculations was $97 \%$.

The two components, $\mathrm{ET}_{\mathrm{g}}$ and $\mathrm{ET}_{\mathrm{b}}$, were retrieved by assuming that they both occur as input in a proportional way (precipitation and irrigation). The results are shown in Figures 2.3a and 2.3b. The maps show the distinction between the croplands and vast desert areas where $\mathrm{P}$ and therefore ET are negligible. For the period of analysis, the evapotranspiration in the Egyptian croplands is mainly due to blue water contribution, especially in the Nile basin area with values up to $80 \mathrm{~mm}$ per month. The contribution of green water to the total ET is concentrated in the coastal regions, yielding values of up to $30 \mathrm{~mm}$ per month.
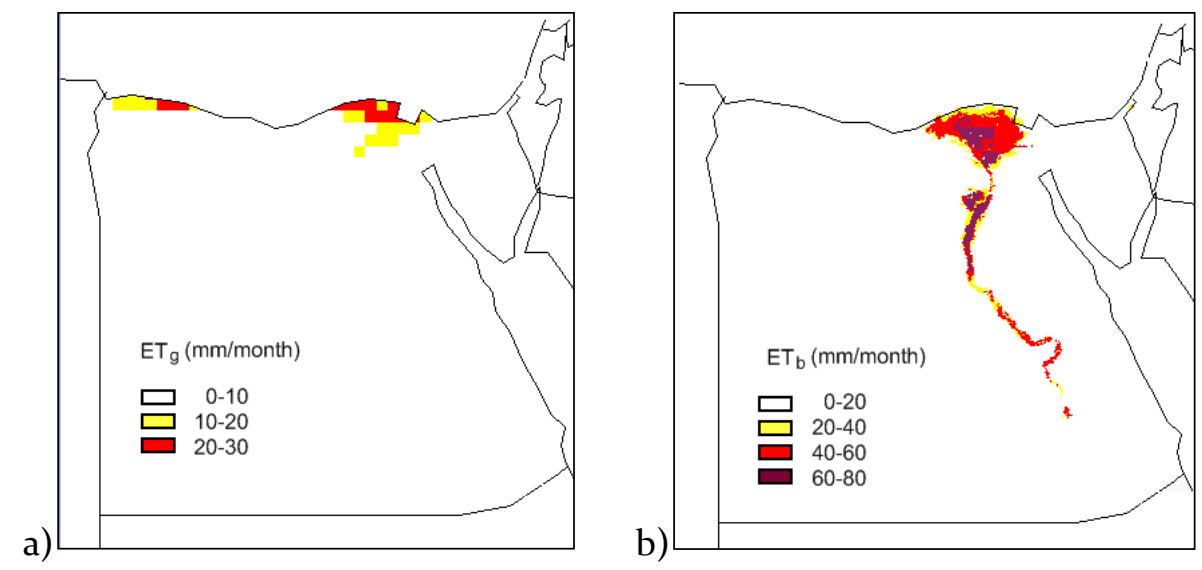

Figure 2.3. (a) Monthly green ET and (b) Monthly blue ET obtained in October 2009, using remote sensing data in Egypt.

Extending these calculations over the entire crop growing period and combining them with data on crop yield and land use, following the approach of Hoekstra et al. (2009), will eventually provide the WF for these crops (equations (2.3) and (2.4)). As an illustration, Table 2.2 provides some existing 
blue and green WFs of wheat for different countries obtained for the period 1996-2005 by Mekonnen and Hoekstra (2010). These countries have the largest blue water footprints of wheat, accounting for $88 \%$ of the total blue WF related to wheat production. Aggregated WF values for all Egypt have a value of 47,330 $\mathrm{Mm}^{3} /$ year obtained for the period 1997-2001 in Hoekstra and Chapagain (2008).

Table 2.2. Blue and green water footprint of wheat in India, China, Pakistan, Iran, Egypt, United States and total in the world obtained for the period 1996-2005 (from Mekonnen and Hoekstra, 2010).

\begin{tabular}{|c|c|c|}
\hline Country & $\begin{array}{c}\text { Blue WF } \\
\left(\mathbf{M m}^{3} / \text { year }\right)\end{array}$ & $\begin{array}{c}\text { Green WF } \\
\left(\mathbf{M m}^{3} \text { /year }\right)\end{array}$ \\
\hline India & 81,335 & 44,025 \\
\hline China & 47,370 & 83,459 \\
\hline Pakistan & 27,733 & 12,083 \\
\hline Iran & 10,940 & 26,699 \\
\hline Egypt & 5,930 & 1,410 \\
\hline United States & 5,503 & 111,926 \\
\hline World & 203,744 & 760,301 \\
\hline
\end{tabular}

\subsection{Discussion}

\subsubsection{Uncertainty}

In this chapter, the use of remote sensing estimates is proposed for mapping actual irrigation, using equation (2.1), where inaccuracies will propagate and combine in the underlying data. The contribution of the different parameters to the total error in I is assessed by means of a sensitivity analysis using the first order Taylor series expansion, where the covariance terms have been neglected and linearity has been assumed:

$$
\begin{aligned}
\sigma(I) & =\sqrt{\left(\frac{\partial I}{\partial P}\right)^{2} \cdot \sigma^{2}(P)+\left(\frac{\partial I}{\partial E T}\right)^{2} \cdot \sigma^{2}(E T)+\left(\frac{\partial I}{\partial Q}\right)^{2} \cdot \sigma^{2}(Q)+2 \cdot\left(\frac{\partial I}{\partial S}\right)^{2} \cdot \sigma^{2}(S)} \\
& =\sqrt{\sigma^{2}(P)+\sigma^{2}(E T)+\sigma^{2}(Q)+2 \cdot \sigma^{2}(S)}
\end{aligned}
$$

where $\sigma(\mathrm{I})$ is the standard deviation in the error of retrieving $\mathrm{I}, \partial / \partial x$ represent the partial derivatives with respect to $x$, with $x$ denoting a factor influencing I, 
and $\sigma(\mathrm{P}), \sigma(\mathrm{ET}), \sigma(\mathrm{Q}), \sigma(\mathrm{S})$ are the standard deviations associated to the errors in estimating $\mathrm{P}, \mathrm{ET}, \mathrm{Q}$ and $\mathrm{S}$. The change in storage $(\mathrm{dS} / \mathrm{dt})$ is calculated as the subtraction of two estimates of $S$, therefore a factor of 2 is added in the sensitivity analysis.

The components of the uncertainty given in equation (2.6) are determined through prior knowledge of the range of their actual values. CMORPH precipitation estimates are highly dependent on the rainfall regime (Ebert et al., 2007; Tian et al., 2007), with biases of $\pm 10 \%$ during the cold season and between $50 \%$ and $175 \%$ during the warm season (Sapiano and Arkin, 2009). Kalma et al. (2008) showed that remote sensing data provided relative errors of $15-30 \%$ in evapotranspiration estimation. The storage term obtained from GRACE contains validation errors, in terms of 'equivalent water height', of 2-3 $\mathrm{cm}$, according to Liu et al. (2010). Finally, runoff estimates are highly dependent on the land surface model used in GLDAS, where validation activities provided annual differences lower than 30\% in the basins of Europe by using the VIC model (Zaitchik et al., 2010). In this analysis, three values for monthly precipitation (50, 100 and $200 \mathrm{~mm}$ ), and errors of $10 \%$ and $100 \%$ are considered. Three scenarios of ET are analyzed with values of 0,5 and 10 $\mathrm{mm} /$ day and a value of $2.5 \mathrm{~cm}$ is assumed for the accuracy of the storage term. An average value of $100 \mathrm{~mm} / \mathrm{month}$ and an error of $15 \%$ are considered for the runoff.

The advantage of using equation (2.6) is that the relative contribution of each error component to the total error level in the irrigation map can be easily computed. The analysis of the relative errors shows that in the case of a low precipitation error, the inaccuracy in I is mainly determined by the storage term, with values between 58 and $83 \%$, increasing with the precipitation value. When a higher precipitation error is considered, the precipitation term contributes to the total error for between 59 and 95\%. In all cases, the influence of ET and runoff errors is lower than $15 \%$. This means that the error in irrigation estimation is mainly influenced by the accuracy of the estimates for precipitation and water storage, and shows the necessity for improving the accuracy of precipitation and water storage figures derived from remote sensing data, as also reported by Sheffield et al. (2009). Alternatively, integration into the model of other data sources, such as higher resolution remote sensing estimates or ground data, may potentially improve the accuracy of the retrievals. Finally, the uncertainty in water footprint 
estimation will obviously also depend on model structure and on inaccuracies in crop classification and yield.

\subsubsection{Limitations}

This chapter proposes the use of EO estimates for mapping actual irrigation on a global scale. However, the combination of the different inputs provides limitations, since the data differ in terms of spatial coverage, spatial and temporal resolution and availability.

Global coverage will only be ensured when global evapotranspiration products become available or alternatively when derived from global remote sensing data as described in Section 2.3.3. Moreover, calculation of ET is partly hampered by clouds, since they are opaque to visible and infrared radiation from the surface, which form the main input for ET estimation. Modeling techniques, such as the work by Farah (2001), are needed to cover these intermediate periods. Special attention has to be paid to this phenomenon in tropical latitudes. Global ET products are foreseen from MODIS based on the Penman-Monteith equation (Mu et al., 2007) and from MSG satellites by applying a two-source model covering Europe, Africa and Mideast (Anderson et al., 2007b).

Moreover, the combination of multi-resolution data implies the use of specific fusion algorithms. Additional techniques are needed when multispectral data are combined, for example when retrieving ET with existing methods. An overview of these fusion techniques is provided in Dong et al. (2009).

The estimates also differ in terms of temporal resolution. This heterogeneity can be solved by aggregating the data to time steps of one month or a season.

Regarding the availability of data, the lack of operative global ET products constitutes one of the main limitations. In the near future, Meteosat 8 and 9 ET data will be operational, thus achieving coverage for Europe and Africa. Other global ET products foreseen are mentioned above and may alternatively be derived from existing remote sensing techniques. The availability of the remaining data in Table 2.1 ensures WF calculations from the year 2002 onwards. 
With respect to historical data, the ECMWF ReAnalysis (ERA 40 and ERA Interim (ECMWF, 2004, 2008)) provides meteorological data since 1979. Precipitation and runoff are obtained by assimilating different types of data, among them remote sensing information. GLDAS (Rodell et al., 2004) has been providing runoff estimates and water storage components, such as snow, soil moisture and canopy storage, since 1979. The land surface models of GLDAS partly incorporate remotely sensed data. Groundwater historical data may be obtained from national and regional administrations, although in a limited temporal and spatial resolution. Alternatively, groundwater may be modeled by using hydrological approaches (Barthel et al., 2009; Chatterjee and Purohit, 2009). Evapotranspiration may be derived from historical data sets like 'Pathfinder AVHRR/8 km land (PAL)' (Agbu and James, 1994), which are available in terms of brightness temperature and top of the atmosphere reflectance for the years 1981-1999.

Furthermore, the combination of parameters obtained from different sources with different methods may lead to consistency problems. For example, precipitation is used in two steps of the calculations. Firstly it is obtained from MW and IR observations in CMORPH. Secondly, precipitation is an input in GLDAS, which is used to estimate runoff. The precipitation in GLDAS is obtained from the US Naval Research Laboratory (NRL) and the Goddard Space Flight Center (GSFC) products, whereas CMORPH estimates are calculated independently. This may lead to methodological differences and therefore special attention must be paid to the consistency of these estimates.

Different data sets are available for estimating the WF as shown in Table 2.1. Of these sets, CMORPH precipitation and MODIS ET products have the highest spatial resolution while providing global coverage. GRACE data have the advantage of accounting for groundwater from a remote sensing point of view, but have a coarse resolution $(400 \mathrm{~km})$. With respect to runoff, consistency of the estimates needs to be assessed as discussed in the example above. Furthermore, runoff must be investigated jointly with precipitation and irrigation in order to properly subdivide ET into blue and green components. 
Recognizing the use of GRACE data constitutes a limitation in this model in terms of spatial resolution, leading to several issues. Firstly, the gravity field based observation techniques are continuously improved, as was shown with the launch in March 2009 of the Gravity field and steady-state Ocean Circulation Explorer (GOCE), which achieves a spatial resolution finer than $100 \mathrm{~km}$. Secondly, GRACE estimates may be combined with soil moisture remote sensing products at a higher resolution, such as the Special Sensor Microwave/Imager (SSM/I) estimates with a spatial resolution of 70 by $45 \mathrm{~km}$ and available since early 9os. Finally, data assimilation may also be considered in the model in order to support the remote sensing data with ground truth observations. This will bring the necessity of harmonization of data, in terms of pixel resampling and calibration, and spatial modeling, so that the data are merged and analyzed in a data information system.

In general, downscaling techniques may be used to increase the resolution of remote sensing data. However, the debate is ongoing in defining the spatial resolution needed for observing the processes, while at the same time preserving feasibility for application with global coverage. For example, ground water and precipitation could be analyzed at lower resolution than evapotranspiration or soil moisture, since the processes occur at a higher scale and they present a lower spatial variability. Therefore, relevant scales should be defined, and in some cases the relation between remote sensing input and the processes that occur in the field will be difficult to observe.

\subsection{Conclusions}

This chapter describes the potential of using remote sensing techniques for global water footprint estimation. The parameters involved in the proposed method are precipitation, evapotranspiration, water storage, surface runoff and land use. These parameters may be acquired from available global products or alternatively may be derived with existing methods. A mass water balance is proposed to calculate the volume of irrigation applied, and green and blue WF are obtained from the green and blue evapotranspiration components. The combination of data in this approach brings several limitations with respect to discrepancies in spatial and temporal resolution and data availability. At the moment of writing this chapter, the major limitation is the lack of operative global ET products to be obtained through remote sensing. Furthermore, the coarse spatial resolution of the water 
storage term obtained with GRACE, may be improved by using techniques of data assimilation and downscaling. Regarding the accuracy of the approach, the sensitivity analysis shows the necessity for improving the accuracy of precipitation and water storage figures derived from remote sensing data. Moreover, the separation of ET into de blue and green components requires a more elaborate modeling for accounting for the diversity of scenarios. In general terms, WF calculations using remote sensing can only be carried out over recent years (2002-present). However, ancillary data taken from alternative sources may be used, such as meteorological data from ECMWF, or land surface models that run with reanalysis data, together with remote sensing databases such as the Pathfinder database. This will ensure time coverage from the year 1979 onwards. 


\title{
Chapter 3
}

\section{A First Approach to Separate Green and Blue Water Evapotranspiration Using Remote Sensing Based Soil Moisture Products and GLDAS Hydrological Data ${ }^{2}$}

\begin{abstract}
In this chapter we propose an approach to decompose the water footprint (WF) using remote sensing data on a global scale. The WF of a crop is defined as the volume of water consumed for its production, where green and blue WF stand for rain and irrigation water usage, respectively. A method has been developed to separate WF into its green and blue components by analysing time series of earth observation data and model simulations on precipitation, soil moisture, evapotranspiration (ET), runoff and water storage. The model takes into account the typical timescale of ET decay in absence of precipitation. Soil moisture estimates are retrieved from the Advanced Microwave Scanning Radiometer-Earth Observing System (AMSRE), and the Global Land Data Assimilation System (GLDAS) are employed as a test dataset. The results show the identification of irrigation events and preliminary green and blue water calculations allowing us to assess the potential of the method.
\end{abstract}

${ }^{2}$ Based on Romaguera et al. (2012b) 


\subsection{Introduction}

The water footprint (WF) was introduced by Hoekstra (2003) as an indicator that relates human water consumption to global water resources. The WF of a crop is defined as the volume of water consumed for its production, where green and blue WF stand for rain and irrigation water usage, respectively. In this context, remote sensing techniques have the potential to improve existing estimations in terms of spatial coverage and temporal and spatial resolution which allow for monitoring the physical processes in appropriate time scales (Romaguera et al., 2010). In this chapter a physical method, based on remote sensing data, is developed to separate the green and blue components of the WF. We describe the methodology and the used data and show the results of irrigation events and preliminary blue and green water estimates.

\subsection{Methodology}

The WF of a crop is defined as the ratio between the evapotranspiration (ET) and the crop yield, computed over the cropping period (Hoekstra et al., 2009). The methodology proposed in this chapter for separating ET to its blue and green components ( $\mathrm{ET}_{\mathrm{b}}$ and $\mathrm{ET}_{\mathrm{g}}$ respectively) is based on the analysis of the hydrological parameters precipitation (P), ET, soil moisture (SM), runoff $(\mathrm{Q})$, and snow and canopy water storage, using remote sensing data and retrieval techniques. A more extended discussion about the potential of remote sensing to WF studies and the approach followed by other authors is described in Romaguera et al. (2010). As a first step, this methodology proposes the identification of irrigation events by analysing the daily time series of P, SM magnitudes and SM standardised anomalies as:

$$
S M_{\text {anom }}=\frac{S M-S M_{\text {mean }}}{\sigma}
$$

where $S M$ is the soil moisture in a particular day and $S M_{\text {mean }}$ and $\sigma$ are the SM mean and standard deviation values calculated over a longer period of time (e.g. one year). An irrigation event is identified in a particular day when $\mathrm{P}$ is insufficient and the $S M_{a n o m}$ is significant. Appropriate thresholds need first to be defined for this purpose. Secondly, in order to quantify the $\mathrm{ET}_{\mathrm{b}}$ values, the 
time scale of one month ' $i$ ' is considered and three contributions of irrigated water are included:

$$
E T_{b i}=I_{i}+I_{i_{(i n)}}-I_{i(o u t)}
$$

where $I_{i}$ is the irrigation water consumed by ET in month ' $i$ ', $I_{i(i n)}$ is the irrigation water in the month ' $i-1$ ' that leads to ET in month ' $i$ ', and $I_{i(\text { out })}$ is the irrigation water in the month ' $i$ ' that transforms into ET in month ' $i+1$ '. These two last terms are related as follows:

$$
I_{i_{+1(\text { in })}}=I_{i_{(\text {out })}}
$$

The value of $I_{i}$ is obtained using the mass conservation equation on a monthly base as suggested by Romaguera et al. (2010):

$$
P_{i}+I_{i}=E T_{i}+Q_{i}+(d S / d t)_{i}
$$

where $P$ is precipitation, $I$ is actual irrigation, ET is actual evapotranspiration, $Q$ is surface runoff/streamflow, and $S$ is water storage in a vertical column (snow, canopy water storage, soil moisture and groundwater). We assume that in water limited conditions the ET decay follows an exponential decay function. Therefore, an irrigation event that occurred about ' $d$ ' days before the end of the month ' $i-1$ ' contributes to the $E T_{b i}$, in a magnitude considered as:

$$
I_{i(i n)}(d)=I_{\text {event }(i-1)} \exp (-5 \cdot d / \lambda) \quad t \leq \lambda
$$

where $\lambda$ is the ET e-folding time (in days) and $I_{\text {event }(i-1)}$ is the magnitude of the irrigation event calculated as the ratio between the total $I_{i-1}$ and the number of irrigation events, obtained following the aforementioned SM anomalies analysis. The value of $\lambda$ depends on soil and crop type, climate and initial soil moisture conditions. However, in absence of precipitation and under conditions where root water uptake by vegetation for ET is limited by the availability of soil moisture storage, it may be modelled by using a time series of daily ET following the approach of Teuling et al. (2006): 


$$
\ln E T(t)=-\frac{t-t_{0}}{\lambda}+\ln E T_{0}
$$

where initial conditions with 'o' subscripts indicate the value at the day of precipitation event, $t$ is the variable time (days) and therefore $\lambda$ is related with the slope of the linear regression.

Finally, the green component of ET in month $i$ will be given by:

$$
E T_{g_{i}}=E T_{i}-E T_{b_{i}}
$$

\subsection{Data}

AMSR-E soil moisture products from the University of Amsterdam (Owe et al., 2008) are used in this chapter for analysing the soil moisture anomalies during 2007. The descending overpass of the polar satellite is used, which provides values around o1:30 h local solar time. These data have a resolution of $0.25^{\circ}$ and provide daily coverage of the globe. Data on ET, Q, P, SM, snow and canopy storage are taken from GLDAS (Rodell et al., 2004) with the land surface model developed by National Centers for Environmental Prediction/Oregon State University/Air Force/Hydrologic Research Lab (Noah) during 2007. The data have a resolution of $0.25^{\circ}$ and a temporal frequency of $3 \mathrm{~h}$. ET and P values are also considered for the period 2001-2009 in order to analyse the climatology of the $\lambda$ parameter.

\subsection{Results}

\subsubsection{Identification of Irrigation Events}

According to the presented methodology, SM anomalies obtained from AMSR-E and P from GLDAS were analysed. Figure 3.1 shows how precipitation events influence the SM anomalies, and how other anomalies may be associated to irrigation events in absence of $\mathrm{P}$, especially in arid and semi-arid areas. For identifying irrigation events in the present chapter, a minimum of 1.0 in the value of SM anomalies is established, together with a $\mathrm{P}$ maximum value of $1 \mathrm{~mm} / \mathrm{d}$, since we consider that values below that threshold do not affect significantly in the SM anomalies. 
(a)

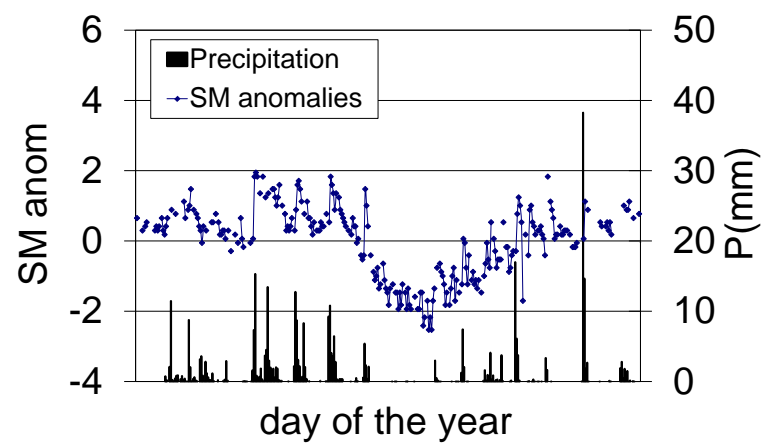

(b)

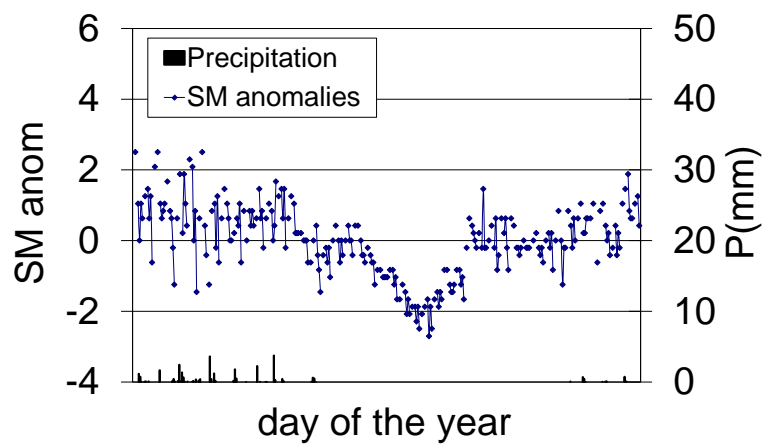

(c)

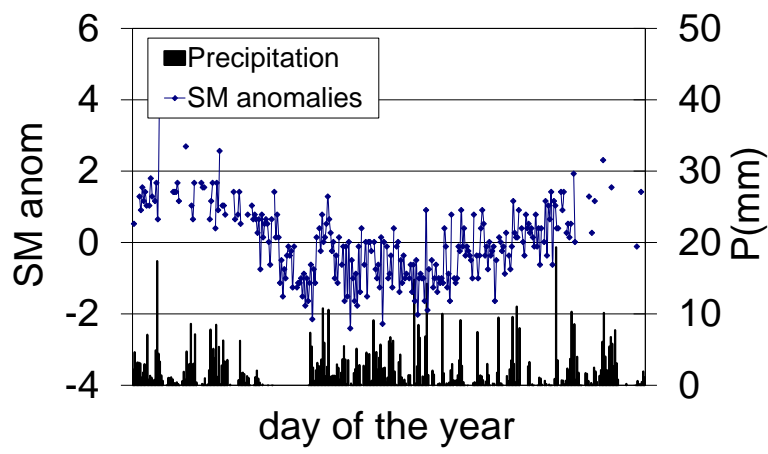

Figure 3.1. Standardized SM anomalies and P during the year 2007 in three areas: (a) a semi-arid crop land area located in Barrax, Spain, (b) an arid crop land located in Egypt, and (c) a humid crop land area in the north of France. 


\subsubsection{Calculation of $\lambda$}

In order to calculate the time scale of the SM depletion $\lambda$, GLDAS ET and P data were computed in a daily base and equation (3.6) was used to carry out the linear regressions. A threshold of $1 \mathrm{~mm} / \mathrm{d}$ was used for precipitation and a minimum of 10 days between precipitation events was set as a requirement. Figure 3.2 shows the $\lambda$ mean value, standard deviation and number of data points used to retrieve $\lambda$, computed for 2001-2009 in the period JulySeptember. Filters were applied when $r^{2}$ was lower than 0.75 and for negative values of $\lambda$. The results show that most of the areas exhibit drying periods lower than 15 days, with standard deviations below 5 days and number of data points up to 10. Figure 3.2 also shows the existence of areas where this approach does not provide any result due to the requirements in terms of precipitation values and dry periods.

\subsubsection{Separation of $E T_{g}$ and $E T_{b}$}

After identifying the irrigation events and obtaining the value of $\lambda$, the proposed methodology was applied to July 2007 for obtaining $\mathrm{ET}_{\mathrm{b}}$ and $\mathrm{ET}_{\mathrm{g}}$. Daily values of $I$ were calculated from equation (3.4) using GLDAS data and assuming constant groundwater values. Anomalies in irrigation were calculated analogously to equation (3.1). Monthly values of $I$ were computed accumulating irrigation values associated to irrigation anomalies higher than 1.o. The results (Figure 3) show a gradient north-south. The ratio green and blue ET is spatially very plausible. The ET in the regions of northern Europe is highly dominated by the green component during the month of July with values up to $140 \mathrm{~mm}$. The blue component has a lower range than the green and is dominant in regions where precipitation is scarce in the period of analysis, e.g. Spain, Italy and Greece. Extending these calculations over the entire crop growing period and combining them with data on crop yield and land use will eventually provide the green and blue WF for these crops. 


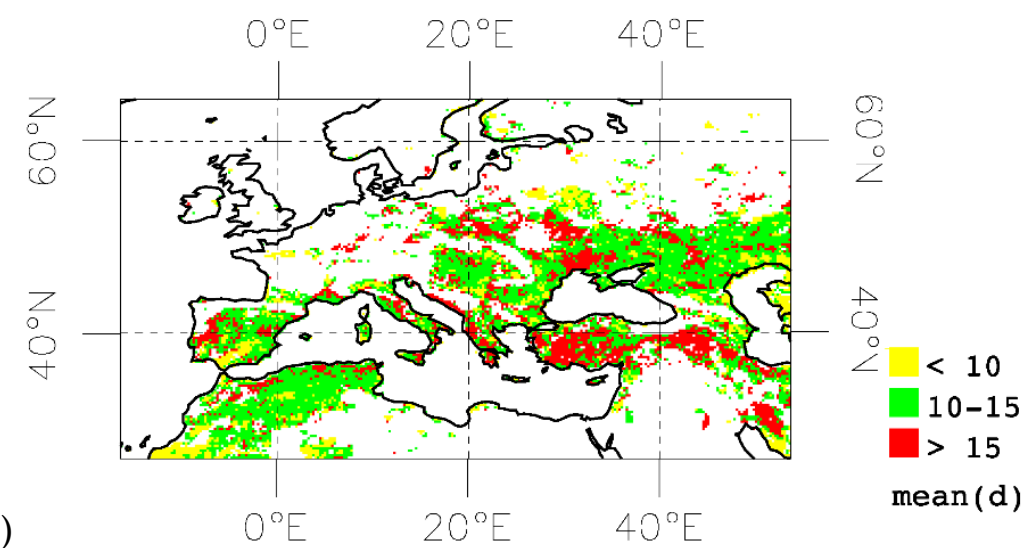

b)
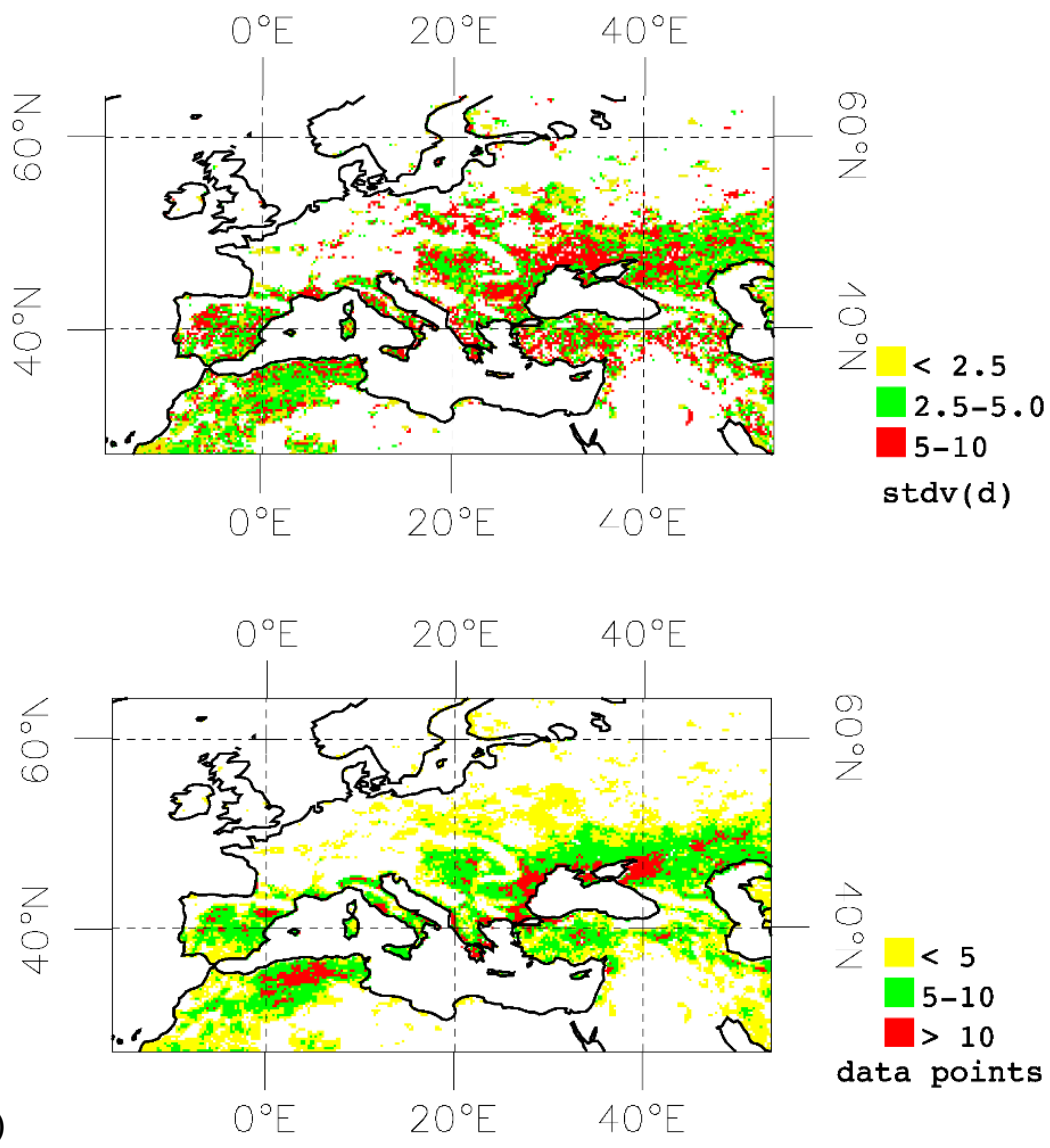

Figure 3.2. (a) Mean value of $\lambda$ (days), (b) standard deviation (days) and (c) number of data points used for the statistics obtained between 2001 and 2009 in the period JulySeptember. 
a)

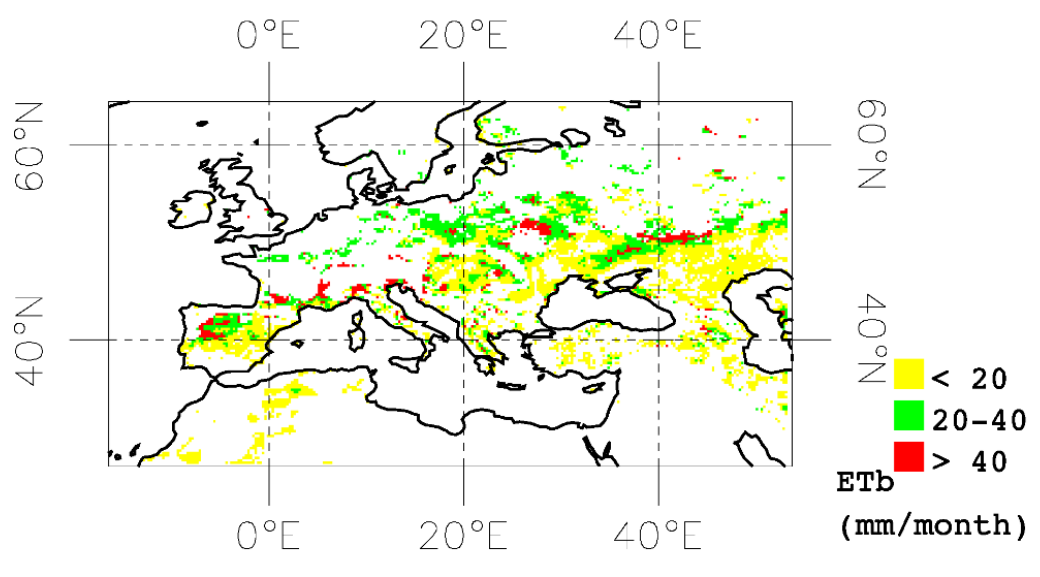

b)

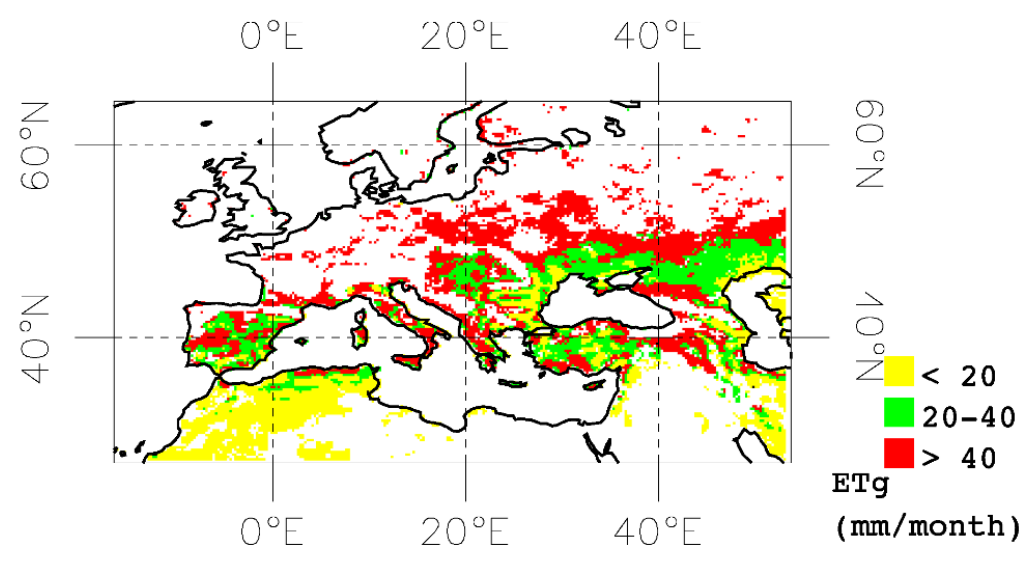

Figure 3.3. (a) Blue and (b) green ET obtained in July 2007 following the proposed methodology.

\subsection{Discussion}

In this chapter we showed the utilities of remote sensing-retrieved soil moisture anomalies and precipitation values for identifying irrigation events at coarse scale. However, special attention needs to be paid to the values of the thresholds and to the time scale of the analysis. Due to the sensor observation geometry, particular areas may not have SM value on specific dates, which would prevent finding anomalies. Moreover, the image acquisition time also plays an important role since precipitation 
and irrigation events may occur after it, and therefore the effect on SM anomalies may not be observed or may be delayed. Time shifts of a day or moving averages may be considered to deal with these issues. Second, thresholds in SM anomalies and precipitation are established based on the data and on physical processes respectively. A more accurate definition may be adopted considering the variability in latitude and seasonal changes.

Semi-arid conditions are found to be optimal for the performance of the method. Arid areas allow identifying irrigation events but $\lambda$ cannot be estimated in specific seasons due to the lack of P. Humid areas present the same difficulty due to frequent $\mathrm{P}$ events. Values of $\lambda$ obtained during other seasons may be used in those cases or relations with the land use should be defined. The results of the ETb and ETg are plausible and look to be highly dependent on the ET input, which presents the observed ET gradient.

Finally, the validation of the method is hampered by the lack of in situ measurements. However, different attempts have been carried out. An analysis in the area of Barrax (not shown here) has shown the agreement in the predicted and in situ irrigation periods during 2009. Indirect tests have been performed (not shown here) by comparing the identification of I events with daily values of I obtained from equation (3.4) using GLDAS inputs and assigning thresholds. The results show confidence on the methods. By knowing that the scale of the analysis is a methodological issue in the proposed approach, the next steps on this research will be focused on resolving it.

\subsection{Conclusions}

In this chapter we developed a method to estimate the blue and green components of WF using remote sensing products of soil moisture and precipitation. It is shown that the green and blue components of WF can be estimated on global scale using remote sensing data and land surface model predictions. The results of $\mathrm{ET}_{\mathrm{b}}$ and $\mathrm{ET}_{\mathrm{g}}$ are plausible and look to be highly dependent on the ET input, which presents the observed ET gradient. The proposed method is sensitive to the thresholds selection, time scale of the analysis, and study area, and therefore spetial attention needs to be paid in these aspects. 


\title{
Chapter 4
}

\section{Determining Irrigated Areas and Quantifying Blue Water Use in Europe Using Remote Sensing Meteosat Second Generation (MSG) Products and Global Land Data Assimilation System (GLDAS) Data $^{3}$}

\begin{abstract}
In this chapter, we propose an innovative method for identifying irrigated areas and quantifying the blue evapotranspiration $\left(\mathrm{ET}_{\mathrm{b}}\right)$, or irrigation water evapotranspired from the field. The method compares actual ET ( $\left(\mathrm{ET}_{\text {actual }}\right)$, or crop water use, values from the Global Land Data Assimilation System (GLDAS) and remote sensing based $\mathrm{ET}_{\text {actual }}$ estimates obtained from Meteosat Second Generation (MSG) satellites. Since GLDAS simulations do not account for extra water supply due to irrigation, it is expected that they underestimate $\mathrm{ET}_{\text {actual }}$ during the cropping season in irrigated areas. However, remote sensing techniques based on the energy balance are able to observe the total $\mathrm{ET}_{\text {actual }}$. In order to isolate irrigation effects from other fluctuations that may lead to discrepancies between the different $\mathrm{ET}_{\text {actual }}$ products, the bias between model simulations and remote sensing observations was estimated using reference targets of rain-fed (nonirrigated) croplands on a daily basis in different areas across the study region (Europe). Analysis of the yearly values of $\mathrm{ET}_{\mathrm{b}}$ (irrigated area and volume obtained for croplands in Europe for 2008) showed that the method identified irrigation when yearly values were higher than $50 \mathrm{~mm}$. The accuracy of the method was assessed by analyzing the spatial representativity of the calculated biases and evaluating the daily $\mathrm{ET}_{\mathrm{b}}$ values obtained. The irrigated areas were compared with the results provided by Siebert et al. (2007) and Thenkabail et al. (2009a), obtaining a spatial match of 47 and $72 \%$ respectively with overestimation of irrigated area on a country scale. Additional evaluation with the $\mathrm{ET}_{\mathrm{b}}$ results of Mekonnen and Hoekstra (2011) showed $75 \%$ of overlap for $\pm 50 \mathrm{~mm}$ range. Finally, validation with in situ data on irrigation volumes proved the cogency of our method with less than $20 \%$ difference between derived and measured values.
\end{abstract}

${ }^{3}$ Based on Romaguera et al. (2012a) 


\subsection{Introduction}

Monitoring and quantification of irrigation practices play an important role in water management activities and global water resources since water is becoming a scarce but essential resource.

In this context, the concept of actual evapotranspiration $\left(\mathrm{ET}_{\mathrm{actual}}\right)$ has been widely used to assess the usage of water resources and irrigation practices by using ground based and/or remote sensing data (D'Urso et al., 2008; Gowda et al., 2008). These studies have been focused on predicting the optimal irrigation supply based on the crop water demand. Other works have established the difference between the blue and green components of $\mathrm{ET}_{\text {actual }}$, that is the irrigation and precipitation water usage (Siebert and Döll, 2010; Mekonnen and Hoekstra, 2011)

Irrigation practices influence water availability for evapotranspiration and $\mathrm{ET}_{\text {actual }}$ at regional scale, which is also reflected in the partitioning of energy between sensible and latent heat flux. As an example, Ozdogan et al. (2010) simulated the effects of including irrigation as an extra water supply in the Noah land surface model (Chen et al., 1996; Koren et al., 1999) and showed that the increment in daily $\mathrm{ET}_{\text {actual }}$ reached up to $5 \mathrm{~mm}$ /day in extreme situations in the United States. Noah is based on the energy and water conservation laws and is forced by precipitation among others. It is a budget based land surface model that does not account for irrigation practices.

In the validation report LSA-SAF (2010b), the Global Land Data Assimilation System (GLDAS) ET $_{\text {actual }}$ products generated with Noah, named GLDAS-ET in the following, are compared with the remote sensed $\mathrm{ET}_{\text {actual }}$ estimates obtained from Meteosat Second Generation (MSG) satellites (GellensMeulenberghs et al., 2007), named MSG-ET in the following. The latter model is based on the physical processes that occur and the inputs are taken from remote sensing retrievals. This comparison shows some differences in several areas especially during summer periods. The authors justify these discrepancies by analyzing the differences in the inputs used in the two models, but no reference is made to the fact that the Noah model does not account for irrigation practices which may lead to the $\mathrm{ET}_{\text {actual }}$ differences that are found along Europe, Africa and South America. The comparison in the aforementioned work was carried out at continental scale in a statistical 
manner by using temporal and/or spatial averages which does not allow extracting more detailed information about the seasonality and spatial variation of these differences.

Therefore, the objective of this chapter is to compare the $\mathrm{ET}_{\text {actual }}$ outputs of the two aforementioned models, GLDAS-ET and MSG-ET, at a daily and grid base with continental coverage, by assuming that the discrepancies are partly due to the fact that irrigation (or blue evapotranspiration, $\mathrm{ET}_{\mathrm{b}}$ ) is only represented in the MSG-ET model. This allows determining irrigated areas and comparing with existing irrigation maps such as the ones obtained by Siebert et al. (2007) and Thenkabail et al. (2009a). Moreover, volumes of $E_{b}$ may be contrasted with the blue water footprint calculations by Mekonnen and Hoekstra (2011).

Section 4.2 of this chapter describes the datasets used and the physical background of the two models. The methodology is explained in section 4.3. In order to isolate the irrigation effects from other sources of differences, such as modeling, type of inputs or scale issues, rain-fed croplands are used to calculate a spatially-dependent reference bias between the models. Based on the analysis of the inputs of the two models and some previous analysis carried out at LSA-SAF (2010b), the MSG observation geometry and the Normalized Difference Vegetation Index (NDVI) and its seasonality appear to be factors that contribute to explain the discrepancies between the models. Therefore, the bias is defined as a function of the MSG viewing zenith angle, maximum value of the NDVI and the season where NDVI is maximum. In results section 4.4 a classification map is produced with a total of 12 reference biases in Europe, and $\mathrm{ET}_{\mathrm{b}}$ is calculated in 2008. The assessment of the accuracy of the method is included in this section. Finally section 4.5 compares the obtained irrigated areas with the irrigation maps given by Siebert et al. (2007) and Thenkabail et al. (2009a), at pixel scale and country aggregated. Additionally, volumes of $\mathrm{ET}_{\mathrm{b}}$ are compared with the results given by Mekonnen and Hoekstra (2011), and in situ values of irrigation are used to compare with downscaled $\mathrm{ET}_{\mathrm{b}}$ values at point scale.

\subsection{Data sets}

The main datasets used in this research are the $\mathrm{ET}_{\text {actual }}$ obtained from MSG satellites (MSG-ET) and the $\mathrm{ET}_{\text {actual }}$ data from the GLDAS dataset (GLDAS- 
ET). Other inputs are the GlobCover land cover classification (UCLouvain and ESA, 2011), the NDVI dataset generated by the Deutsches Zentrum für Luft- und Raumfahrt (DLR) and the MSG viewing zenith angle (VZA). In order to evaluate the accuracy of the proposed method, the results are compared with the Global Map of Irrigation Areas (Siebert et al. 2005, 2007), the Global Irrigated Area Map (Thenkabail et al. 2009a) and the blue Water Footprint results given by Mekonnen and Hoekstra (2011). Table 4.1 shows the main specifications of these data.

From a technical point of view, the combination of data with different spatial resolution, extent and projection was tackled by creating a layer stack where the data were resampled and re-projected to a common output projection and pixel size. The classification map was created at a resolution of $1 \mathrm{~km}$. The reference biases were calculated in rain-fed pixels using data at $300 \mathrm{~m}$ in order to preserve the resolution of the GlobCover map. Finally, the $\mathrm{ET}_{\mathrm{b}}$ outputs were obtained at $1 \mathrm{~km}$ resolution and rescaled to 5 arc minutes in order to compare with the existing maps.

\subsubsection{MSG-ET Data}

The $\mathrm{ET}_{\text {actual }}$ products from the MSG satellites are provided by the Land Surface Analysis Satellite Application Facility (LSA-SAF) at a resolution of $3 \mathrm{~km}$ at sub-nadir point which increases with the satellite observation angle, and a temporal frequency of 30 minutes. These data cover the continents of Europe and Africa and partly South-America and are available since January 2007 for Europe and September 2009 for the rest.

The methodology to retrieve $\mathrm{ET}_{\text {actual }}$ is based on the physical processes and exchange of energy between the ground surface (soil and canopy) and the atmosphere, and uses inputs derived from the MSG satellites. 
Table 4.1. Specifications of the datasets used in this chapter.

\begin{tabular}{|c|c|c|c|c|c|}
\hline Data & Source & $\begin{array}{c}\text { Spatial } \\
\text { coverage }\end{array}$ & $\begin{array}{l}\text { Spatial } \\
\text { Resol. }\end{array}$ & $\begin{array}{l}\text { Temporal } \\
\text { Resol. }\end{array}$ & Details \\
\hline \multirow{2}{*}{$\mathbf{E T}_{\text {actual }}$} & MSG & MSG disk* & $\begin{array}{l}3 \mathrm{~km} \text { at } \\
\text { nadir }\end{array}$ & $30^{\prime}$ & $\begin{array}{l}\text { Availability of data: } \\
\text { Europe: Jan. } 2007 \text {-present } \\
\text { The rest: Sept. 2009-present }\end{array}$ \\
\hline & GLDAS & Global & $\begin{array}{l}0.25^{\circ} \\
(\sim 30 \mathrm{~km} \text { at } \\
\text { equator })\end{array}$ & $3 \mathrm{~h}$ & $\begin{array}{l}\text { Availability of data: } \\
\text { February 200o-present }\end{array}$ \\
\hline Class & MERIS & Global & $300 m$ & Static & $\begin{array}{l}\text { GlobCover map calculated in } \\
\text { year } 2009\end{array}$ \\
\hline NDVI & AVHRR & Europe & $1 \mathrm{~km}$ & Monthly & $\begin{array}{l}\text { Composites obtained in year } \\
1997\end{array}$ \\
\hline VZA & MSG & MSG disk* & $\begin{array}{l}5 \text { arcmin } \\
(\sim 10 \mathrm{~km} \text { at } \\
\text { equator })\end{array}$ & Static & Range: $0-90^{\circ}$ \\
\hline \multirow{3}{*}{ Irrigation } & GMIA & \multirow{3}{*}{ Global } & \multirow{3}{*}{$\begin{array}{l}5 \text { arcmin } \\
(\sim 10 \mathrm{~km} \text { at } \\
\text { equator })\end{array}$} & \multirow{3}{*}{ Static } & $\begin{array}{l}\text { Siebert et al. (2007) } \\
\text { Calculated around year } 2000 \\
\text { Data: \% of irrigated area }\end{array}$ \\
\hline & GIAM & & & & $\begin{array}{l}\text { Thenkabail et al. (2009a, b) } \\
\text { Calculated around year } 1999 \\
\text { Data: Irrigation source, } \\
\text { intensity \& crop dominance }\end{array}$ \\
\hline & Blue WF & & & & $\begin{array}{l}\text { Mekonnen \& Hoekstra (2011) } \\
\text { Data: annual blue WF }\end{array}$ \\
\hline
\end{tabular}

${ }^{*}$ Meteosat disk covers latitudes between $-60^{\circ}$ and $+60^{\circ}$ and longitudes between $-60^{\circ}$ to $+60^{\circ}$.

**List of acronyms: MSG (Meteosat Second Generation), GLDAS (Global Land Data Assimilation System), MERIS (Medium Resolution Imaging Spectrometer), AVHRR (Advanced Very High Resolution Radiometer), GMIA (Global Map of Irrigated Areas), GIAM (Global Irrigated Area Map), WF (Water Footprint) 
The method is based on forcing a Soil-Vegetation-Atmosphere-Transfer (SVAT) scheme with relevant data (short and long-wave radiation fluxes $(S \downarrow$ and $L \downarrow$ ), surface albedo $(\alpha)$, leaf area index (LAI), fraction of vegetation cover (FVC) and snow cover) derived from Meteosat and auxiliary data (air temperature, specific humidity, wind speed, atmospheric pressure, etc.) from other sources, mainly from the European Center for Medium-Range Weather Forecast (ECMWF) (Gellens-Meulenberghs et al., 2007). It is an energy balance model aiming to compute the partition of net radiation $\left(\mathrm{R}_{\mathrm{n}}\right)$ into sensible heat flux $(\mathrm{H})$, latent heat flux (LE) and heat conduction flux into the ground $(\mathrm{G})$ according to:

$$
R_{n}-H-L-G=0
$$

The computations are carried out at tile level and an iteration method is needed to solve the involved equations. A gap filling procedure is implemented in pre-processing when $S \downarrow$ is not available and in postprocessing when $\mathrm{ET}_{\text {actual }}$ cannot be calculated because of missing input variables or no convergence of the algorithm (LSA-SAF, 2010a). This process allows generating $\mathrm{ET}_{\text {actual }}$ products including cloudy pixels.

In the research presented, daily MSG-ET values were obtained by temporal integration of the 48 instantaneous values per day, during the year 2008 . Linear interpolation in time was used to fill in missing data, due to non acquisitions. Daily $\mathrm{ET}_{\text {actual }}$ values were not considered if missing data occurred during periods of one hour or longer. In general terms, the daily $\mathrm{ET}_{\text {actual }}$ was calculated for $85 \%$ of the days along the year 2008, and for $94 \%$ if the 5 month period May-September was considered.

Additional data from 2009 were used to test the method with in situ data, for which MSG-ET data were acquired between July $10^{\text {th }}$ and September $8^{\text {th }}$. Daily $\mathrm{ET}_{\text {actual }}$ was obtained for the $89 \%$ of the days in this case.

\subsubsection{GLDAS-ET Data}

The GLDAS datasets are available from the NASA Goddard Earth Sciences Data and Information Services Center (GES DISC). (http://disc.sci.gsfc.nasa.gov/ hydrology/data-holdings). 
The system ingests satellite and ground-based observational data products and uses land surface modeling and assimilation techniques in order to generate optimal fields of land surface states and fluxes (Rodell et al., 2004). The GLDAS data used in this chapter are generated with the Noah land surface model (Chen et al., 1996; Koren et al., 1999) at a resolution of $0.25^{\circ}$ and a temporal frequency of 3 hours. These data cover the whole globe since February 2000.

The model is based on the principles of water and energy conservation laws, in particular, the water budget is formulated by:

$$
\frac{d W}{d t}=P-E T_{\text {actual }}-Q
$$

where $\mathrm{dW} / \mathrm{dt}$ is the change in the total water storage within a time period (dt) $[\mathrm{mm}], P$ is the amount of precipitation within a time period $[\mathrm{mm}]$, $\mathrm{ET}_{\text {actual }}$ is the total evapotranspiration in a time period $[\mathrm{mm}]$ and $\mathrm{Q}$ is the total runoff in a time period $[\mathrm{mm}]$.

In Noah, the calculation of the fluxes LE and $H$ start from potential LE $\left(\operatorname{LE}_{\mathrm{p}}\right)$, based on the soil moisture, atmosphere states and vegetation characteristics. Constrains to $\mathrm{LE}_{\mathrm{p}}$ are applied resulting in the actual LE, which is composed out of three components: direct evaporation from soil, transpiration via plant stomata and evaporation of canopy intercepted water. Input data for these calculations are $S \downarrow, L \downarrow$, atmospheric forcings, $\alpha$, LAI, vegetation parameters, skin temperature, land cover, soil type, elevation and slope and precipitation. In the present research daily $\mathrm{ET}_{\text {actual }}$ values of GLDAS-ET were obtained by temporal averaging of the eight provided $\mathrm{ET}_{\text {actual }}$ rates per day. No missing data were found in this dataset.

\subsubsection{GlobCover Land Cover Map}

The Medium Resolution Imaging Spectrometer (MERIS) GlobCover (v. 2.3) product for the year 2009 (UCLouvain and ESA, 2011) is a land cover map produced at a $300 \mathrm{~m}$ resolution at a global scale. This map is based on classification techniques by using the surface reflectivities observed by the MERIS sensor, and distinguishes 22 cover classes defined with the United Nations Land Cover Classification system (LCCC), among them the post- 
flooding or irrigated croplands and rain-fed croplands. The latter was used in this research. Other classes describe different types and combinations cover types, such as shrublands, forests and grasslands. The idea behind the use of the MERIS product was to profit from the high resolution product as well as generating the irrigation areas and the $\mathrm{ET}_{\mathrm{b}}$ based on an independent dataset. This allowed comparing with the irrigation area provided by existing methodologies such as Siebert et al. (2007) and Thenkabail et al. (2009a).

\subsubsection{Monthly NDVI Products}

The monthly NDVI products that are employed in this research were generated from the Advanced Very High Resolution Radiometer (AVHRR) by the Deutsches Zentrum für Luft- und Raumfahrt (DLR). They were obtained during the year 1997, in Europe and at a resolution of $1 \mathrm{~km}$ (Mucher et al. 2001).

\subsubsection{MSG Viewing Zenith Angle}

The MSG's are geostationary satellites located at $36000 \mathrm{~km}$ of altitude. In particular, Meteosat-9, whose products are used in this research, was centred at $o^{\circ}$ latitude over the equator at the moment of writing this chapter. The satellite viewing zenith angle ranges from o up to $90^{\circ}$ in the edge of the field of view. In the region of Europe, this observation angle is higher than $40^{\circ}$.

\subsubsection{Irrigation Maps}

Siebert et al. $(2005,2007)$ provided a Global Map of Areas equipped for Irrigation (GMIA) with a spatial resolution of 5 arc minutes, around the year 20oo. This method combined sub-national statistical data with land cover information, providing results in terms of percentage of surface area equipped for irrigation.

Thenkabail et al. (2009a) developed the Global Irrigated Area Map (GIAM) with 28 classes and a spatial resolution of $10 \mathrm{~km}$, around year 1999. The method is based on classification and identification techniques to establish different classes of irrigated areas and to differentiate irrigated areas from non-irrigated areas, as it was also carried out by Thenkabail et al. (2007). 
Temporal series of remote sensing data were used in this work, such as reflectance values, brightness temperatures and NDVI. Precipitation data, a digital elevation model and a global tree cover map were also used as input as well, as well as ground data and Landsat Enhanced Tematic Mapper Plus (ETM+) mosaics. The global map provides classes labeled based on irrigation source (surface water, groundwater or conjunctive use), intensity (single, double or continuous crop) and crop dominance. In the present chapter, an aggregated map with 8 classes which provide watering method, irrigation type and intensity was used.

Mekonnen and Hoekstra (2011) estimated the global blue and green water footprint (WF), that is the water consumed for crop production, where blue and green WF stand for irrigation and rain water usage respectively. In their method, $\mathrm{ET}_{\text {actual }}$ and irrigation requirements were calculated according to Allen et al. (1998) using crop and stress coefficients. The total WF at each grid cell was estimated to be the weighted average of the WFs in a rain-fed and an irrigated scenario. The results were averaged between 1996-2005 at a resolution of 5 arc minutes.

\subsection{Method}

\subsubsection{Overview}

The method to assess irrigation is based on the comparison of the GLDAS-ET and MSG-ET products on a daily base. Differences in $\mathrm{ET}_{\text {actual }}$ are expected due to differences in forcing inputs, modeling and aggregation of different spatial scales. The idea behind this work is to achieve a major isolation of the modeling part, which as a hypothesis, is related to irrigation influence. Figure 4.1 shows an example of the comparison carried out during the year 2008 in an irrigated cropland in Spain and in a rain-fed cropland area in France, selected using the GlobCover map.

Figure 4.1 shows how the $\mathrm{ET}_{\text {actual }}$ estimates differ substantially during the cropping period in the irrigated area, especially during spring and summer seasons. This may be partly due to the additional water supply, which is observed by the remote sensing techniques but it is not modeled in the GLDAS-ET. The two curves in the rain-fed cropland have a similar pattern but also show a structural bias in summer. These general patterns are found across the croplands in Europe. 

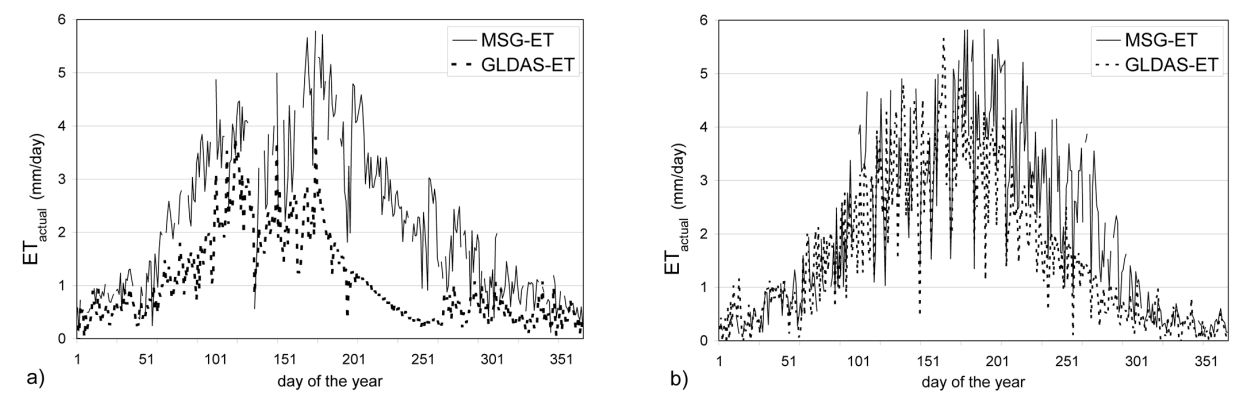

Figure 4.1. Comparison of MSG-ET and GLDAS-ET in (a) an irrigated cropland in Spain and (b) rain-fed cropland in France.

In order to remove the effect of different inputs in the bias between the models, we firstly refer to the work carried out in the Validation Report of the MSG-ET product at LSA-SAF (2010b). In this report MSG-ET estimates are compared with GLDAS-ET that use the Noah model. In a statistical manner, their results show differences that, according to the authors of that paper, are associated to the differences in the inputs of $S \downarrow$, the ratio between LAI and the stomatal resistance $\left(R_{s}\right)$, and land cover type. However, no mention is given to the possible extra water supply in form of irrigation. In the aforementioned work, $S \downarrow$ appears to be the factor that influences these differences in Europe the most, especially during spring and summer, where instantaneous values show differences between $15-30 \%$. The influence of the ratio $\mathrm{LAI} / \mathrm{R}_{\mathrm{s}}$ shows a seasonality with local maxima around the months of April and June/July. Finally, they show that land cover differences are quite spatially limited and play a smaller role. The results of this work are spatial and/or temporal integrated and therefore more detailed information about the differences along the year in a particular area cannot be directly extracted.

Here we propose to calculate for rain-fed croplands (non-irrigated) a reference bias evapotranspiration (bias ET $_{\text {) }}$ defined as the difference between MSG-ET and GLDAS-ET on a daily base, that allows removing the effects of the input differences when comparing the $\mathrm{ET}_{\text {actual }}$ products. Spatial variability needs to be considered when defining the reference bias, since different areas show different curves along the year. As an example, Figure 4.2 shows the bias in two rain-fed pixels located in Spain and the Ukraine, selected using the GlobCover map. 


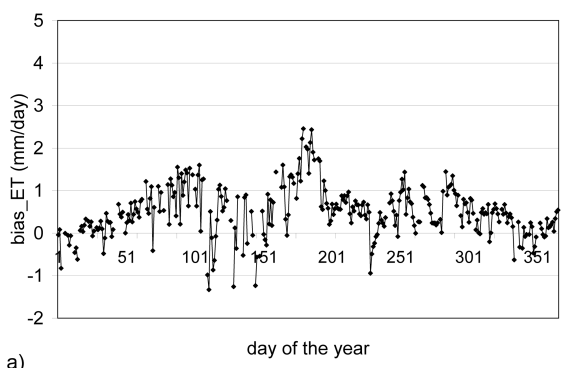

a)

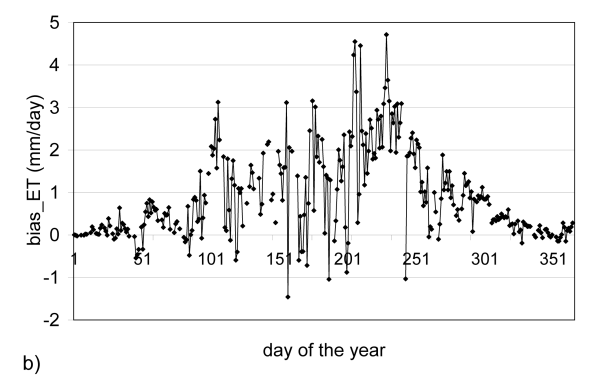

Figure 4.2. Bias between MSG-ET and GLDAS-ET in two rain-fed areas in a) Spain $\left(42^{\circ} 17^{\prime} 25^{\prime \prime} \mathrm{N}, 4^{\circ} 5^{\prime} 5^{\prime \prime} \mathrm{W}\right)$ and b) Ukraine $\left(4^{\circ} 57^{\prime} 25^{\prime \prime} \mathrm{N}, 34^{\circ} 52^{\prime} 25^{\prime \prime} \mathrm{E}\right)$ during 2008.

The bias in the region of Spain reaches local maxima around the days 90 and 180 , and the maximum amplitude of the bias is around $2 \mathrm{~mm}$ /day during summer time. However, the bias in the region of Ukraine reaches local maxima around the days 90 and 215, thus the summer peak is shifted with respect to the area in Spain. Moreover, the amplitude of the bias reaches values up to $4.5 \mathrm{~mm} /$ day.

Taking these issues into consideration, together with the fact that the final objective is to generate outputs at a large scale, this work proposes to generate a classification map based on criteria that allow parameterizing the bias obtained in different areas.

\subsubsection{Classification map}

The selection of the criteria for the classification was based on the results obtained at the validation report LSA-SAF (2010b) and some additional model input analysis. As explained in section 4.3.1, differences in $S \downarrow$ and LAI/R appear to explain the discrepancies between GLDAS-ET and MSG-ET products according to LSA-SAF (2010b). In the present work, the criteria selected for the classification were the MSG viewing zenith angle (VZA), the season where NDVI reaches the maximum value $\left(t_{-\max }\right)$, and the maximum value of NDVI (NDVI $\left.I_{\max }\right)$. These aspects are explained and justified in the following.

An analysis was carried out to identify the differences in the inputs of the two models. In both methods, atmospheric forcing is taken from models such as 
the ECMWF. Regarding the radiative inputs, $S \downarrow$ and $\mathrm{L} \downarrow$ are modelled based on the cloud cover and type. The cloud mask used by the MSG products is based on thresholds applied to the channels of the sensor on board the geostationary MSG (NWC-SAF, 2010). However, the cloud information in the $S \downarrow$ of GLDAS-ET incorporates both geostationary and polar-orbiting observations (Rodell et al., 2004). This means that there is a difference in the data in terms of geometry of observation. The products obtained from MSG (ET actual, $\mathrm{S} \downarrow$, cloud mask) are more influenced by the satellite viewing zenith angle, which reaches values up to $90^{\circ}$. The pixel size increases with the observation angle, and the accuracy of the estimates decreases because the atmospheric correction is more critical. This fact is also confirmed by the radial gradients observed in the bias in $S \downarrow$ shown in LSA-SAF (2010b). Therefore the MSG viewing zenith angle (VZA) was one of the criteria for the classification.

The methodologies for obtaining the LAI also contain some differences. MSGET products obtain the LAI from the ECOCLIMAP database (Masson et al., 2003). These are obtained by taking in situ maximum and minimum values of LAI and considering AVHRR NDVI series to impose seasonality per class cover. For Europe, monthly NDVI composites during the year 1997 produced by the DLR (Mucher et al., 2001) are considered, and for the rest of the world, the International Geosphere-Biosphere Programme Data (IGBP) 1Km AVHRR NDVI composites from April 1992 till March 1993 (Belward et al., 1999). However, GLDAS-ET take the LAI products derived at the University of Maryland (Myneni et al., 2002), which are physically based and use the Moderate Resolution Imaging Spectroradiometer (MODIS) channels and scattering properties for the modelling. Alternatively, literature based LAI are used in GLDAS-ET.

The NDVI was selected as second criterion for the classification, since it is one of the main inputs for one of the analyzed methodologies and it contributes to the seasonality of the data. Differences in the methods are expected to be higher for increasing NDVI. The position of the NDVI maximum (t_max) allows differentiating areas that have the peak in the bias $_{\mathrm{ET}}$ in different seasons, such as the ones shown in Figure 4.2. The absolute value of the NDVI maximum (NDVI_max) allows differentiating areas that have different amplitude in the bias $\mathrm{ET}$. 


\subsubsection{Estimation of $E T_{b}$}

The calculation of the $\mathrm{ET}_{\mathrm{b}}$ in a daily base is given by:

$$
E T_{b}=\Delta E T-\text { bias }_{E T}
$$

where $\Delta \mathrm{ET}$ is the difference between MSG-ET and GLDAS-ET. The value of bias $_{\mathrm{ET}}$ depends on the class assigned to every pixel based on the criteria mentioned in section 4.3.2 which are elaborated in next sections.

\subsection{Results}

\subsubsection{Classification Map}

In order to produce the classification map the following criteria were taken into account. Figure 4.2 shows maximum bias around 2.5 and $5 \mathrm{~mm}$ under VZA of 48 and $65^{\circ}$. These data provide an indication of the rate at which the bias increases. Therefore, intervals of 10 degrees in VZA were considered in the present work.

Sobrino and Raissouni (2000) proposed NDVI thresholds to distinguish between soil pixels $(\mathrm{NDVI}<0.2)$ and pixels of full vegetation (NDVI>0.5) obtained from AVHRR. These values were also used with the same purpose with other remote sensed sensors as it is explained in Sobrino et al. (2008b). In order to include also medium-high vegetated pixels, a reasonable NDVI value of 0.4 is taken in this work to distinguish between high and low vegetated pixels.

Due to differences in latitude, seasonal warmer periods arrive at different times in different areas and therefore the growing season is shifted. In order to take into account this effect and be able to generalize the method at other continents, the position of the NDVI_max was taken as a reference and two options were considered, t_max between April-September or outside that period. In order to be consistent with the $\mathrm{ET}_{\text {actual }}$ inputs of the proposed model, NDVI data were taken from the same source as the MSG-ET NDVI input. Figures 4.3 and 4.4 illustrate the criteria used for the classification, and Figure 4.5 the resulting classification map, generated at a resolution of $1 \mathrm{~km}$ approximately. 

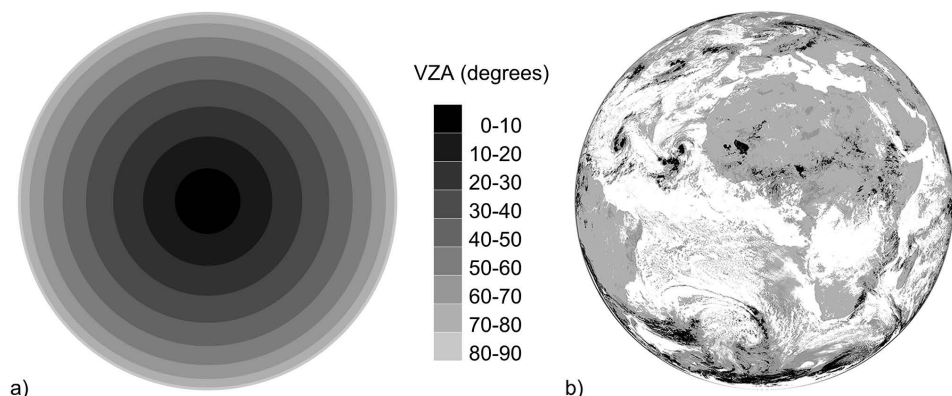

reflectivity

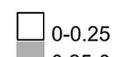

$0.25-0.50$

$0.50-0.75$

$0.75-1$

Figure 4.3. MSG field of view. (a) Viewing zenith angle (VZA) and (b) for reference, reflectivity image acquired in the visible spectrum.

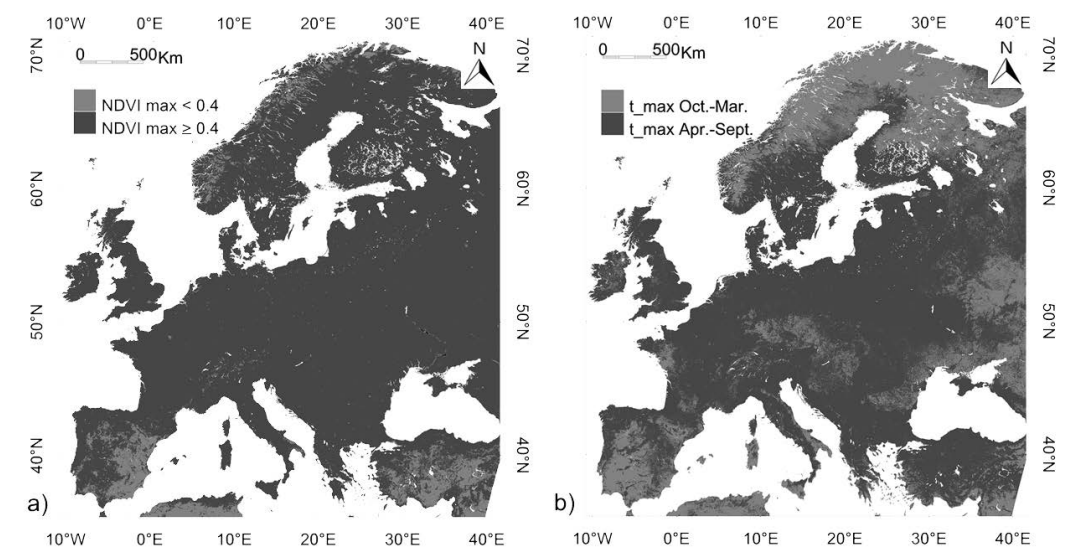

Figure 4.4. (a) NDVI max during 1997, (b) Season when NDVI max occurs (t_max), calculated from the DLR data.

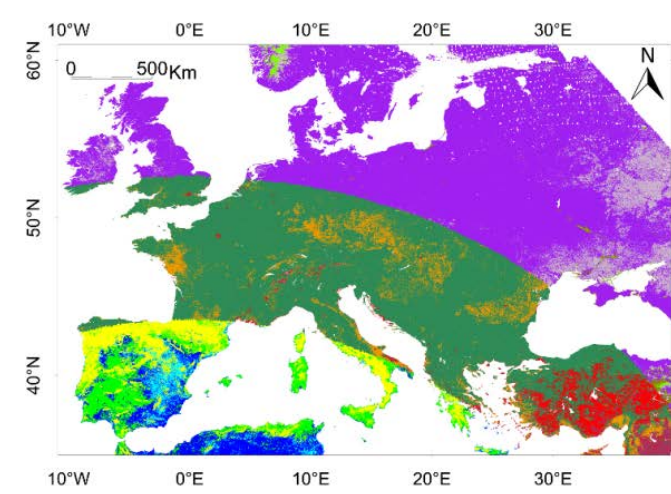

\begin{tabular}{|c|c|c|c|c|}
\hline & $\begin{array}{l}\text { VZA } \\
\left(^{\circ}\right)\end{array}$ & t_max & $\begin{array}{l}\text { NDVI } \\
\text { max }\end{array}$ & label \\
\hline & \multirow{4}{*}{ low } & \multirow{2}{*}{ winter } & high & LWH \\
\hline & & & low & LWL \\
\hline & & \multirow{2}{*}{ summer } & high & LSH \\
\hline & & & low & LSL \\
\hline & \multirow{4}{*}{ medium } & \multirow{2}{*}{ winter } & high & MWH \\
\hline & & & low & MWL \\
\hline & & \multirow{2}{*}{ summer } & high & MSH \\
\hline & & & low & MSL \\
\hline & \multirow{4}{*}{ high } & \multirow{2}{*}{ winter } & high & HWH \\
\hline & & & low & HWL \\
\hline & & \multirow{2}{*}{ summer } & high & HSH \\
\hline & & & low & HSL \\
\hline
\end{tabular}

Figure 4.5. Classification map of Europe for obtaining different bias $\mathrm{ET}_{\mathrm{ET}}$ and table defining the classes. Viewing zenith angles (VZA) are labeled as 'low' $\left(40-50^{\circ}\right)$, 'medium' $\left(50-60^{\circ}\right)$ and 'high' $\left(>60^{\circ}\right)$. The season when NDVI maximum occurs is labeled as 'winter' (period October-March) and 'summer' (period April-September). The value of NDVI maximum is labeled as 'high' $(\geq 0.4)$ and 'low' $(<0.4)$. The label of every class corresponds to the combination of the first letter of these three sub-labels. 


\subsubsection{Estimation of Reference bias $_{E T}$}

In order to obtain the bias in $\mathrm{ET}_{\text {actual }}$ for the different classes, four big areas covering the angle ranges of $40-50^{\circ}, 50-60^{\circ}$ and higher than $60^{\circ}$ were selected, namely Iberian Peninsula (classes LWH, LWL, LSH and LSL according to Figure 4.5), Mid-South Germany (classes MWH, MWL, and MSH) plus Turkey (class MSL) and Mid-East Ukraine (classes HWH, HWL, HSH and HSL), for which the difference between MSG-ET and GLDAS-ET was calculated per pixel and per class, only in rain-fed areas according to the GlobCover map. These calculations were carried out at the resolution of the GlobCover map (300 m) and in order to ensure homogeneity, pixels were taken into account only when the surrounding pixels were also classified as rain-fed in a 3 by 3 pixels window. Figure 4.6 shows the mean values of the biases for the 12 classes obtained in Europe. These curves were smoothed by using moving averages of \pm 2 days.

Figure 4.6 shows increasing amplitude in the bias with higher VZA, and differences in the profiles of the curves. Higher values of the bias are found when the NDVI_max is higher than o.4, especially in summer periods. Moreover, the position of the peak of the bias is shifted somewhat when comparing classes with different t_max (see for example classes LWH and LSH).

Although some of the bias curves have similar patterns, and some of the classes are less abundant in the continent selected, all 12 biases have been kept in this analysis, in order to provide a general method that can be developed and applied in other regions of the globe, where other differences may arise and distribution of classes may change. 
(mu) $\perp \exists^{-}$se!̣

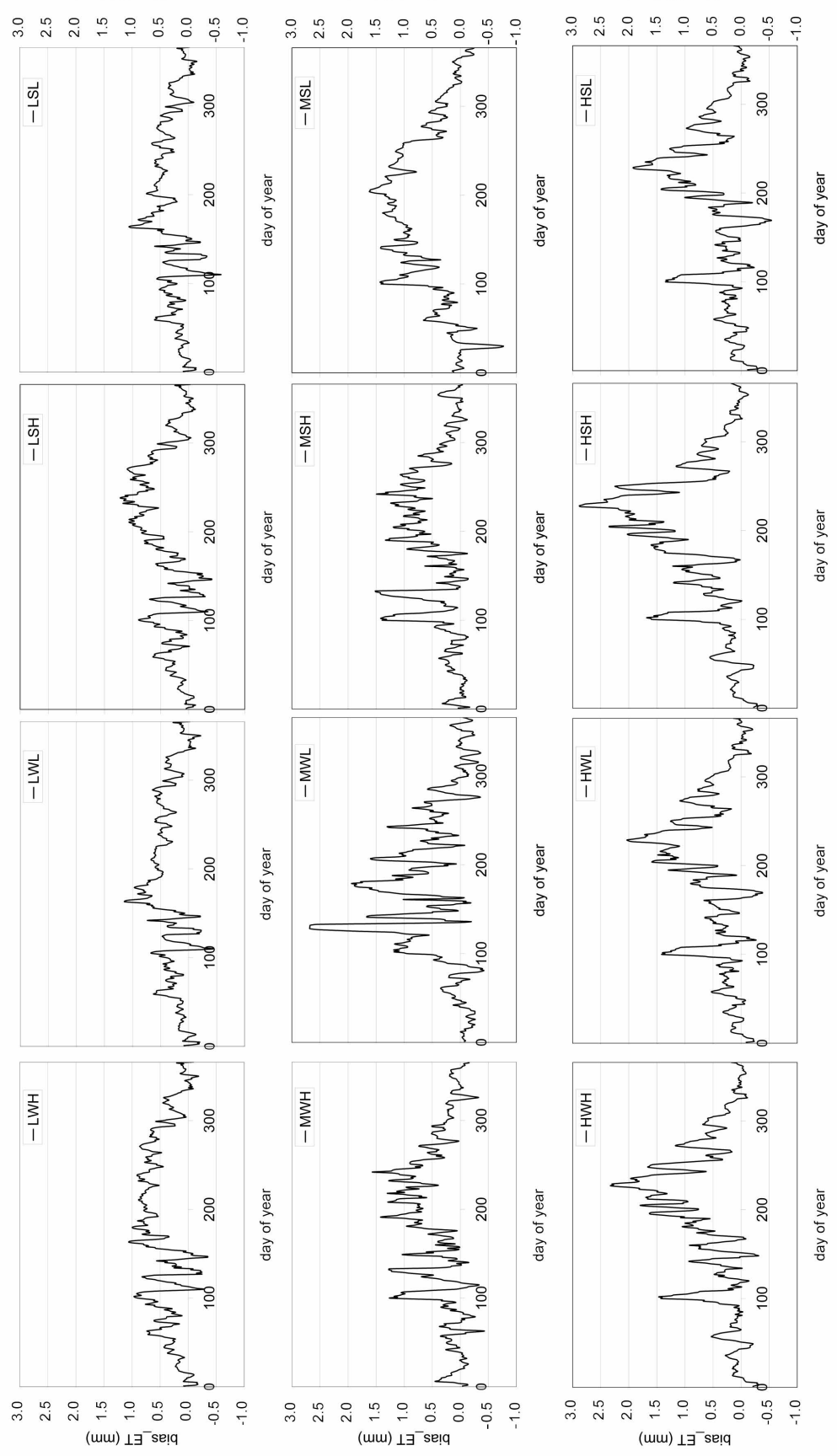

Figure 4.6. Bias between ET $_{\text {actual }}$ products, MSG-ET and GLDAS-ET, for rain-fed pixels, calculated for the defined classes (see labels in Figure 4.5). 


\subsubsection{Calculation of $\mathrm{ET}_{\mathrm{b}}$}

$\mathrm{ET}_{\mathrm{b}}$ on a daily base was calculated following equation (4.3) at a resolution of $1 \mathrm{~km}$ and rescaled to 5 arc minutes $(\sim 10 \mathrm{~km})$ for further comparison with other data. As an example, Figure 4.7a shows $\mathrm{ET}_{\mathrm{b}}$ during 2008 in an irrigated pixel in Spain. Spring and summer periods show higher values of $\mathrm{ET}_{\mathrm{b}}$ compared to the rest of the year. The accumulated $\mathrm{ET}_{\mathrm{b}}$ during the year 2008 is also shown in Figure 4.6b in two irrigated pixels in Romania and Spain, where differences in accumulated $\mathrm{ET}_{\mathrm{b}}$ are observed and may be explained by geographical and meteorological characteristics which, in the case of Romania, result in extensive irrigation practices (Virsta et al., 2010).
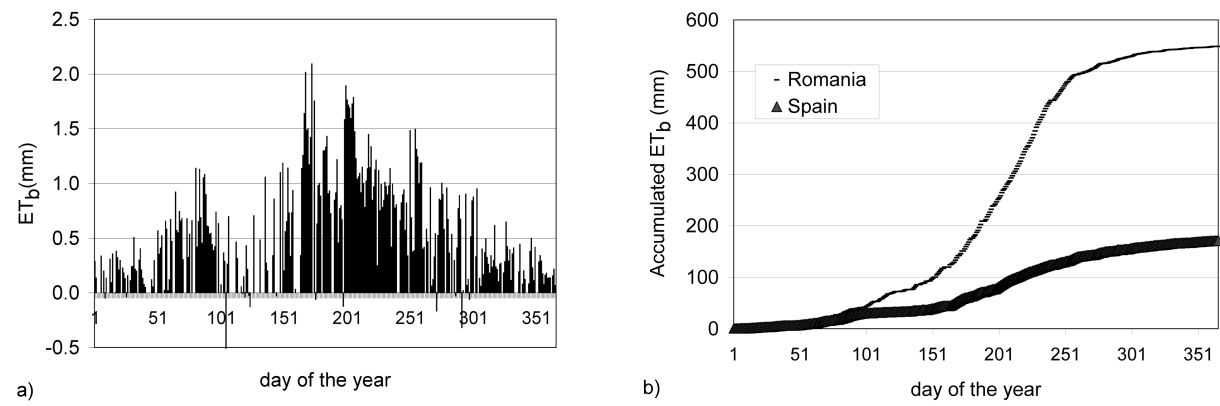

Figure 4.7. (a) Daily $\mathrm{ET}_{\mathrm{b}}$ obtained in an irrigated pixel in Spain during the year 2008 with the proposed method. (b) Accumulated $\mathrm{ET}_{\mathrm{b}}$ in two irrigated pixels in Spain and Romania.

Yearly $\mathrm{ET}_{\mathrm{b}}$ at continental coverage were calculated by summing up the positive daily $\mathrm{ET}_{\mathrm{b}}$ values. An additional mask was applied in order to filter the land covers that are out of the scope of this chapter, which are forests, grasslands, shrub-lands and sparse vegetation. The classes irrigated, rain-fed and mosaics of croplands and vegetation were used in this analysis. The GlobCover classification map was used for this purpose. The histogram of frequency of $\mathrm{ET}_{\mathrm{b}}$ values is shown in Figure 4.8, where a relatively high amount of pixels have a value below $50 \mathrm{~mm} /$ year. These areas are considered non irrigated croplands. Therefore a reasonable value of $50 \mathrm{~mm}$ may be taken as the minimum value for which the proposed method is able to detect irrigation.

Figure 4.9 shows the $\mathrm{ET}_{\mathrm{b}}$ image generated with the proposed method. The pixels labeled by the GlobCover map as irrigated or rain-fed croplands, and 
pixels with mixed classes that include croplands, are plotted in the figure. Forests, grassland, shrublands and sparse vegetation are masked and considered non irrigated, as well as $\mathrm{ET}_{\mathrm{b}}$ values below the defined threshold (50mm/year). As an example, when $\mathrm{ET}_{\mathrm{b}}$ country aggregated values are computed in Spain, Italy and Greece, they provide values of 23000, 5300 and $10300 \mathrm{Mm}^{3} /$ year, which have the same order of magnitude than the ones provided by Mekonnen and Hoekstra (2011).

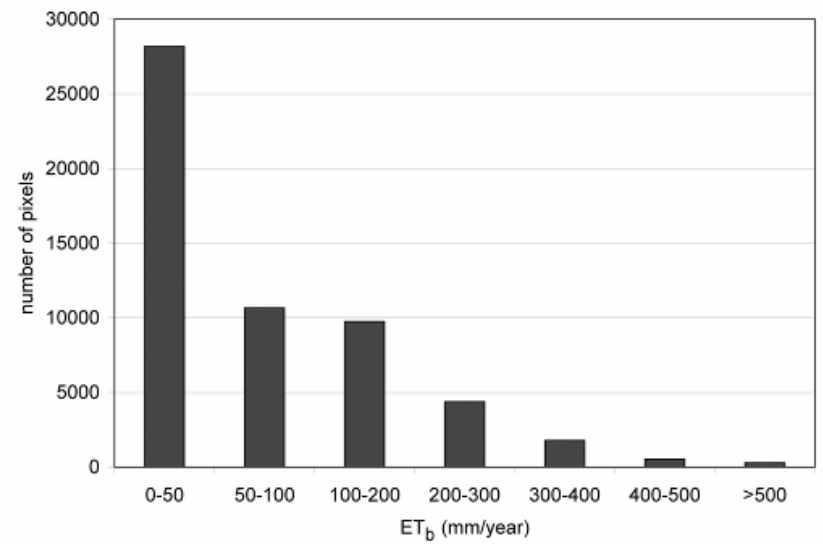

Figure 4.8. Yearly accumulated $\mathrm{ET}_{\mathrm{b}}$ histogram in the region of Europe.

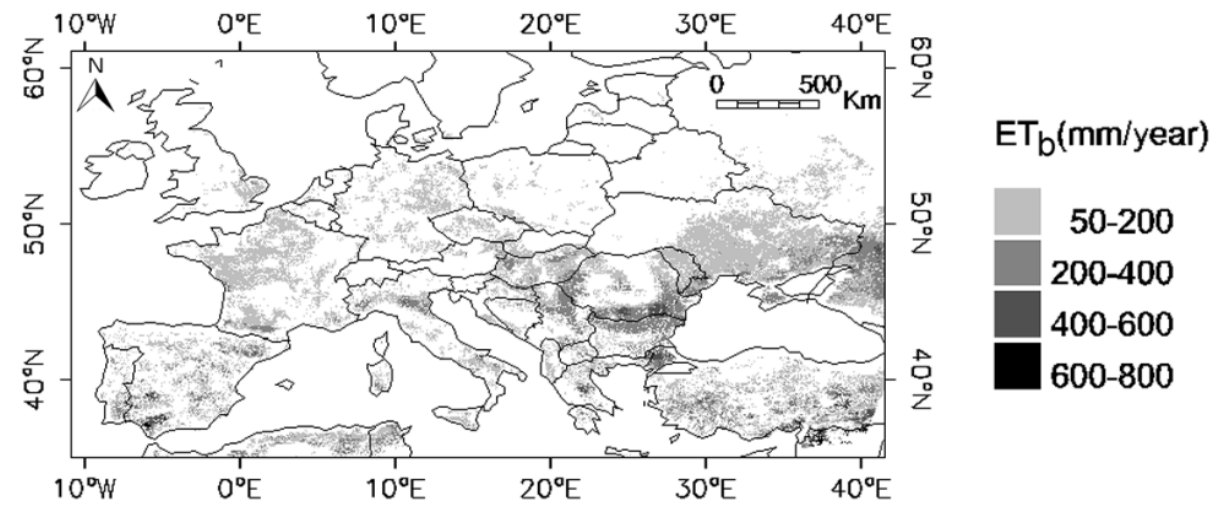

Figure 4.9. Yearly $\mathrm{ET}_{\mathrm{b}}$ obtained with the proposed method in Europe during 2008 calculated in croplands according to the GlobCover map (irrigated and rain-fed croplands, and mixed classes that include croplands). 


\subsubsection{Accuracy of the Method}

Accuracy assessment of the method was carried out in two ways, by evaluating the representativity of the defined bias and by analyzing the significance of the negative daily $\mathrm{ET}_{\mathrm{b}}$ values that are obtained in some cases.

In order to evaluate the representativity of the defined biases, a similar analysis was carried out extending the reference areas to all rain-fed croplands that belong to the same class in the classification map. The study was carried out at a coarser resolution $(1 \mathrm{~km})$, and in order to ensure homogeneity, pixels were taken into account only when the surrounding pixels were also classified as rain-fed in a 3 by 3 pixels window. The results (not shown here) provide similar mean bias curves for the classes LWH, LWL, LSH, MWH MSH and HWH with differences lower than $0.5 \mathrm{~mm} /$ day. Classes LSL and HSH provide lower values of the bias during summer, up to 1 $\mathrm{mm}$ /day. Classes MWL, HWL and HSL are less abundant and are highly affected by the rescaling process, especially because the number of rain-fed pixels is low and they are very scattered. Class MSL presents a different bias pattern when all scattered pixels outside the region of Turkey are included, with lower and negative amplitude in the summer time. The results show that for the most abundant classes, the reference bias may be considered as representative. However, the results also suggest how the bias in some classes may differ depending on the region where it is calculated; this mainly applies to less abundant classes and classes with higher VZA. In the present work, bearing in mind the application of the method, it seems reasonable to assign the bias obtained in the 4 defined windows to every class since they are obtained in cropland areas.

Moreover, Figure 4.7a shows that the method provides some negative $\mathrm{ET}_{\mathrm{b}}$ values. In general, negative $\mathrm{ET}_{\mathrm{b}}$ values are not physical and may occur due to noise in the inputs, especially at higher latitudes where the evapotranspiration rate is relatively low. Moreover, misclassification of pixels, e.g. forests, or non homogeneous classes may provide unrealistic results in areas for which the method is not appropriate. In order to evaluate the significance of these negative outputs, they were summed up during 2008 and combined with the yearly $\mathrm{ET}_{\text {actual }}$ calculated by accumulating the daily MSGET. Figure 4.10 shows the ratio between the accumulated negative $\mathrm{ET}_{\mathrm{b}}$ and the accumulated $\mathrm{ET}_{\text {actual }}$. The ratio is lower than $25 \%$ in most of the study 
area. However, the significance of this ratio increases in some areas, such as next to mountains like The Alps, or in higher latitudes in Poland or Denmark. Misclassification of pixels and high latitudes may explain the obtained results. Moreover, some regions in South France, Italy and Hungary are relatively far from the areas where the reference biases were calculated. In these cases, the representativity of the bias may be lower and the resulting $\mathrm{ET}_{\mathrm{b}}$ may be affected. Additionally, arid areas in Turkey or Spain with relatively low $\mathrm{ET}_{\text {actual }}$ rate are also prone to misclassification. Finally, the region of North Ukraine is located in the border of detection of MSG, and therefore the inaccuracies in $\mathrm{ET}_{\text {actual }}$ estimation may be higher due to the effects of the observation angle.

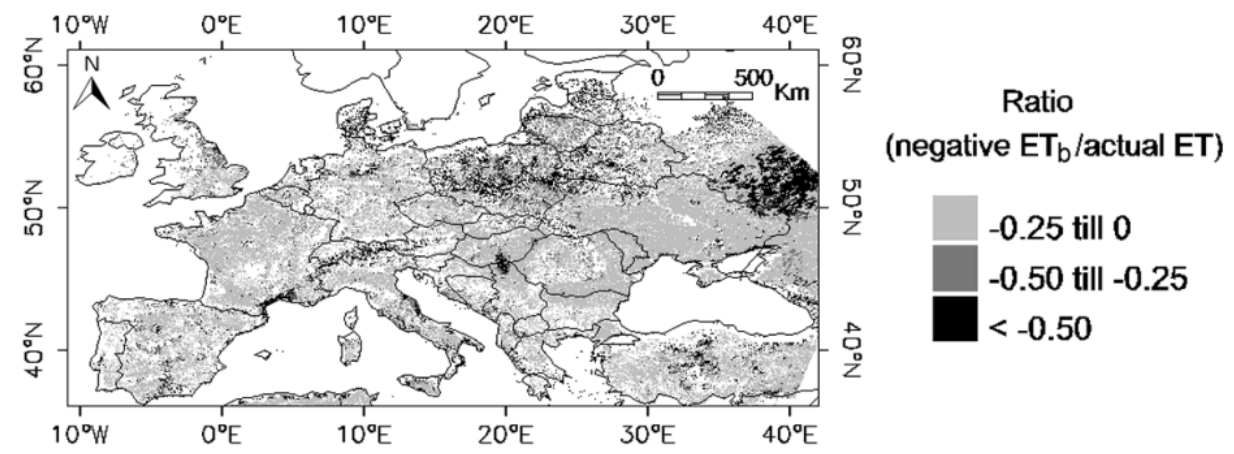

Figure 4.10. Ratio between the accumulated negative $\mathrm{ET}_{\mathrm{b}}$ values obtained with the proposed method during 2008 and the accumulated $\mathrm{ET}_{\text {actual }}$ obtained from MSG-ET, calculated in croplands according to the GlobCover map (irrigated and rain-fed croplands, and mixed classes that include croplands).

\subsection{Test of the Method}

The test of the proposed method was carried out using three approaches. The first one compared the irrigated area with the Global Map of Areas equipped for Irrigation (Siebert et al., 2007) and the Global Irrigated Area Map (Thenkabail et al., 2009a). Irrigated area aggregated to country level was also compared with the results given by Siebert et al. (2007) and Thenkabail et al. (2009a). Secondly, the $\mathrm{ET}_{\mathrm{b}}$ volumes were compared with the results of Mekonnen and Hoekstra (2011). Finally 10-day $\mathrm{ET}_{\mathrm{b}}$ estimates were compared at a pixel scale with in situ values of irrigation water in an irrigated cropland in Spain. 


\subsubsection{Irrigated Area Map}

In order to compare the results with other products in terms of irrigated area, a binary classification was built for each map based on the following criteria. The label 'irrigated' was assigned to the pixels in Figure 4.9 with $\mathrm{ET}_{\mathrm{b}}$ higher than $50 \mathrm{~mm}$ /year. The rest were labeled as 'non irrigated'. In the GMIA map (Siebert et al., 2007) pixels were labeled as 'irrigated' when a percentage of area equipped for irrigation was given; the rest were 'non irrigated'. Additionally, a threshold of $10 \%$ in the GMIA data was considered for labeling as 'irrigated'. Classes 1 to 8 in the aggregated GIAM map (Thenkabail et al., 2009a) were labeled as 'irrigated', and the rest as 'non irrigated'.

Table 4.2 shows the results obtained when assessing the accuracy of the generated map with respect to the other products. The overall accuracy is calculated by summing the number of pixels classified correctly and dividing by the total number of pixels. The kappa coefficient (Congalton and Green, 2009) is a more robust measure since it takes into account the agreement occurring by chance.

Table 4.2. Overall accuracy and Kappa coefficient obtained when comparing the irrigated area map obtained with the proposed methodology and existing products: Thenkabail et al. (2009a), Siebert et al. (2007) and Siebert et al. (2007) with a threshold of $10 \%$ in the area equipped for irrigation.

\begin{tabular}{|l|c|c|c|}
\cline { 2 - 4 } \multicolumn{1}{c|}{} & Thenkabail et al. (2009a) & Siebert et al. (2007) & $\begin{array}{l}\text { Siebert et al. (2007) } \\
\text { (Threshold= 10\%) }\end{array}$ \\
\hline $\begin{array}{l}\text { Overall } \\
\text { accuracy }\end{array}$ & $72 \%$ & $47 \%$ & $72 \%$ \\
\hline $\begin{array}{l}\text { Kappa } \\
\text { coefficient }\end{array}$ & 0.109 & -0.0064 & 0.1513 \\
\hline
\end{tabular}

Table 4.2 shows a percentage of overlap of $72 \%$ when comparing with the map of Thenkabail et al. (2009a). A more detailed analysis (not shown here) illustrated that the disagreements are mainly due to pixels that the proposed method assigned to 'irrigated' and were 'non irrigated' in the reference map. This comparison provided a kappa of 0.109 , which can be interpreted as a poor or very poor agreement (Monserud and Leemans, 1992). 
The comparison with the map of Siebert et al. (2007) provided a percentage of overlap of $42 \%$. The negative kappa means that the two maps agree less than would be expected by chance. The agreement improved when a threshold in the percentage of area equipped for irrigation is applied, which suggested that a less conservative binary classification would result in better agreements.

\subsubsection{Irrigated Area per Country}

The irrigated area was obtained for 2008 by considering the pixels with $\mathrm{ET}_{\mathrm{b}}$ higher than 5omm/year. The map of Ramankutty (2008) was used to weight the pixel size with the fraction of gridcell with crop. The results were aggregated to a country level and compared with the results given by Siebert et al. (2007) and Thenkabail et al. (2009a).

Figure 4.11 shows the results obtained for 13 countries in Europe, namely France, Spain, Germany, Poland, Italy, Romania, Greece, Bulgaria, Hungary, Portugal, Albania, Moldavia and The Netherlands. The figure shows the agreement of the comparison in some countries, as it can be observed with values close to the 1:1 line. However, the irrigated area in general is overestimated in the proposed method with respect to the values in the literature. The countries with higher disagreements are France, Rumania and Spain.

Different aspects may influence the differences that arise from the comparison. Firstly, from a methodological point of view, the data provided by Siebert et al. (2007) are area equipped for irrigation obtained from statistical data bases and the data from Thenkabail et al. (2009a) are based on classification techniques, whereas the proposed method estimates the existence of irrigation based on physical processes that occur and using a threshold in the yearly $\mathrm{ET}_{\mathrm{b}}$. The year of the data that are used in the methods may also play a role, in this case the years 2000, 1999, and 2008 respectively, since irrigation areas may have changed and the meteorological conditions vary and therefore influence the inputs of the proposed method and also the approach of Thenkabail et al. (2009a). Moreover, the proposed method may lead to overestimation since it assumes that irrigation is met in the whole crop area within the pixel. Understanding the subpixel composition and 
heterogeneity, and the influence of the spatial resolution in estimating irrigated areas is analyzed in detail in Velpuri et al. (2009).

Finally, it is worth to mention that the literature shows discrepancies in the comparison of the two aforementioned existing datasets, which is explained in detail in Thenkabail et al. (2009a).

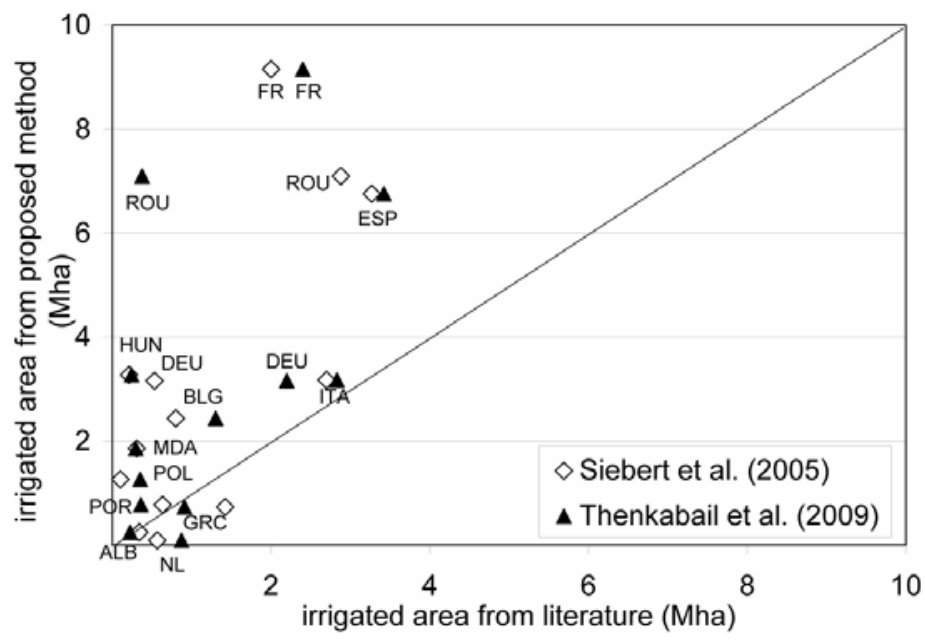

Figure 4.11. Comparison of the irrigated area provided by the proposed method and the country aggregated values given by Siebert et al. (2007) and Thenkabail et al. (2009a) in 13 countries in Europe. The figure also shows the 1:1 line. Country codes are: Albania (ALB), Bulgaria (BLG), France (FR), Germany (DEU), Greece (GRC), Hungary (HUN), Italy (IT), Moldova (MDA), The Netherlands (NL), Poland (POL), Portugal (POR), Romania (ROU) and Spain (ESP).

\subsection{3. $E T_{b} M a p$}

This section compares the $\mathrm{ET}_{\mathrm{b}}$ obtained in 2008, denoted by ROM in the following, with the blue water footprint (WF) values given by Mekonnen and Hoekstra (2011) in mm/year, named MH in the following.

Being aware that the two sources of data were obtained for different periods of time, an initial visual comparison was carried out in the region of Europe. In general terms the position of the peaks in $\mathrm{ET}_{\mathrm{b}}$ shown in $\mathrm{MH}$ were consistent with the ones provided by ROM, which were found in Greece and mid-south of Spain and Portugal and north-east of Spain. Other relative maxima in $\mathrm{MH}$ in lower range of values appeared also in ROM, namely north 
and east of Italy, south of France, south of Ukraine, North of Africa and Turkey. However, ROM presented high values of $\mathrm{ET}_{\mathrm{b}}$ in the regions of Romania, Serbia and Hungary which were not described by MH. These areas are equipped for irrigation according to the Global Map of Irrigated areas from Siebert et al. (2007). In particular, the southern part of Romania and easternmost tip of Serbia is called the Romanian Plain and it is known for its intensive irrigation (Virsta et al., 2010).

From a quantitative point of view, the overlap between the two maps is $75 \%$ when taking a range of $\pm 50 \mathrm{~mm} /$ year.

\subsubsection{Comparison of ET $T_{b}$ with In Situ Data}

The area selected for the test is located in Barrax, Spain $\left(39^{\circ} 3^{\prime} \mathrm{N}, 2^{\circ} 6^{\prime} \mathrm{W}\right.$ ), which has been used for agricultural research for many years (Guanter et al., 2007; Sobrino et al., 2008a; Su et al., 2008). The area is characterized by a flat morphology and large, uniform land use units. Differences in elevation range up to $2 \mathrm{~m}$. The regional water table is about $20-30 \mathrm{~m}$ below the land surface. The region consists of approximately $65 \%$ dry land and 35\% irrigated land with different agricultural fruits. In particular, the in situ data were provided by the local institution Servicio de Asesoramiento de Riegos del Instituto Técnico Agronómico Provincial (ITAP) in Albacete (Spain) (Montoro et al., 2011), and consisted of volumes of irrigated water supplied to a corn field during the year 2009, corn being one of the dominant crops in the test area.

The comparison of $\mathrm{ET}_{\mathrm{b}}$ with in situ data was carried out by using an Advanced Spaceborne Thermal Emission and Reflection Radiometer (ASTER) image in order to downscale the data. The ASTER image was acquired on the $18^{\text {th }}$ of July of 2004 in the framework of the Spectra Barrax Campaign (SPARC). The visible and near infrared channels have a spatial resolution of $15 \mathrm{~m}$ and they were used to compute the NDVI as an indicator of the amount of vegetation cover. Two areas which contained the corn field were selected, with dimensions around $6 \times 6 \mathrm{~km}^{2}$ and $13 \times 10 \mathrm{~km}^{2}$ and a threshold of 0.4 was selected to define highly vegetated covers. Additionally, an NDVI threshold of o.6 was set in order to analyze the influence in the results. Figure 4.12 shows the NDVI mask when using these two thresholds, together with the size of the areas of interest and the location of the corn field. 


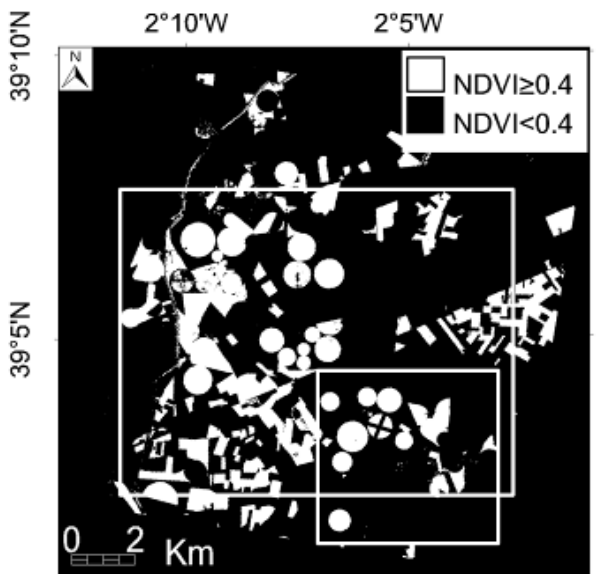

a)

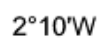

$2^{\circ} 5^{\prime} \mathrm{W}$

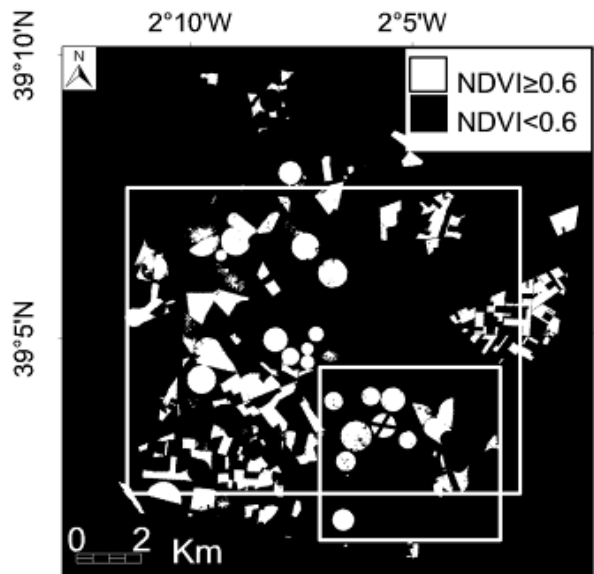

b)

$2^{\circ} 10^{\prime} \mathrm{W}$

$2^{\circ} 5^{\prime} \mathrm{W}$

Figure 4.12. ASTER NDVI mask in the region of test in Spain with thresholds in (a) 0.4 and (b) o.6. The size of the study area and the location of the corn field for which in situ data are available, are also indicated with rectangles and a cross respectively.

This test assumed that all crops with NDVI higher than the threshold behaved like the corn pivot, for which in situ irrigation data were available. The final result in the areas of interest was obtained multiplying the corn irrigation value by the percentage of fully vegetated cover taken from the NDVI mask.

Additionally $\mathrm{ET}_{\mathrm{b}}$ was calculated following the proposed method between July $10^{\text {th }}$ and September $8^{\text {th }}$, period for which MSG-ET products were available in the region. The daily $\mathrm{ET}_{\mathrm{b}}$ was obtained only for the $89 \%$ of the days due to lack of data as explained in section 4.2.1.

Table 4.3 shows the comparison of the results by accumulating $\mathrm{ET}_{\mathrm{b}}$ every 10 days in the two areas using the two NDVI thresholds. Negative $\mathrm{ET}_{\mathrm{b}}$ values obtained in some pixels of Area 2 summed up a total of $1.2 \mathrm{~mm}$ for the whole period and were not considered.

When comparing the modeled $\mathrm{ET}_{\mathrm{b}}$ in Area 1 with in situ values in periods of 10 days, the differences were not systematic and had positive and negative values, being higher when the selected NDVI threshold was 0.4. Although individual values may present high percentages of discrepancy, the total value presented differences of 10 and 6\% when NDVI threshold was 0.4 and 0.6 
respectively. A similar pattern was observed in Area 2 with 16 and $20 \%$ of difference with respect to the in situ values, and noticing that the method slightly overestimated $\mathrm{ET}_{\mathrm{b}}$ in the 10-days periods when the selected NDVI threshold was o.6.

Table 4.3. $\mathrm{ET}_{\mathrm{b}}$ values obtained in the two areas of interest by using the model proposed in this chapter and by using in situ data with NDVI thresholds of 0.4 and o.6.

\begin{tabular}{|c|c|c|c|c|c|c|}
\hline & \multicolumn{3}{|c|}{$\mathrm{ET}_{\mathrm{b}} \operatorname{Area} 1(\mathrm{~mm})$} & \multicolumn{3}{|c|}{$\mathrm{ET}_{\mathrm{b}}$ Area $2(\mathrm{~mm})$} \\
\hline $\begin{array}{c}\text { 10-days } \\
\text { period number }\end{array}$ & method & in situ 04 & in situ o6 & method & in situ 04 & in situ o6 \\
\hline $\mathbf{1}$ & 10.4 & 13.5 & 11.5 & $15 \cdot 3$ & 20.9 & 14.6 \\
\hline 2 & $15 \cdot 7$ & 11.6 & $9 \cdot 9$ & 21.5 & 18.0 & 12.6 \\
\hline 3 & 11.3 & 13.6 & 11.5 & 16.9 & 21.0 & 14.7 \\
\hline 4 & 10.2 & $9 \cdot 7$ & 8.2 & 13.5 & 15.0 & 10.5 \\
\hline 5 & $7 \cdot 3$ & $7 \cdot 7$ & 6.6 & 11.7 & 12.0 & 8.4 \\
\hline 6 & 7.8 & 13.6 & 11.5 & 11.9 & 21.0 & 14.7 \\
\hline $\begin{array}{c}\text { total } \\
\text { (\% difference) }\end{array}$ & 62.6 & $\begin{array}{l}69.6 \\
(10 \%)\end{array}$ & $\begin{array}{l}59.2 \\
(6 \%)\end{array}$ & 90.7 & $\begin{array}{l}108.0 \\
(16 \%)\end{array}$ & $\begin{array}{l}75 \cdot 4 \\
(20 \%)\end{array}$ \\
\hline
\end{tabular}

In this context, it is important to highlight that the in situ irrigation data were values discrete in time, whereas the model provided continuous $\mathrm{ET}_{\mathrm{b}}$ daily values. This fact may explain the high discrepancies in some of the periods, since remote sensing observes the delayed effects of irrigation in terms of $\mathrm{ET}_{\text {actual }}$ and in situ values are assigned to particular days.

\subsection{Discussion}

This section describes aspects to be taken into account when interpreting the method and the results obtained in this chapter.

Firstly, the proposed method is highly influenced by the inaccuracies of the inputs. In particular, the method may lead to errors due to the misclassification of rain-fed pixels in the land cover map input, since it is the base for the calculation of the reference bias of the proposed method. This fact is also affecting the forest, grasslands, shrublands and sparse vegetation mask applied to generate the $\mathrm{ET}_{\mathrm{b}}$ image. Other maps that define irrigated and rain-fed areas and were developed specifically to describe croplands are the 
ones given by Thenkabail et al. (2009a, b), and may be considered as alternative inputs for the proposed method. Moreover, the existence of data gaps in the MSG-ET inputs influences the daily assessments of $\mathrm{ET}_{\mathrm{b}}$ and therefore the yearly accumulated value. In this work, a linear interpolation was carried out to fill in missing data and daily $\mathrm{ET}_{\text {actual }}$ values were not considered if the lack of data occurred during periods of one hour or longer, achieving a total of $94 \%$ of daily $\mathrm{ET}_{\mathrm{b}}$ if the 5 month period May-September was considered. In general, a more accurate approach may be considered to incorporate those days in the calculations as well as to evaluate the relevance of not including them.

The bias-pattern and the classification constitute one of the main bases of the method. The classes and criteria selected are explained in the text. Nevertheless, other approaches may have been used based for example on climatic classifications or forcing parameters as shown by Roerink et al. (2003). In general, for the main classes the bias pattern defined was representative for the whole class. However, the bias of minority classes presented more variability, especially when the pixels were scattered.

The validation of the method presents some difficulties because of the unavailability of MSG-ET remote sensing data during the years analyzed in the existing literature. Moreover, water resources and irrigation are politically critical issues and generally in situ quality data are difficult to access. In this context, this work shows the strength of a remote sensing based method that allows locating and quantifying irrigation practices from an independent data set. The potential of using remote sensing techniques in this field was also described by Romaguera et al. (2010). Despite the lack of time coincident data for validation, this chapter shows the comparison of $\mathrm{ET}_{\mathrm{b}}$ volumes and irrigated area with existing methodologies and the differences and similarities were discussed.

Regarding the in situ test, different issues need to be mentioned. The NDVI image used for the threshold of fully vegetated covers was acquired in 2004 and is assumed to be valid for the year 2009 and static along the period of analysis. Changes in cover type may affect the results. Moreover, different crops may have different water requirements than corn and not all irrigation water supplied will be evapotranspired. 
Finally, regarding the generalizability of the method, areas where all production is irrigated and precipitation is too small for rain-fed production may present difficulties for defining the reference bias due to the lack of rainfed areas. Although differences in the inputs MSG-ET and GLDAS-ET are also expected in this case, further research needs to be carried out to adapt the method and quantify $\mathrm{ET}_{\mathrm{b}}$. For these areas, the method described in Romaguera et al. (2010) may be sufficient. Moreover, the availability of MSGET input data at the moment of writing this chapter, only allows calculating $\mathrm{ET}_{\mathrm{b}}$ in Europe from January 2007 to date, and in Africa and part of South America from September 2009 to date. However, the main concept of the method proposed can be generalized and applied to other $\mathrm{ET}_{\text {actual }}$ data with wider spatial and time coverage, by using the recently available official

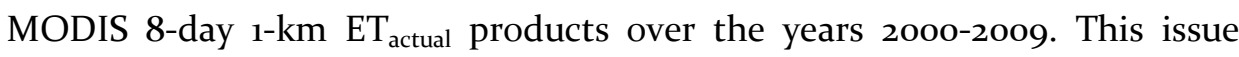
constitutes one of the lines of further research for the authors.

\subsection{Conclusions}

This chapter provided an innovative and relatively simple method to identify irrigated areas and blue evapotranspiration $\left(\mathrm{ET}_{\mathrm{b}}\right)$, or evapotranspiration of irrigation water from the field. It was based on the comparison of the actual evapotranspiration $\left(\mathrm{ET}_{\text {actual }}\right)$ products from the remotely sensed Meteosat Second Generation (MSG) and model simulations from the Global Land Data Assimilation System (GLDAS), and the production of a spatially dependent bias. The method was able to detect irrigation when yearly values of $\mathrm{ET}_{\mathrm{b}}$ were higher than 5omm. Accuracy assessment showed that the method performed satisfactory for the majority of the study area (Europe). $\mathrm{ET}_{\mathrm{b}}$ was produced in Europe for the year 2008. The comparison with the existing maps of irrigated area from Siebert et al. (2007) and Thenkabail et al. (2009a) provided a spatial match of 47 and $72 \%$ respectively, with some overestimations on country aggregates. These differences can be associated to the subpixel heterogeneity and the influence of the spatial resolution in the analysis, as well as to methodological issues and data type. The spatial comparison of $\mathrm{ET}_{\mathrm{b}}$ values with the ones given by Mekonnen and Hoekstra (2011) resulted in a $75 \%$ of overlap when a range of $\pm 50 \mathrm{~mm}$ was considered. Validation with point based in situ data showed a difference of less than $20 \%$ between measured and derived values. The proposed method provides an operational framework for quantifying and monitoring of irrigation at large scale and high temporal frequency. The approach can be easily generalized in time and space by 
defining the proper biases and analyzing the inputs of the models, at the continental scale of MSG data (including Africa), or by using the recently available global $\mathrm{ET}_{\text {actual }}$ products from the remotely sensed Moderate Resolution Imaging Spectroradiometer (MODIS) sensor. 


\title{
Chapter 5
}

\section{Hydrometeorological Classification of Europe. A Comparison of Classifiers for Improving Blue Water Evapotranspiration Estimation ${ }^{4}$}

\begin{abstract}
The estimation of evapotranspiration of blue water $\left(\mathrm{ET}_{\mathrm{b}}\right)$ from farmlands, due to irrigation, is crucial to improve water management, especially in regions where water resources are scarce. Large scale $\mathrm{ET}_{\mathrm{b}}$ was previously obtained based on the differences between remote sensing derived actual ET and values simulated from the Global Land Data Assimilation System (GLDAS). In this chapter we improve on the previous approach by enhancing the classification scheme employed so that it represents regions with common hydrometeorological conditions. Bias between the two data sets for reference areas (non-irrigated croplands) were identified per class and used to adjust the remote sensing products. Different classifiers were compared and evaluated based on the generated bias curves per class and their variability. The results in Europe show that the k-means classifier was better suited to identify the bias curves per class, capturing the dynamic range of these curves and minimizing their variability within each corresponding class. The method was applied in Africa and the classification and bias results were consistent with the findings in Europe. The $\mathrm{ET}_{\mathrm{b}}$ results were compared with existing literature and provided differences up to 50 $\mathrm{mm} /$ year in Europe, while the comparison in Africa was found to be highly influenced by the assigned cover type and the heterogeneity of the pixel. Although further research is needed to fully understand the $\mathrm{ET}_{\mathrm{b}}$ values found, this chapter shows a more robust approach to classify and characterize the bias between the two sets of ET data.
\end{abstract}

${ }^{4}$ Based on Romaguera et al. (2014a) 


\subsection{Introduction}

Water management in agriculture has been always important, especially in areas where water resources are scarce. In this context, it is relevant to distinguish between the sources of the usage: water supplied by precipitation (called green water) and irrigation (called blue water).

Recent studies obtained blue and green waters use in agriculture at large scale using data from national agricultural statistics, reports and climatic databases, and making use of hydrological models based on the calculation of actual evapotranspiration ( $\mathrm{ET}_{\text {actual }}$ ) (Hanasaki et al., 2010; Liu and Yang, 2010; Mekonnen and Hoekstra, 2011; Siebert and Döll, 2010). Moreover, several studies tackled the problem of retrieving global irrigated areas by using national statistics of areas equipped for irrigation (Siebert et al., 2005) and by statistically analyzing remote sensing products (Thenkabail et al., 2009a).

The potential of using remote sensing data for global studies of green and blue waters use and water footprint estimations is discussed in Romaguera et al. (2010). The first approaches to exploit those data at large scale are shown in Romaguera et al. (2012a, b), where the use of the different components of the water cycle is explored, together with the use of land surface models. Other works used remote sensing to evaluate irrigation performance at regional scale (Bastiaanssen and Bos, 1999; D'Urso et al., 2012; Santos et al., 2010).

In particular, Romaguera et al. (2012a) obtained large scale blue water evapotranspiration $\left(\mathrm{ET}_{\mathrm{b}}\right)$, i.e. due to irrigation, based on the differences between remote sensing $\mathrm{ET}_{\text {actual }}$ obtained from the Meteosat Second Generation (MSG) satellites (Ghilain et al., 2011) and $\mathrm{ET}_{\text {actual }}$ values simulated from the Global Land Data Assimilation System (GLDAS) (Rodell et al., 2004). In general, it was found that there was a systematic bias between the two datasets in rain-fed pixels and that this difference was variable in time and space. The bias amplitude changed along the year roughly resembling a positive concave curve. The maximum amplitude value reached up to 3 $\mathrm{mm}$ /day and occurred in the months of spring and summer in northern latitudes. The spatial variability of the bias was associated in this paper to vegetation characteristics and the remote sensing observation angle. Romaguera et al. (2012a) calculated the bias per day and used three 
parameters to generate a classification map for Europe to discriminate areas with different bias patterns: the maximum value of the NDVI $\left(\mathrm{NDVI}_{\max }\right)$, the season where $\mathrm{NDVI}_{\max }$ occurred, and the viewing zenith angle (VZA) of the sensor on board MSG. Thresholds were assigned to distinguish between classes. Recent work from Romaguera et al. (2012c) showed that the classification scheme was not sufficient to describe the variability of the bias estimates in the continent of Africa and proposed the inclusion of a climatic index in the selection of parameters for the classification.

Similar results in terms of bias between these two datasets were obtained by Ghilain et al. (2011) and LSA-SAF (2010), who showed that the bias might be explained by the differences in the inputs of incoming solar radiation, the ratio between leaf are index (LAI) and stomatal resistance, and land cover type. Yilmaz et al. (2014) identified discrepancies in insolation inputs and analyzed differences in soil moisture, when comparing these data sets in the region of the Nile River basin.

Romaguera et al. (2012a) emphasized that the GLDAS simulations did not account for extra water supply due to irrigation and consequently it was expected that they underestimate $\mathrm{ET}_{\text {actual }}$ during the cropping season in irrigated areas. Therefore in the aforementioned work, the differences between these two estimates were corrected for the bias in rain-fed croplands, to obtain blue water evapotranspiration according to:

$$
E T_{b}=\Delta E T \text {-bias }
$$

$\triangle E T$ is the difference between MSG $\mathrm{ET}_{\text {actual }}$ (MSG-ET in the following) and GLDAS $\mathrm{ET}_{\text {actual }}$ (GLDAS-ET in the following), and bias is this difference in $\mathrm{ET}_{\text {actual }}$ calculated in reference areas, i.e. rain-fed croplands where irrigation practices are not present.

In this chapter we intend to solve the drawbacks of the previous methodology by improving the classification scheme in order to achieve a better spatial representation of the bias in rain-fed croplands, which results in better estimates of $\mathrm{ET}_{\mathrm{b}}$. 
First, a better choice of parameters is proposed to represent regions with common hydrometeorological conditions, based on three processes at which $\mathrm{ET}_{\text {actual }}$ estimation may be affected, namely vegetation characterization, atmosphere/forcing definition and land-atmosphere interaction. Secondly, an alternative strategy for classification is adopted, based on the use of classifiers, instead of the selection of thresholds published in the aforementioned work. This makes the methodology generic and robust. The suitability of these classifiers is explored via the classification maps and the bias curves obtained per class.

Section 5.2 explains the selection of parameters for the classification and the properties of the selected classifiers. Next, in Section 5.3 the datasets used in this chapter are detailed. The Results section includes the classification maps, the bias curves and $\mathrm{ET}_{\mathrm{b}}$ outputs compared with the original methodology. The application of the method to the region of Africa is shown in Section 5.5, together with the comparison of the results with existing literature. Finally relevant issues about the proposed improved methodology can be found in the Discussion and Conclusions sections.

\subsection{Method}

The objective of this work is to improve the existing methodology for $\mathrm{ET}_{\mathrm{b}}$ estimation (Romaguera et al., 2012a) on two aspects: the selection of parameters for the classification of the study area and the classification method.

\subsubsection{Selection of Parameters for the Classification}

The hypothesis here is that the classification output discriminates between areas with different bias curves, i.e. differences along the year of MSG-ET and GLDAS-ET estimates. Therefore potential variables need to be identified in order to explain the differences in $\mathrm{ET}_{\text {actual }}$ retrievals. In the present work, a more complete selection of parameters is carried out by accounting for three processes at which $\mathrm{ET}_{\text {actual }}$ estimation from both sources may differ, namely vegetation characterization, atmosphere/forcing definition and landatmosphere interaction. In order to account for the vegetation properties, a typical indicator is selected, the NDVI, and in particular its maximum value along the year, $\mathrm{NDVI}_{\max }$. Precipitation and net radiation are combined into a 
climatic index (CI) to account for the driving forces for $\mathrm{ET}_{\text {actual, }}$, as follows (Roerink et al., 2003):

$$
C I=\frac{L P}{R_{n}}
$$

where $\mathrm{L}(\mathrm{J} / \mathrm{kg})$ is the latent heat of vaporization, $\mathrm{P}(\mathrm{mm})$ is the annual precipitation and $R_{n}\left(W / m^{2}\right)$ is the annual net radiation (obtained as the sum of net shortwave $\left(S_{n}\right)$ and net longwave $\left(L_{n}\right)$ radiation). In other words, the LP term is the amount of energy necessary to evaporate the available precipitation $(\mathrm{P})$.

The land-atmosphere interaction is included in the selection of parameters by means of the monthly accumulated $\mathrm{ET}_{\text {actual }}$, and in particular the maximum value along the year $\left(\mathrm{ET}_{\mathrm{mmax}}\right)$. This aggregated value is chosen in order to reduce relative errors in $\mathrm{ET}_{\text {actual }}$ estimation. Since the focus of this chapter is to obtain the ET bias curves per class, including ET itself in the classification inputs contributes to capture the observed variability. Moreover, as shown in previous literature (Ghilain et al., 2011; Romaguera et al., 2012a), a seasonality was found in this bias. The position of the bias maxima was variable, and

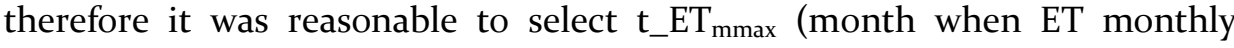
maxima occurs) to account for these different patterns.

Being aware that other potential variables might have been included in this selection, such as land surface temperature and albedo, effective precipitation, soil moisture, LAI or topography, the number was limited in order to reduce data redundancy when the parameters were correlated or equivalent in terms of climate and vegetation interaction. Moreover, the use of too many variables in a classification procedure may decrease the classification accuracy (Price et al., 2002).

\subsubsection{Classification Methods}

Many classification methods exist in the literature and all have their own merits. However, the question of which classification approach is suitable for a specific study is not easy to answer (Lu and Weng, 2007). Romaguera et al. (2012a) used a basic classification method based on thresholds, as follows: $\mathrm{NDVI}_{\max }$ higher/lower than 0.4, October to March and April to September periods for the $\mathrm{NDVI}_{\max }$ to occur, and VZA intervals of $10^{\circ}$. 
In this chapter, the use of three different classifiers was explored and discussed. Firstly, a common classification approach was chosen: an unsupervised classification based on k-means. Secondly, a more advanced learning method was selected: an unsupervised classification based on the expectation-maximization algorithm. These two approaches do not use training samples, they work per pixel, they are hard classifiers (i.e. output is a definitive decision) and they do not use spatially neighboring pixel information for the classification, all aspects that are appropriate to this study. Thirdly, an image transform of the selected parameters was carried out by using the principal component analysis in order to reduce data redundancy of correlated bands and concentrate the information contents in the transformed images, exploring the possible clustering.

\subsubsection{Unsupervised Classification Based on K-means}

An unsupervised classification of the study area was executed in order to cluster pixels based on the k-means statistical technique (Tou and Gonzalez, 1974). This method calculates initial mass means evenly distributed in the data space and then iteratively clusters the pixels into the nearest class using a minimum distance technique. In each iteration, classes' means are recalculated and pixels are reclassified with respect to the new means. All pixels are classified to the nearest class unless a standard deviation or distance threshold is specified, in which case some pixels may be unclassified if they do not meet the selected criteria. This process continues until the number of pixels in each class changes by less than the selected pixel change threshold or the maximum number of iterations is reached. The 4-layer input file contained $\mathrm{NDVI}_{\max }, \mathrm{ET}_{\operatorname{mmax}}, \mathrm{t}_{-} \mathrm{ET}_{\operatorname{mmax}}$ and $\mathrm{CI}$ as described in the previous section. A maximum of 100 iterations was fixed to ensure completion of the algorithm, and the default value of $5 \%$ was conserved for the pixel change threshold (Exelis Visual Information Solutions, 2006).

Neither standard deviation nor distance thresholds were fixed. In order to select the optimal number of clusters and to evaluate the clustering found by the algorithm, a scattering distance (SD) quality index was calculated according Rezaee et al. (1998), which accounts for the intra-cluster and intercluster distances as:

$$
S D(c)=a \operatorname{Scat}(c)+\operatorname{Dis}(c)
$$


where $c$ is the number of clusters, Scat(c) is the average scattering and indicates the average compactness of the clusters (i.e. intra-cluster distance), $\operatorname{Dis}(c)$ is the total separation between the $c$ clusters (i.e. an indication of inter-cluster distance), and $a$ is a weighing factor equal to Dis(cmax), where cmax is the maximum number of input clusters.

A small value of Scat(c) indicates a compact cluster. The second term Dis(c) is influenced by the geometry of the cluster centers and increases with the number of clusters. The optimal value for the number of clusters present in the data set is such that minimizes the SD index.

In the present research, the maximum number of clusters for the unsupervised classification was set to 20 , assuming a reasonable minimum percentage of pixels per class of $5 \%$. The classification was obtained for 5 up to 10 clusters and SD was calculated. As a result, the number of clusters for which the SD quality index was minimized was found to be 6 in the region of Europe.

\subsubsection{Unsupervised Classification Based on the Expectation-Maximization}

Algorithm (EM)

The Expectation-Maximization algorithm (Dempster et al., 1977) is an iterative procedure that estimates the probabilities of the elements to belong to a certain class, based on the principle of maximum likelihood of unobserved variables in statistical models. The EM iteration alternates between performing an expectation (E) step, which creates a function for the expectation of the log-likelihood evaluated using the current estimate for the parameters, and a maximization (M) step, that computes parameters maximizing the expected log-likelihood found on the E step. These parameter estimates are then used to determine the distribution of the latent variables in the next $\mathrm{E}$ step. This classification was performed using the machine learning software WEKA version 3.6.9 (Waikato Environment for Knowledge Analysis) (Hall et al., 2009), using the implemented Simple EM classifier. This software contains tools and algorithms for the analysis of data and predictive modeling, where the system is trained and can learn from the data and provide classified outputs. EM assigns a probability distribution to each instance which indicates the probability of it belonging to each of the cluster 
and can decide how many clusters to create by cross validation. In the current research, the maximum number of iterations was set to 100 to ensure completion of the algorithm. Moreover, the software allowed to test the model output by using the $66 \%$ of the data as a training set and the rest for testing.

\subsubsection{Classification Using Principal Component Analysis (PCA)}

The principal component analysis (PCA) (Richards and Jia, 1999) consists of a transformation of the input dataset (multilayer file with $\mathrm{NDVI}_{\max }, \mathrm{ET}_{\operatorname{mmax}}$, $\mathrm{t}_{-} \mathrm{ET}_{\operatorname{mmax}}$ and $\left.\mathrm{CI}\right)$ to produce uncorrelated output bands, segregate noise components, and reduce the dimensionality of data sets. The characteristic matrix (covariance matrix or correlation matrix) of the variables, the eigen values, the eigen vectors (which are the directions of the principal components (PC)), and the coordinates of each data point in the direction of the PC's were calculated. A new set of orthogonal axes was found, which had their origin at the data mean and which were rotated so the data variance was maximized. PC output bands were linear combinations of the original spectral bands and were uncorrelated. The relationships found between the principal components which led to the clustering of the data are shown in the results section.

\subsection{Data Sets}

Table 5.1 describes the main characteristics of the datasets used in the present work which are detailed in the following subsections.

From a technical point of view, the combination of data of different spatial resolution, extent and geographical projection was tackled by creating a layer stack where the data were resampled and re-projected to a common output projection. The present work was carried out at the resolution of the MSG-ET products. 
Table 5.1. Specifications of the data sets used in the present work.

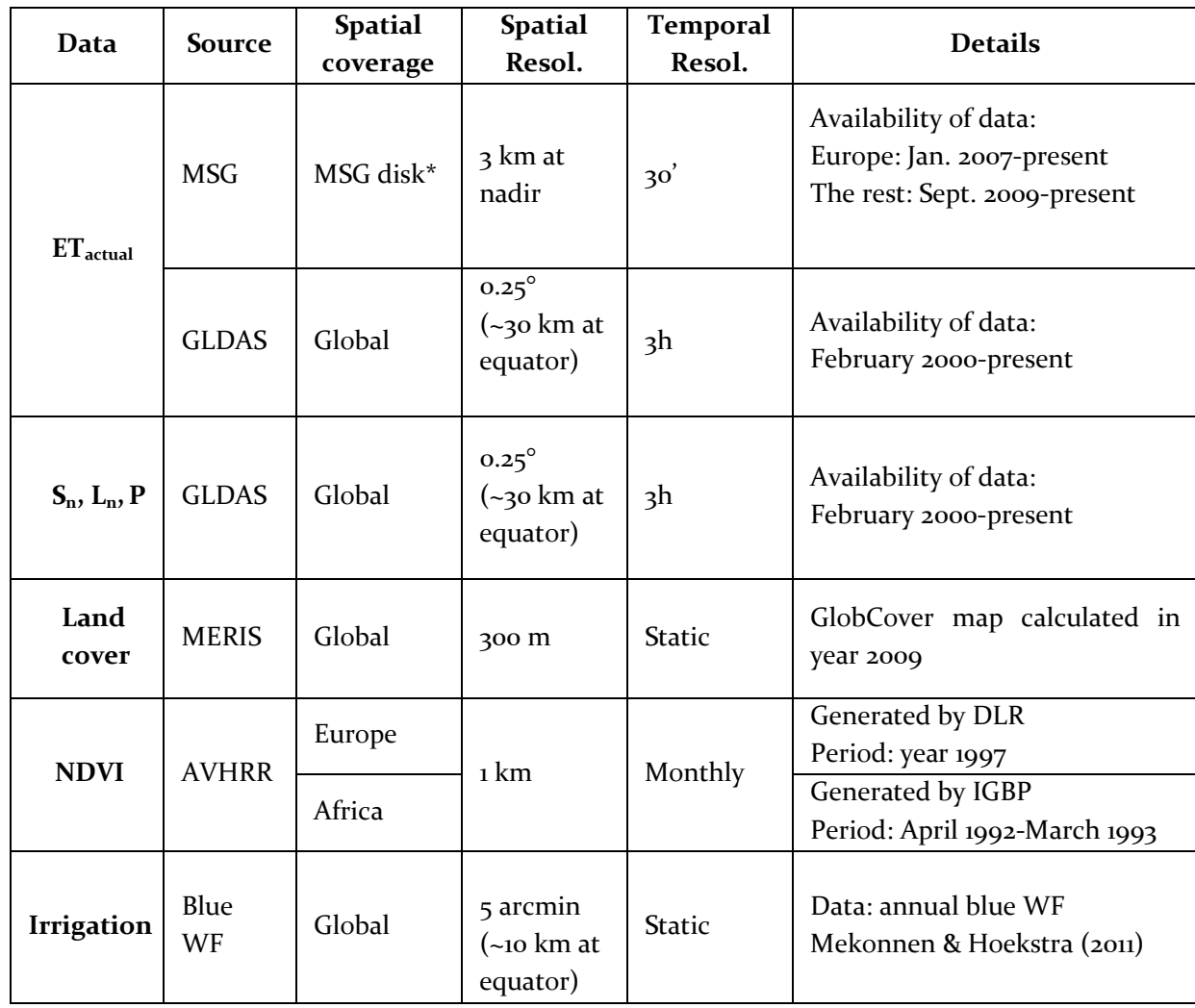

${ }^{*}$ Meteosat disk covers latitudes between $-60^{\circ}$ and $+60^{\circ}$ and longitudes between $-60^{\circ}$ to $+60^{\circ}$.

**List of acronyms: MSG (Meteosat Second Generation), GLDAS (Global Land Data Assimilation System), MERIS (Medium Resolution Imaging Spectrometer), AVHRR (Advanced Very High Resolution Radiometer), DLR (Deutsches Zentrum für Luft- und Raumfahrt), IGBP (International Geosphere-Biosphere Programme Data) and WF (Water Footprint).

\subsubsection{Evapotranspiration and Cover Type Data}

Based on equation (5.1), the main datasets for obtaining the $\mathrm{ET}_{\mathrm{b}}$ were the $\mathrm{ET}_{\text {actual }}$ products from the MSG satellites provided by the Land Surface Analysis Satellite Applications Facility (LSA-SAF) (Ghilain et al., 2011) (MSGET) and $\mathrm{ET}_{\text {actual }}$ from the Global Land Data Assimilation System (GLDAS) generated with the Noah land surface model (Chen et al., 1996; Koren et al., 1999) (GLDAS-ET). These datasets are available from the LSA-SAF website (http://landsaf.meteo.pt/) and the NASA Goddard Earth Sciences Data and 
Information Services Center (GES DISC) (http://disc.sci.gsfc.nasa.gov/ hydrology/data-holdings) respectively.

The GlobCover land cover map (ver 2.3) (UCLouvain and ESA, 2011) was used to identify the land cover type, e.g. rain-fed croplands (where the bias was calculated) and bare areas (where $\mathrm{ET}_{\text {actual }}$ rates are low) (see Figure 5.1). More detailed information about these datasets can be found in Romaguera et al. (2012a).

In the research presented, daily MSG-ET values were obtained by temporal integration of the 48 instantaneous values per day, during the year 2010. Linear interpolation in time was used to fill in missing data, due to nonacquisitions. Daily MSG-ET were not considered if missing data occurred during periods of one hour or longer. Daily GLDAS-ET values were obtained by temporal averaging of the eight provided $\mathrm{ET}_{\text {actual }}$ rates per day. No missing data were found in this dataset.

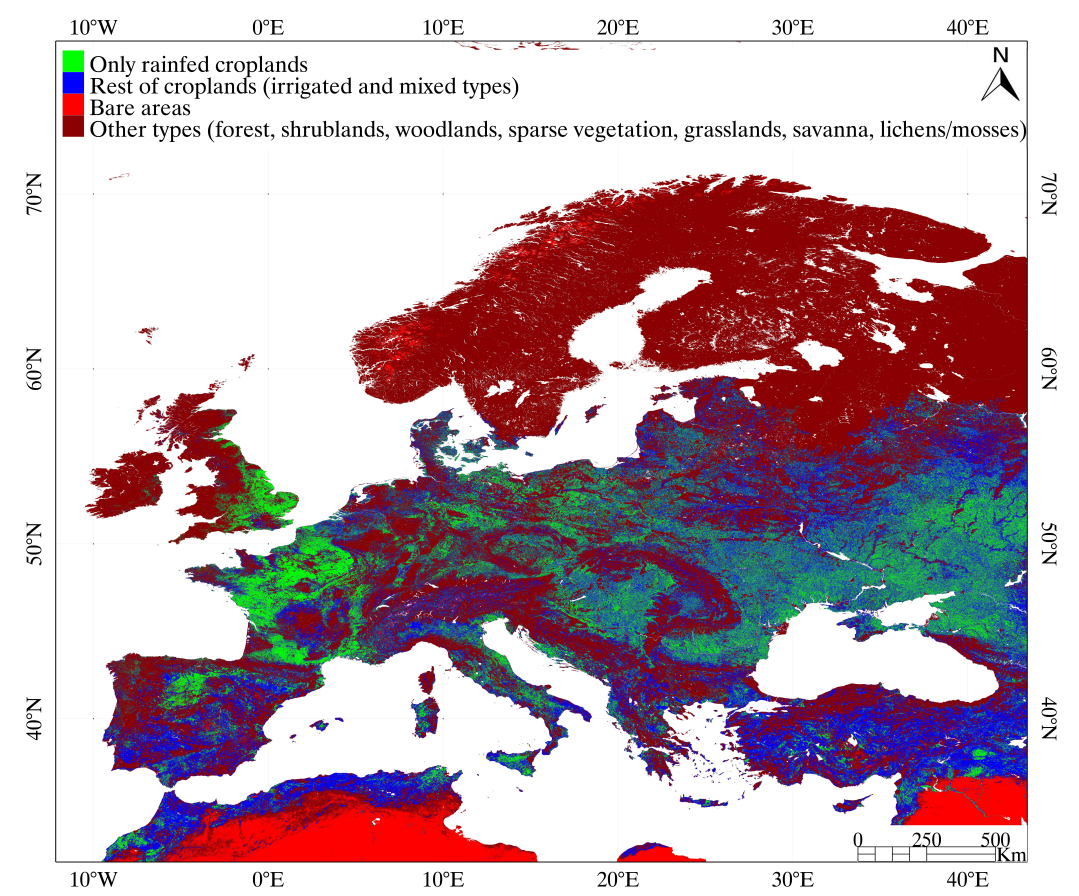

Figure 5.1. Pixel type (only rain-fed croplands, rest of croplands, bare areas, others) from the GlobCover classification map. 


\subsubsection{Data for the Classification}

As explained in previous sections, four parameters were selected for the classification of the study area: a) $\mathrm{NDVI}_{\max }, \mathrm{b}$ ) a climate index (CI) based on net radiation, latent heat of vaporization and precipitation, c) the maximum value of monthly aggregated $\mathrm{ET}\left(\mathrm{ET}_{\mathrm{mmax}}\right)$ and $\mathrm{d}$ ) the month where the $\mathrm{ET}_{\operatorname{mmax}}$ occurs $\left(\mathrm{t} \_\mathrm{ET}_{\operatorname{mmax}}\right)$. The selected study area was Europe and the year was 2010 . Additionally, the classification was also obtained in Africa for testing the method.

In order to ensure consistency of the data, the $\mathrm{NDVI}_{\max }$ was extracted from the source related to MSG-ET retrieval. That is the ECOCLIMAP database (Masson et al., 2003), which includes the LAI values that are used in the MSGET algorithm. These values are obtained by taking in situ maximum and minimum values of LAI and considering Advanced Very High Resolution Radiometer (AVHRR) NDVI series to impose seasonality per class cover. For Europe, the monthly NDVI values generated during the year 1997 by the Deutsches Zentrum für Luft- und Raumfahrt (DLR) (Mucher et al., 2001) are considered, and for Africa the International Geosphere-Biosphere Programme Data (IGBP) 1 km AVHRR NDVI composites from April 1992 until March 1993 (Belward et al., 1999). Although these values may not represent irrigated vegetation in the year of analysis, they influence the MSG-ET retrieval and therefore the difference with GLDAS-ET, which is the focus of this research.

CI was calculated for the year 2010 according to equation $(5.2)$ by yearly aggregating $R_{n}$ and $P$. Net radiation was obtained as the sum of net shortwave $\left(S_{n}\right)$ and net longwave $\left(L_{n}\right)$ radiation, which were obtained from the GLDAS dataset, together with the precipitation values.

GLDAS-ET values were aggregated monthly and the maximum value was obtained $\mathrm{ET}_{\operatorname{mmax}}$, as well as the month when it occurred ( $\left.\mathrm{t} \mathrm{ET}_{\operatorname{mmax}}\right)$. Radiation and $\mathrm{ET}_{\text {actual }}$ values in GLDAS were given as rates every 3 hours, so the proper way to calculate the yearly/monthly values was by temporal averaging of the data corrected by the time conversion factor.

The data sets were filtered according to the following criteria. Firstly, bare pixels defined by the GlobCover classification map were masked. These are 
arid areas, where the estimation of $\mathrm{t} \_\mathrm{ET}_{\mathrm{mmax}}$ may be affected by fluctuations of the low values of $\mathrm{ET}_{\text {actual. }}$. Secondly, coastal pixels with nonrealistic values were also masked. This effect appeared when resampling the data to a common grid and pixel size. Finally, pixels with negative $\mathrm{NDVI}_{\max }$ value were also masked for the calculations. These were found in the datasets in areas close to water bodies. Figure $\mathbf{5 . 2}$ shows the selected data sets for the classification and the study area. Finally, every dataset was normalized dividing by its maximum and the generated 4-layer file was used for the classifications.

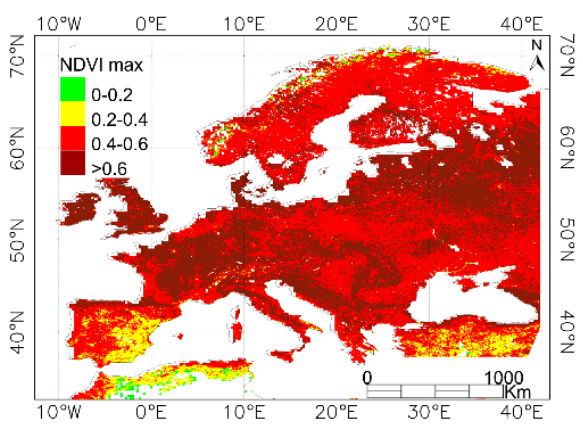

(a)

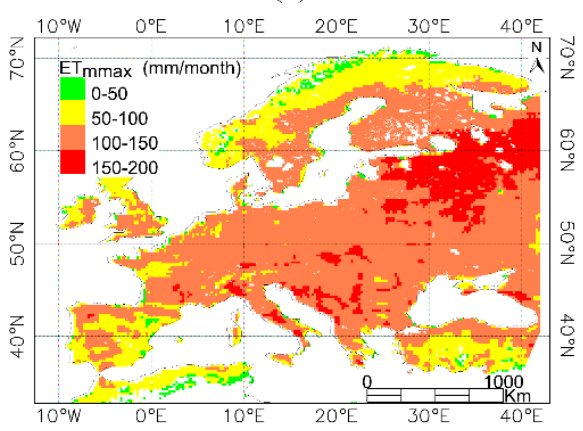

(c)

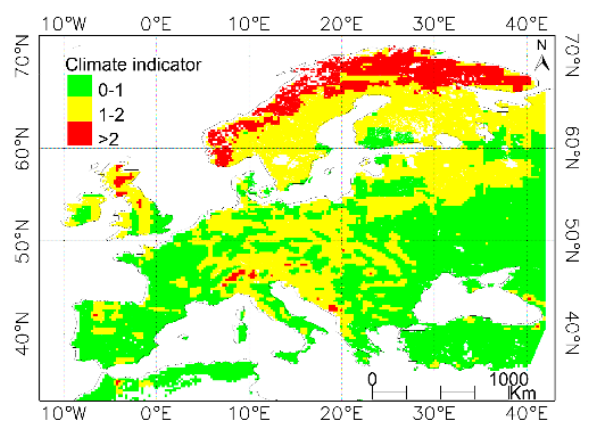

(b)

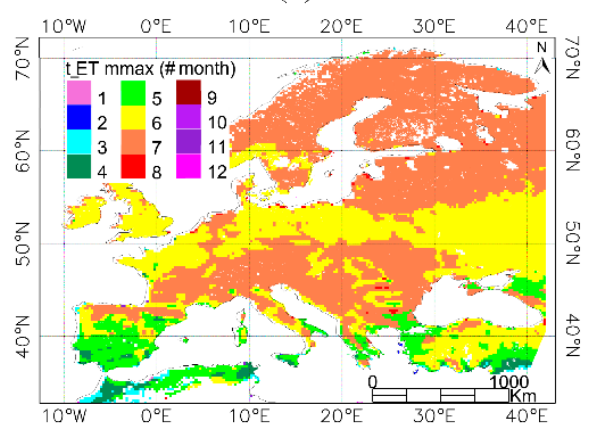

(d)

Figure 5.2. Study area and inputs used in the present chapter: (a) $\mathrm{NDVI}_{\max },(\mathbf{b}) \mathrm{CI},(\mathbf{c})$ $\mathrm{ET}_{\text {mmax }},(\mathbf{d}) \mathrm{t}_{-} \mathrm{ET}_{\text {mmax }}$.

\subsubsection{Data for the Test of the Method}

The global blue water footprint $\left(\mathrm{WF}_{\mathrm{b}}\right)$ of crop production estimated by Mekonnen and Hoekstra (2011) was used to compare the $\mathrm{ET}_{\mathrm{b}}$ outputs produced in Europe and Africa. The water footprint (WF) is defined as the 
water consumed for crop production, where green and blue stand for precipitation and irrigation water usage. In their method, the computations of crop evapotranspiration were done following Allen et al. (1998) for the case of crop growth under non-optimal conditions. The model takes into account the daily soil water balance and climatic conditions for each grid cell. Climatic and reference evapotranspiration inputs are averaged for the period 1996-2005 and results are given as average over that time interval. WFs are typically given in units of $\mathrm{m}^{3} /$ ton or $\mathrm{mm} /$ year. In the last case, the yield is not considered and therefore $\mathrm{WF}_{\mathrm{b}}$ corresponds to total $\mathrm{ET}_{\mathrm{b}}$. This product has global coverage and a spatial resolution of 5 arc minutes.

\subsection{Results}

This section shows the classification maps generated with the three selected methods. The k-means and EM classifiers have a straightforward application. For the PC approach, the relationship between the first and third PC allowed identifying 11 vertical clusters, whose pixels were assigned to 11 classes (named from 1 to 11 , from left to right of the Figure 5.3). Neither clear relationships nor groupings could be established between the $\mathrm{PC}_{1}$ and the components $\mathrm{PC}_{2}$ and $\mathrm{PC}_{4}$.

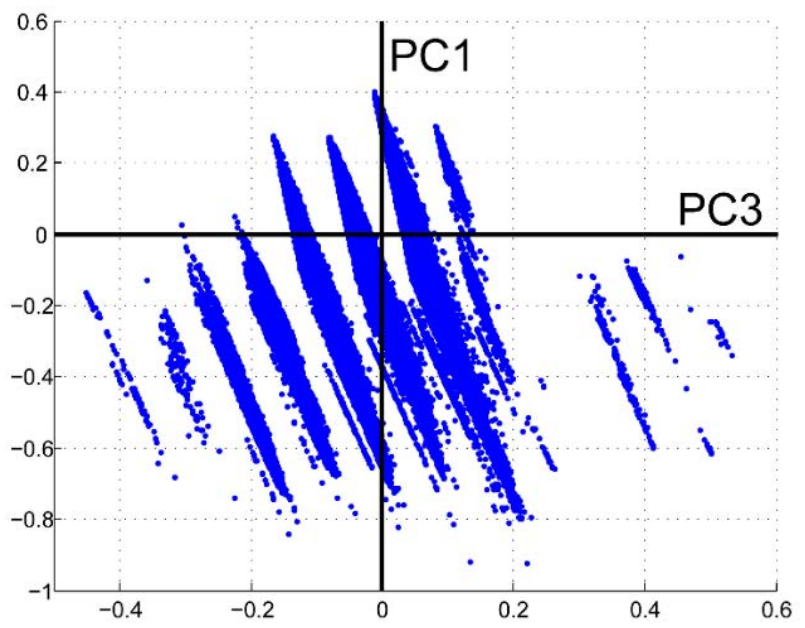

Figure 5.3. Scatter plot of first principal component $\left(\mathrm{PC}_{1}\right)$ versus the third $\left(\mathrm{PC}_{3}\right)$ obtained in Europe from the classification dataset proposed in this chapter. 


\subsubsection{Classification Maps}

Figure 5.4 shows the classification maps obtained using the new set of input parameters and the three classifiers in the region of Europe. The map generated in Romaguera et al. (2012a) (ROM in the following) is also included for the sake of comparison. Information about the abundance of different cover types is shown per class. Three cover types are considered: i) only rainfed croplands, ii) rest of croplands (irrigated and mixed types) and iii) others (forests, shrublands, woodlands, sparse vegetation, grassland, savanna, lichens/mosses), according to the GlobCover map. Additionally, the number of rain-fed croplands (RC) and the ratio of these over the total croplands $(\mathrm{RC} / \mathrm{TC})$ are incorporated.

The number of classes generated was 12, 6, 8 and 11 in the ROM, k-means, EM and PCA classifications respectively. The numbers assigned to the classes must be understood as labels and their value is not necessarily related between the different classification outputs. In general, the proposed classifications had a visually more continuous spatial distribution than ROM, which presented the characteristic rings due to the intervals chosen in the VZA criteria. Moreover, some similar grouping can be observed in the generated classifications, such as the areas of Spain and East and center Europe in EM and PCA or Eastern part of Norway in k-means and EM, although this comparison is not easy to evaluate. The distribution of the classes in the k-means and EM classification showed the influence of all four input parameters, whereas in the PCA classification output, the parameter determining the classes was the $t \_\mathrm{ET}_{\operatorname{mmax}}$. This is associated to the fact that the third component of the PCA captures the variability (after transformation) of the discrete values of $\mathrm{t}_{-} \mathrm{ET}_{\operatorname{mmax}}$.

Two majority classes were found in the ROM classification, as well as in PCA. That is represented in Figure $5.4 \mathrm{~b}$ by the total height of the columns. However, the abundance of the classes in k-means and EM was more balanced, with no significant minority classes in the case of k-means. 


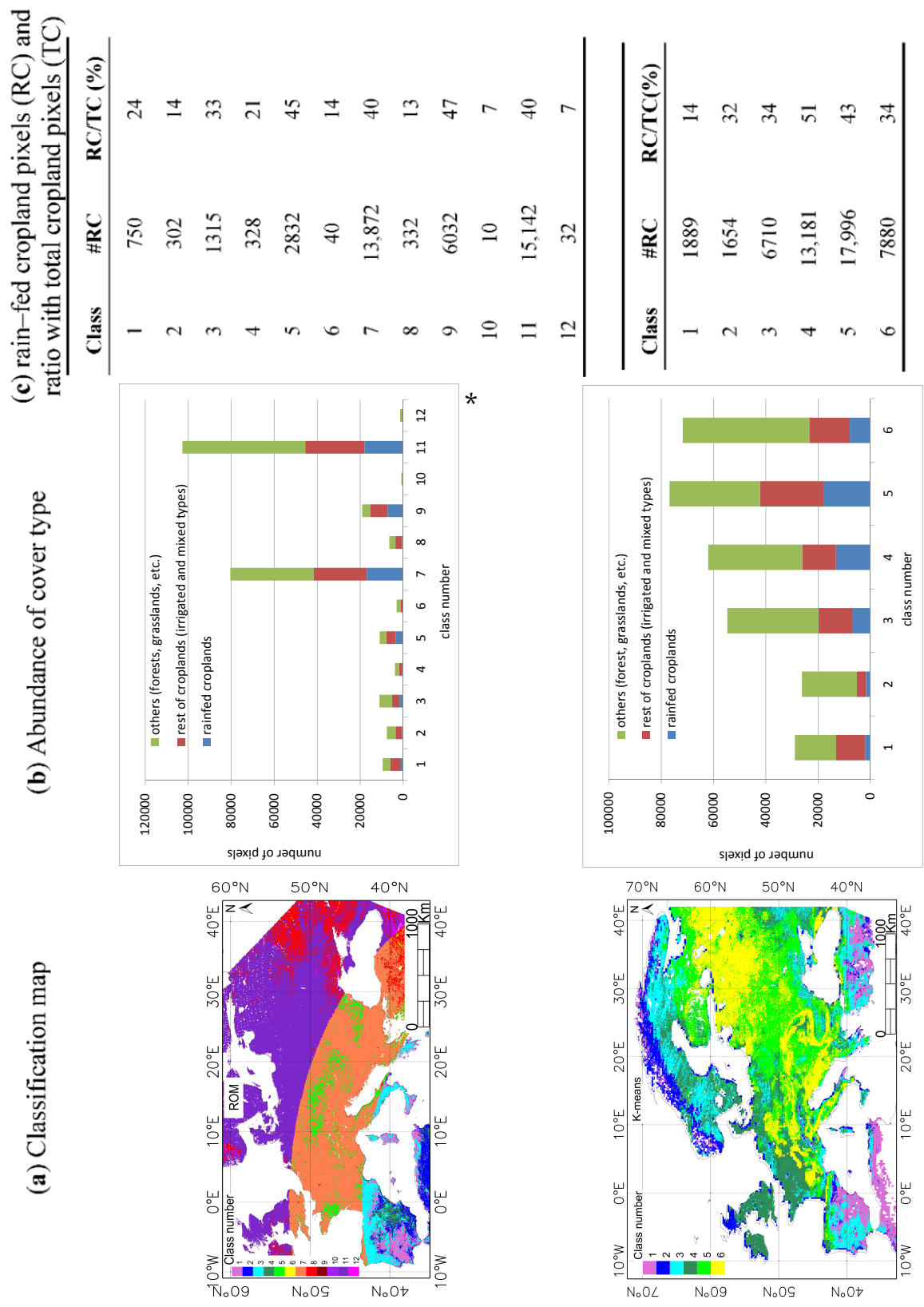

Figure 5.4. (a) Classification maps obtained using the methods ROM, k-means, EM and PCA. (b) Abundance of cover type per class (i) only rain-fed croplands, (ii) rest of croplands (irrigated and mixed types) or (iii) others (forests, shrublands, woodlands, sparse vegetation, grassland, savanna, lichens/mosses). (c) Total of rain-fed cropland pixels (RC) per class and ratio between $\mathrm{RC}$ and the total number of cropland pixels $(\mathrm{RC} / \mathrm{TC}) .{ }^{*}$ Only pixels on the map are counted for plotting 

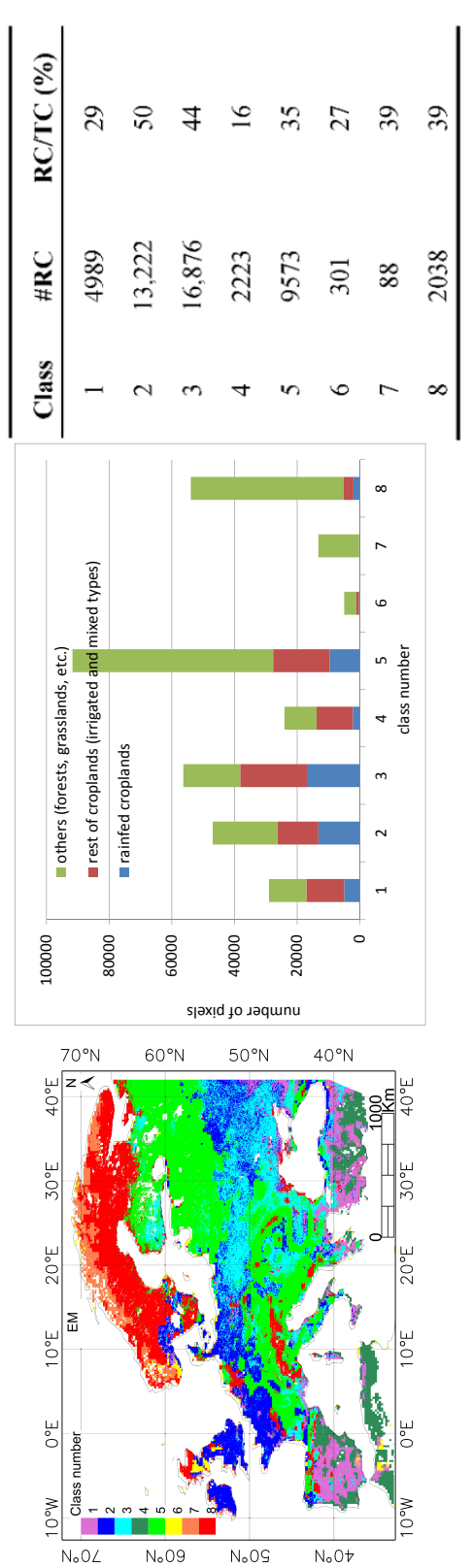

Figure 5.4. Cont.

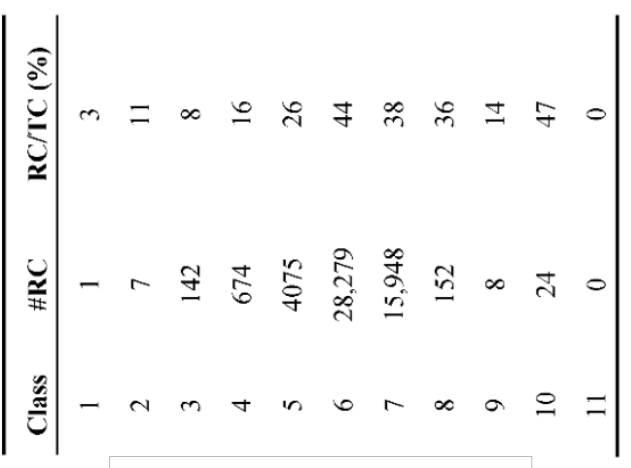
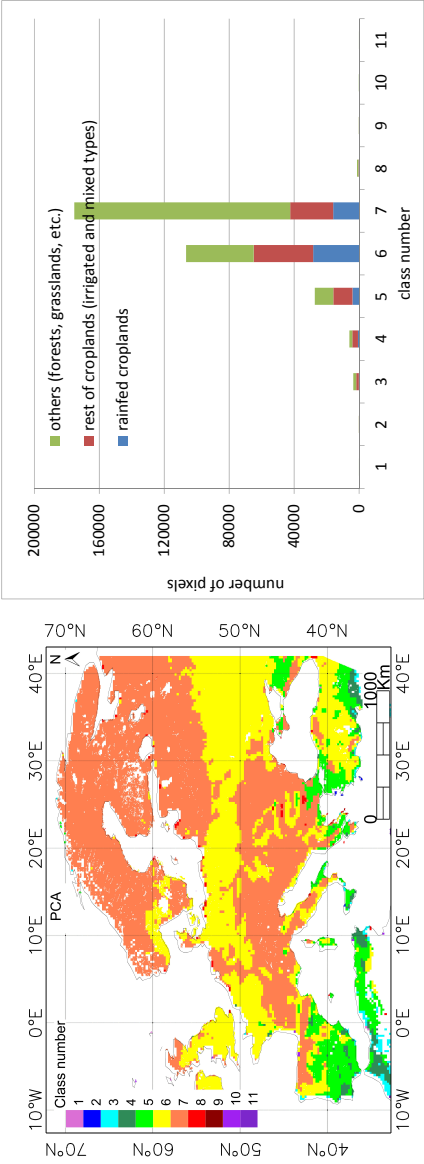
The blue color in the graphs indicates the amount of rain-fed croplands per class, which is also indicated in Figure 5.4c. This number is important since the bias is calculated in this cover type. Therefore in classes 6, 10, 12 from ROM and classes 1, 2, 9 and 10 from PCA, the bias was calculated with relatively few samples. Additionally, class 11 in PCA had no rain-fed pixels and the bias could not be calculated.

Another relevant factor is the relative abundance of rain-fed croplands with respect to the total number of croplands (rain-fed plus rest of croplands) per class. The $\mathrm{ET}_{\mathrm{b}}$ is ultimately calculated in all croplands, and therefore this ratio (named $\mathrm{RC} / \mathrm{TC}$ in the following) is important. The higher $\mathrm{RC} / \mathrm{TC}$ is, the more representative the bias is for all the pixels in a class, that is in classes 3, 5, 7, 9, 11 from ROM, 2 till 6 in k-means, 2, 3, 5, 7, 8 in EM and 6, 7, 8, 10 in PCA. These classes had a ratio higher than $30 \%$, as it can be observed in Figure $5 \cdot 4 \mathrm{c}$.

As a result of this analysis, it was concluded that the k-means and EM classification schemes improved the existing one (ROM) in two aspects: the spatial pattern of the classification map and the increase in number of rainfed pixels and RC/TC per class, with less minority classes, showing the kmeans a better performance. The PCA approach showed weaker changes.

\subsubsection{Bias Curves}

The bias values were obtained per pixel at monthly scale. Monthly $\mathrm{ET}_{\text {actual }}$ values were obtained from the daily MSG-ET and GLDAS-ET estimates during 2010. Due to the lack of some MSG-ET data, and in order to obtain a consistent bias curve, the daily values were only aggregated when both datasets existed. Then, monthly bias values were obtained per pixel and yearly curves were averaged per class, using rain-fed pixels only, for each of the classifications.

Figure 5.5 shows the bias curves using the 3 proposed classifiers and ROM. Additionally the mean bias curve using all rain-fed croplands is plotted as a reference. Note that they are discrete monthly values that are connected to facilitate visual interpretation. 


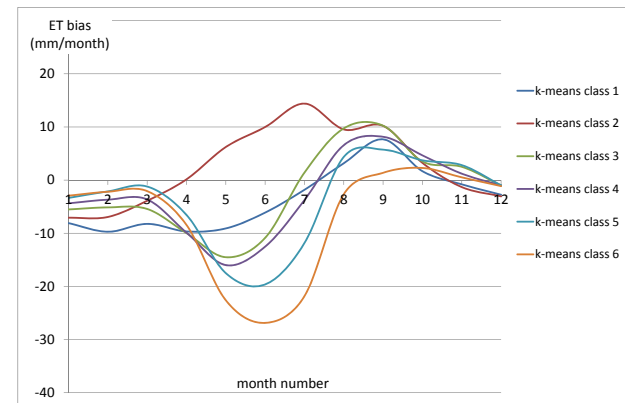

(a) k-means

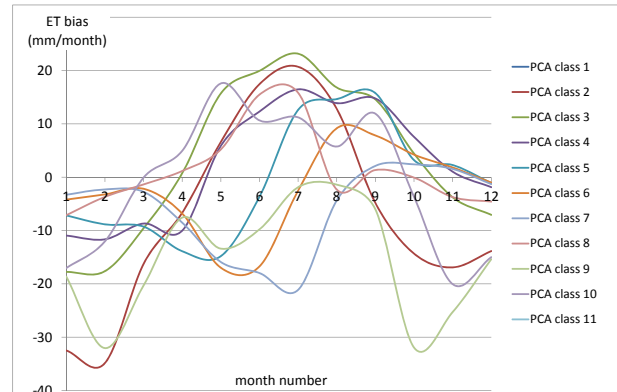

(c) PCA

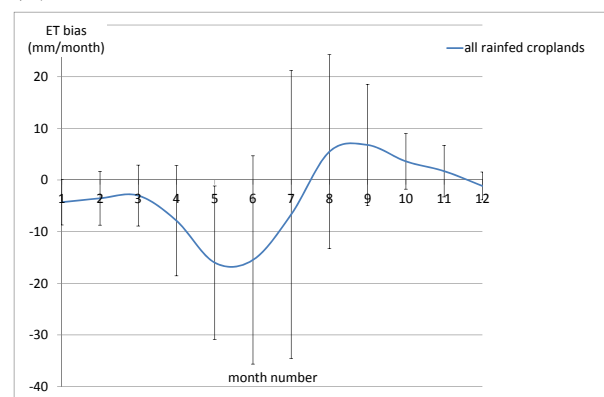

(e) All rain-fed pixels

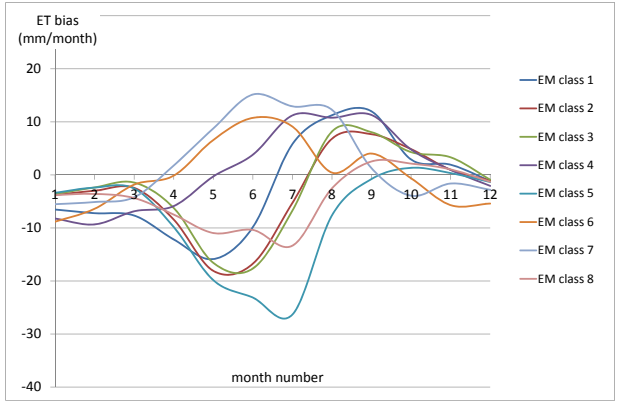

(b) EM

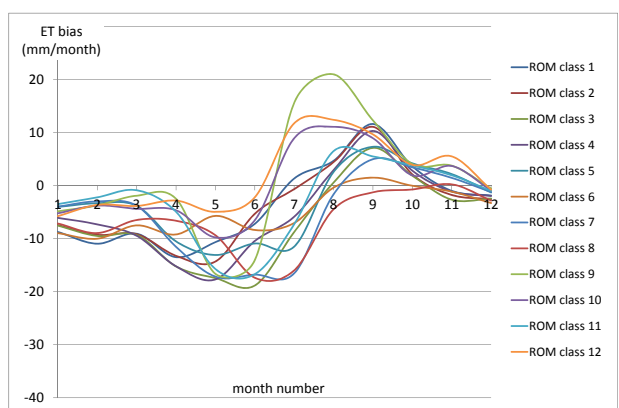

(d) ROM

Figure 5.5. Bias between MSG-ET and GLDAS-ET obtained in rain-fed pixels and averaged per class, using different classifiers. (a) k-means, (b) EM, (c) PCA, (d) ROM, (e) all rain-fed pixels. Note: Monthly discrete values are connected to facilitate visual interpretation.

In general it was observed that the k-means and EM classifications achieved a better separation of the bias curves, compared with ROM and PCA. The kmeans curves (Figure 5.4a) presented a minimum around the month of June in classes 3, 4, 5 and 6 with a general convex shape and amplitude up to -28 $\mathrm{mm} / \mathrm{month}$. A local maximum was found around August. The curves of classes 1 and 2 were concave and corresponded to classes with relatively low 
number of rain-fed croplands, achieving for class 1 the lowest RC/TC ratio (see Figure 5.4C).

Classes 1, 2, 3, 5 and 8 in EM also presented a convex bias with maximum amplitude around May-June with values up to $-28 \mathrm{~mm} / \mathrm{month}$. A local maximum was found around August. Classes 4, 6 and 7 were concave; 4 and 6 corresponded to lowest ratio $\mathrm{RC} / \mathrm{TC}$ and class 7 to lowest value of rain-fed croplands.

In the PCA classification, classes 5, 6 and 7 behaved in a similar way as the convex curves described for k-means and EM. These were the classes with higher number of rain-fed pixels and also high RC/TC. Classes 2, 3, 4, 8 and 10 were concave and presented more irregular bias curves. These were less abundant classes, some of them not even noticeable visually in the figure, in general they had lower ratio RC/TC and relatively low number of pixels. Class number 9 presented an intermediate pattern and classes 1 and 11 were not plotted since they contained only one rain-fed pixel or none.

The biases obtained from the ROM classification were more fuzzy and irregular. Some of the classes $(3,5,7,8,9$ and 11) presented a convex shape similar to the aforementioned curves, but the pattern was irregular and it was difficult to distinguish between classes and extract conclusions regarding the amount of rain-fed croplands and RC/TC.

Finally, Figure 5.5e shows the variability of the bias curve when all rain-fed croplands are averaged and no classes are taken into account. The position of the minimum and local maxima is consistent with what it has been described in this chapter, and the amplitude is in general flattened due to the averaging.

In general the k-means and EM approach represented an improvement with respect to the ROM bias results in terms of separation of the bias curves, which means a better discrimination of the classes. Furthermore, differences in the maximum amplitude of the curves were also found. In order to understand them better, Figure 5.6 shows the comparison of the bias values around the maximum (month 6) (represented as dots) together with the standard deviation associated to it (represented as error bars and also in columns). This was obtained for all the classes and for the mean curve where no classes are assigned (Figure 5.5e). 
Figure 5.6 shows how the standard deviation ( $\sigma$, in columns and secondary $Y$ axis) changed when adding a classification in the method instead of using a single bias curve averaged for all rain-fed croplands. In general, the diminution of $\sigma$ was found in majority classes. In the case of the k-means classifier, $\sigma$ was reduced in classes 4,5 and 6 and slightly increased in classes 1, 2 and 3. For the EM classifier, $\sigma$ increased in classes 1, 4, 6, 7 and 8. In general terms, $\sigma$ increased in the PCA classification, and the values in ROM fluctuated depending on the class. It was also observed that the increase of $\sigma$ was related with the decrease of number of rain-fed croplands and RC/TC in the class.

In terms of the bias value, the classifiers captured different intervals of variability: between -27 and $10 \mathrm{~mm} /$ month in k-means, between -23 and $15 \mathrm{~mm} /$ month for EM, between -18 and $20 \mathrm{~mm} /$ month for PCA and between -19 and $-2 \mathrm{~mm} / \mathrm{month}$ for ROM. The value of the bias for the single curve was $-15 \mathrm{~mm} / \mathrm{month}$. Therefore the proposed classifiers captured a higher range of bias with respect to $\mathrm{ROM}$.

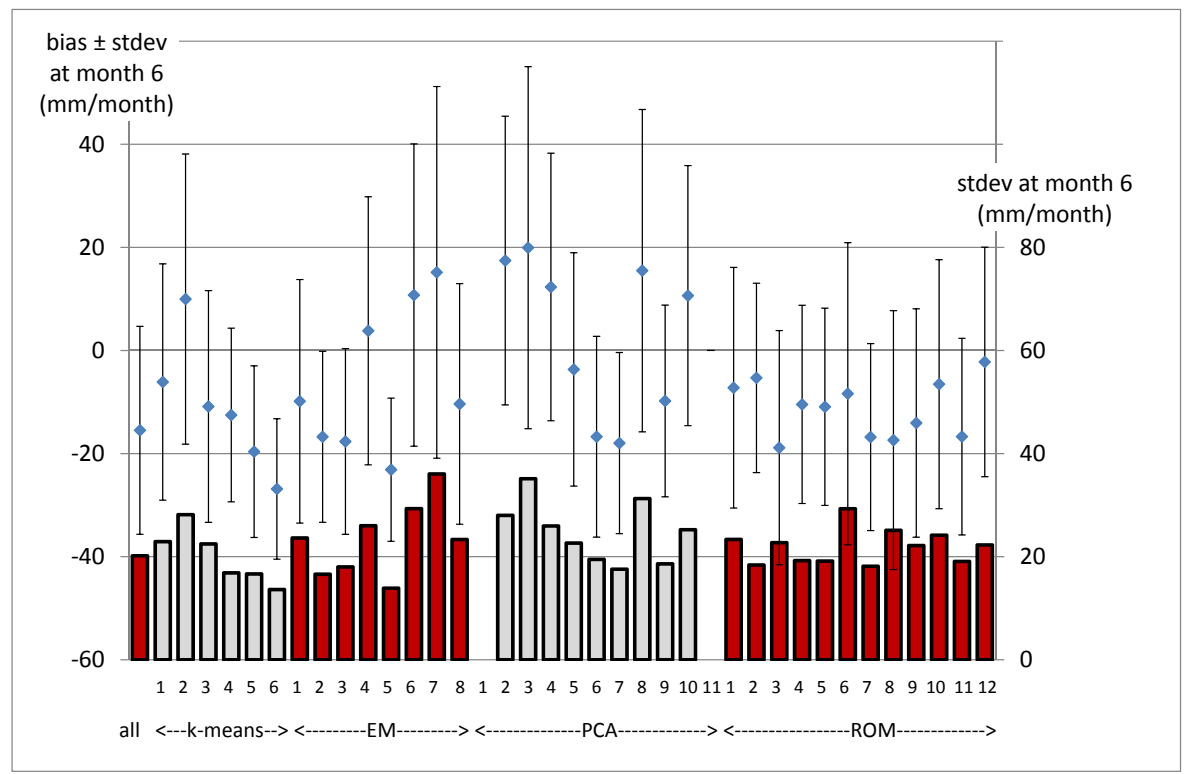

Figure 5.6. ET bias at month 6 and standard deviation (error bars and columns) obtained for all the classifiers and classes discussed in this chapter. The label 'all' refers to the calculation with all rain-fed croplands, where no classes are assigned. 
Previous literature showed the differences between MSG-ET and GLDAS-ET (Gellens-Meulenberghs et al., 2007; Ghilain et al., 2011). For the region of Europe, these studies showed the bias relative to the mean MSG-ET, with values ranging from -0.5 to 0.5. The mean MSG-ET in the month of July was also plotted in this literature, with a value of $0.22 \mathrm{~mm} / \mathrm{h}$ calculated in the range 9-12UTC. If we assume a constant $\mathrm{ET}_{\text {actual }}$ rate, and 10 hours of sun, the aggregated value is $66 \mathrm{~mm} / \mathrm{month}$. This value combined with the \pm 0.5 values of relative bias, produces values of absolute bias up to $33 \mathrm{~mm}$, which is consistent with the intervals found with the proposed classifiers.

As a result of this analysis, the k-means approach showed to improve the existing methodology and perform better than EM and PCA in different aspects related with the bias estimation; first, the ability to differentiate bias curves; second, by reducing the standard deviation of the data when introducing the classes; third, by capturing the expected variability of the maximum bias.

Therefore based on the conclusions extracted from the classification and bias analysis, the k-means is used in the following to estimate $\mathrm{ET}_{\mathrm{b}}$, since it was shown to be the most suitable approach for this research.

\subsubsection{ET $T_{b}$ Estimation}

$\mathrm{ET}_{\mathrm{b}}$ was obtained in the region of Europe in 2010 following equation (5.1), the $\mathrm{k}$-means classification and the bias results. $\Delta$ ET values were calculated daily when both datasets were available and then accumulated monthly. Monthly bias corrections were undertaken, and the resulting positive $\mathrm{ET}_{\mathrm{b}}$ values were aggregated to a yearly scale.

According to the method described in Romaguera et al. (2012a), the GlobCover map was used to mask all cover types except for the rain-fed croplands, irrigated croplands and mixed types that include croplands. Although in that publication a value of $50 \mathrm{~mm}$ was suggested as a threshold from which the method was able to detect irrigation, in the current research, no threshold was considered based on the fact that small values of $\mathrm{ET}_{\mathrm{b}}$ may be also representative for heterogeneous pixels. 
The same procedure was used to obtain $\mathrm{ET}_{\mathrm{b}}$ using the classification scheme provided in the literature (ROM). The comparison showed how the outputs changed when using a different classification scheme. $\mathrm{ET}_{\mathrm{b}}$ reached differences up to $60 \mathrm{~mm} /$ year, being $\mathrm{ET}_{\mathrm{b}}$ (k-means) higher in some regions of Ukraine and lower in some regions of Spain, Turkey and coast of France. The spatial distribution of these differences is related with the classification maps, being for example the red areas in Figure 5.7 associated with class number 2 of the k-means classification that has a convex shaped bias.

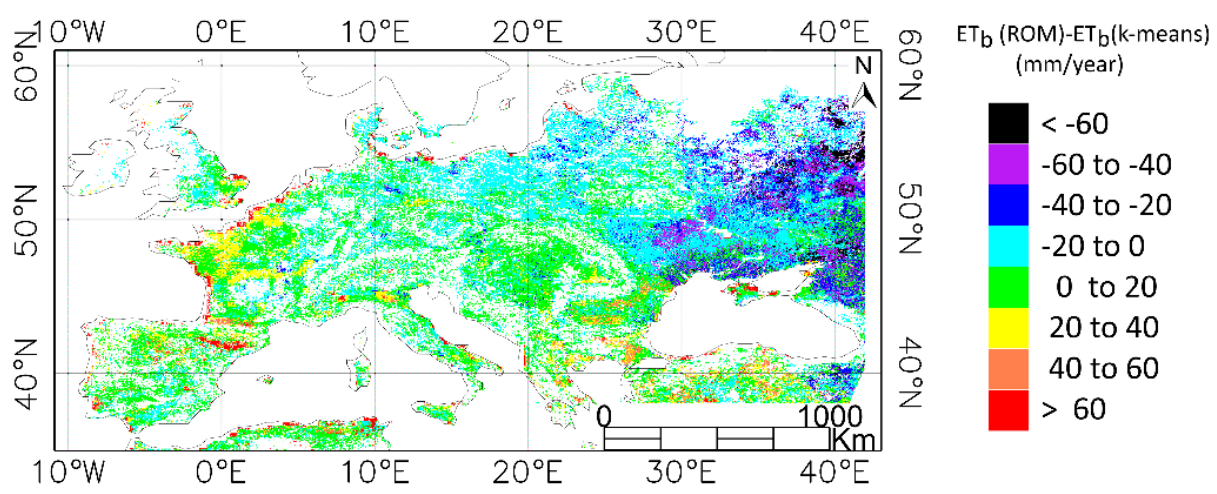

Figure 5.7. Difference between yearly $\mathrm{ET}_{\mathrm{b}}(\mathrm{ROM})$ and $\mathrm{ET}_{\mathrm{b}}$ (k-means) obtained for the year 2010.

\subsection{Application of the Method}

The study area selected to test the method was the whole Meteosat observation disk, which included Europe and Africa, in the year 2010. The analysis was carried out by separating it in three sectors namely Europe, North Africa and South Africa, like the MSG-ET products delivered by LSASAF. These sections are separated at the latitudes of $34^{\circ} \mathrm{N}$ and the equator approximately.

Following the method explained in the present chapter, a classification of every sector was carried out with the k-means algorithm using the proposed input data sets. Pixels labeled as bare areas by the GlobCover map were excluded from the classification. The optimal number of classes was calculated per sector following the procedure explained in Section 5.1.2.1. The bias curves per class in the rain-fed pixels of North Africa and South Africa are plotted in Figure 5.8. 


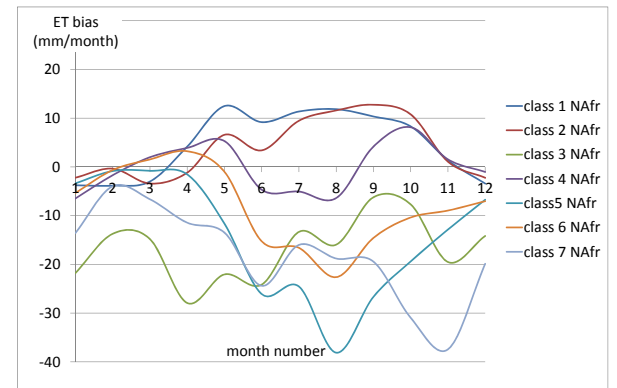

(a)

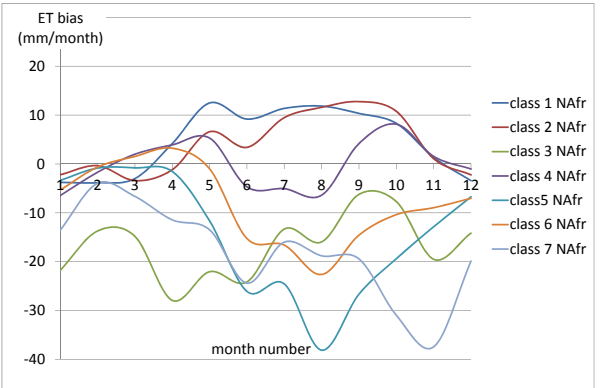

(b)

Figure 5.8. Bias curves obtained in rain-fed pixels of the sectors (a) North Africa and (b) South Africa.

Similarly to the conclusions found in Europe using the k-means approach (Figure 5.5), the curves present distinguishable patters with different amplitudes and shapes. Classes 1, 4 and 6 in North Africa present more defined convex bias curves which correspond to highest numbers of rain-fed pixels and ratio RC/TC, whereas classes 3 and 7 are represented by the lowest number of rain-fed pixels and ratio RC/RT. In the sector of South Africa, the curves present a shift of about six months with respect to the sectors of Europe and North Africa. This is due to the seasonality patterns of the southern Hemisphere. The most abundant classes in terms of rain-fed pixels were classes 2, 4 and 7. However, due to the relatively low quantity of rain-fed pixels in this sector, the ratio RC/TC is below $10 \%$ for all the classes in South Africa.

Equation (5.1) was used in all the study area to calculate monthly $\mathrm{ET}_{\mathrm{b}}$ and the positive values were aggregated to a yearly scale. These were compared with the values of blue water footprint $\left(\mathrm{WF}_{\mathrm{b}}\right)$ for crop production estimated by Mekonnen and Hoekstra (2011). For consistency, the areas labelled with no irrigation croplands in Mekonnen and Hoekstra (2011) were masked (see Figure 5.9)

The mean value of the differences found in Europe and Africa was 27 and 62 $\mathrm{mm} /$ year with standard deviation of 62 and $142 \mathrm{~mm} /$ year, and rmse of 44 and $155 \mathrm{~mm} /$ year. No straightforward correlation was found between the two datasets. Differences between the two methods were found to be below 50 $\mathrm{mm} /$ year in most of Europe and in some regions of Africa, although in this area the discrepancies (in positive and negative sign) were higher as also 
shown by the statistical indicators. Several reasons exist to explain the magnitude and sign of the differences.

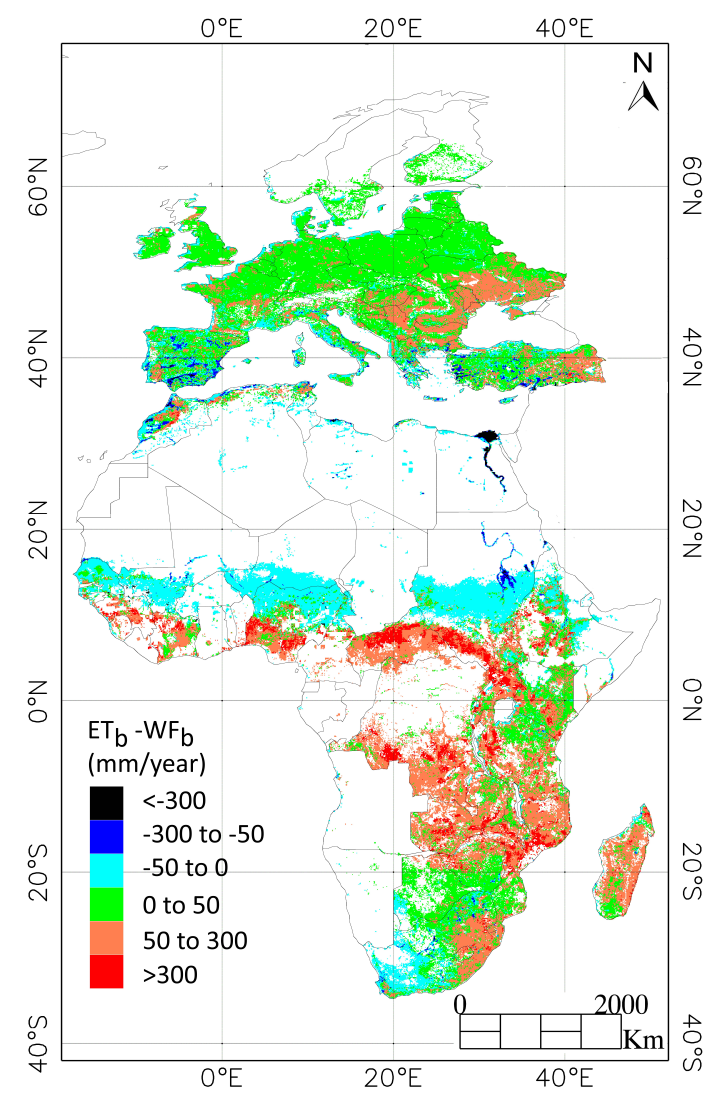

Figure 5.9. Difference between $\mathrm{ET}_{\mathrm{b}}$ generated in this chapter and the $\mathrm{WF}_{\mathrm{b}}(\mathrm{mm} / \mathrm{year})$ given by Mekonnen and Hoekstra (2011).

First, from a methodological point of view, Mekonnen and Hoekstra (2011) used the cropmap of Monfreda et al. (2008) to correct the calculated $\mathrm{ET}_{\text {actual }}$ with the percentage of cropland per pixel, and then the irrigated area map from Portmann et al. (2010) to correct for the area used for irrigation. This resulted in values of annual $\mathrm{ET}_{\mathrm{b}}$ lower than the ones generated in this chapter, as it can be observed in most of Europe and some regions in Africa indicated with green color.

Higher discrepancies (in orange and red) were found in mid Africa. This can be explained based on the cover type and pixel heterogeneity, since these are areas labelled as forests and shrublands by the GlobCover map. The method 
by Mekonnen and Hoekstra (2011) provided low values of $\mathrm{ET}_{\mathrm{b}}$ (below $1 \mathrm{~mm}$ /year) in these mixed pixels due to low value of irrigated cropland area. However, the method presented in this chapter and the bias estimation were not developed for cover types different than croplands, and therefore the values obtained in these areas are not realistic and should be masked as indicated by Romaguera et al. (2012a). This is the case also of the forested areas in Spain, Italy, Greece and Turkey.

The region of Ukraine presented higher values of $\mathrm{ET}_{\mathrm{b}}$ compared with the estimates given by Mekonnen and Hoekstra (2011). This can be explained by a combination of factors. Low values of $\mathrm{ET}_{\mathrm{b}}$ were obtained by Mekonnen and Hoekstra (2011) in the majority of this area. Higher values were obtained by the proposed method, which were influenced by the high values of $\Delta \mathrm{ET}$ found in the inputs. Moreover, this region is located in the extremes of the Meteosat observation disk, which might influence the accuracy of the remote sensed $\mathrm{ET}_{\text {actual }}$ estimates.

Areas painted in cyan were labelled as bare areas by the GlobCover map and were masked in the classification carried out in the present chapter. That was done to avoid misclassification caused by the fluctuation of low $\mathrm{ET}_{\text {actual }}$ rates in these areas. Therefore the method did not provide $\mathrm{ET}_{\mathrm{b}}$ values, whereas Mekonnen and Hoekstra (2011) estimated values of $\mathrm{ET}_{\mathrm{b}}$ below $1 \mathrm{~mm} /$ year. Moreover, other bare areas were also masked in the present chapter and they provided significantly high values of $\mathrm{ET}_{\mathrm{b}}$ in the estimates of the literature. That was the case of the White Nile in Sudan and some areas in Morocco.

Mekonnen and Hoekstra (2011) provided significantly higher values of $\mathrm{ET}_{\mathrm{b}}$ in the region of the Nile basin. These are areas where the assigned cropland irrigated area from Portmann et al. (2010) was higher than $100 \%$, a fact that was related to multiple cropping practices. $\mathrm{ET}_{\mathrm{b}}$ estimates were higher than $1000 \mathrm{~mm} /$ year in this case. However, the method presented in this chapter relied only on the differences between the $\mathrm{ET}_{\text {actual }}$ inputs from MSG and GLDAS and the bias correction, achieving annual values in this region of $600 \mathrm{~mm} /$ year.

Moreover, the discrepancies in some mountainous areas like Mozambique, Ethiopia or north of Italy, may be associated to the effect of the terrain on the radiation. In zones of complex topography, variability in elevation, surface 
slope and aspect create strong spatial heterogeneity in solar distribution, which determines air temperature, soil temperature, ET, snow melt and landair exchanges. Therefore, MSG-ET satellite retrievals may need a slope and aspect correction to radiation inputs in areas of significant relief. Some remote sensing methods that include this geometric correction for calculating ET are given by Allen et al. (2007) and Chen et al. (2013).

Finally, together with the aforementioned methodological reasons, the differences between the two estimates might be related to the accuracy and parameterization of the input data, and the period of comparison, since the datasets were obtained at different time spans.

\subsection{Discussion}

\subsubsection{Uncertainty}

5.6.1.1. Performance of the Classifications

Evaluating the performance of the generated classifications is not an easy task, especially due to the fact that a 'ground truth classification map' that explains the different classes in terms of the biases between MSG-ET and GLDAS-ET does not exist. However, in order to optimize the performance of the methods, different strategies were adopted. The k-means settings were adjusted to a maximum of 100 iterations in order to ensure completion of the algorithm and the optimal number of clusters was calculated using a quality index (Rezaee et al., 1998) that accounts for the intra-cluster and inter-cluster distances, as it is shown in Section 5.2.2.1.

The EM algorithm was trained with $66 \%$ of the data, and tested in the rest of the dataset providing a $\log$ likelihood of 7.04 in the test. The overall likelihood is a measure of the "goodness" of the clustering and increases at each iteration of the EM algorithm. The larger this quantity is, the better the model fits the data. In order to interpret this number, the model was applied to the whole dataset, obtaining a log likelihood of 7.6. This value was expected to be higher than using only the test dataset since the inputs included also the training data. However, the two log likelihood values were similar, which served as an indicator of the good performance of the classifier. 
Moreover, the EM algorithm found the optimal number of clusters for which the log likelihood had a maximum value.

Finally the PC analysis was carried out by using two matrixes, the covariance and the correlation matrixes. The results showed the same clustering using both procedures, where the groups could be visually identified as it is shown in Figure 5.3. The usefulness of the generated classifications in the application that is presented in this chapter (bias estimation and $\mathrm{ET}_{\mathrm{b}}$ ), is discussed in Section 5.4.2.

\subsubsection{Uncertainty of $\mathrm{ET}_{\mathrm{b}}$ Estimations}

It was pointed out in Romaguera et al. (2012a) that equation (5.1) provided some negative values of $\mathrm{ET}_{\mathrm{b}}$ which were not physically correct and were due to the uncertainties in the input data and in the bias curves definition. In the present work, these negative values were not used in the calculation of the annual $\mathrm{ET}_{\mathrm{b}}$ and in order to evaluate their significance they were aggregated during 2010 and combined with the yearly MSG-ET. The ratio between these two (not shown here) was less than $10 \%$ in most of the croplands in the study area. The impact of the negative values was concentrated in areas labeled as 'others' (see Figure 5.1) or in their proximity, like next to the Alps and the Carpathian mountains.

Therefore, it was shown that with the proposed method the non-croplands pixels are more sensitive to errors and therefore they should be masked when producing $\mathrm{ET}_{\mathrm{b}}$.

\subsubsection{Limitations}

This chapter focused on the improvement of the classification scheme proposed by Romaguera et al. (2012a). The analysis presented showed satisfactory results when producing the classification maps and obtaining the bias curves. General limitations and aspects to be taken into consideration when obtaining $\mathrm{ET}_{\mathrm{b}}$ are extensively discussed in the aforementioned literature, and are related to the inaccuracies of the inputs, data availability, validation drawbacks and generalization of the method. 
Regarding the classification approach presented in this chapter, several aspects need to be discussed.

First, the selection of the parameters for the classification is justified in the text. However, additional parameters may have been used and a sensitivity analysis might be carried out to select the optimal set to describe the study area.

Regarding the selection of the classifier, this work showed three strategies, different in concept and complexity. The k-means showed to work better in this research. Nevertheless, having in mind the coarse resolution of the data used, subpixel classifiers may be explored in order to account for mixed pixels and subpixel heterogeneity. In that case, aspects like avoiding over classification and tradeoffs in accuracy, time consumption and computing resources would need to be taken into account. Also, the better performance of the k-means approach, as compared to EM and PCA, was not tested in the application for Africa.

The dimensions of the study area may play an important role when the classifier finds similar pixels apart of each other (e.g. North and South Africa). The bias value may be influenced by the averaging of rain-fed areas in these distant areas. Therefore, a preliminary test on qualitative differences in subcontinental bias patterns is advised to avoid these effects and select reasonable study area sizes.

The GlobCover land cover map was used in several steps in this chapter, to mask bare areas in the classification, to identify rain-fed croplands where the bias curves were obtained and finally to filter other land covers for $\mathrm{ET}_{\mathrm{b}}$ estimation. The results are therefore influenced by the inaccuracies of this input, since pixels may be misclassified.

From a technical point of view, the rescaling and resampling of the input data to achieve a common spatial resolution may have an impact in the analysis. The nearest neighbor resampling technique was used in this research. In general, impacts on the results are expected due to the heterogeneity of the surface and the question of how representative are the low resolution data disaggregated to a higher scale. Up-downscaling techniques tackle this issue 
by using the parameters of surface temperature or NDVI (Anderson et al., 2007; Jia et al., 2011).

The $\mathrm{ET}_{\mathrm{b}}$ results compared with existing literature provided differences of 50 $\mathrm{mm} /$ year in most of Europe. In Africa, the comparison was highly influenced by the assigned cover type and the heterogeneity of the pixel. Results over regions of high topographic relief point to the need for slope and aspect corrections to radiation inputs to the MSG-ET algorithm. Bearing in mind the advantages of both approaches (literature and present chapter), the synergy between them may allow to benefit from the temporal frequency of the remote sensed data and from the better definition of the subpixel heterogeneity.

The in situ validation of the $\mathrm{ET}_{\mathrm{b}}$ estimates produced in this chapter is hampered by the scarcity of good quality spatial data on irrigation at regional scale. The availability of irrigation water management information on a detailed scale like farmer fields or for entire river basins is not common. Data to quantify performance indicators are rarely collected. If collected, data frequently is unreliable or not easily accessible (Bastiaanssen and Bos, 1999). An attempt was made in previous literature to validate the methodology in a corn field in a cropland area in Spain (Romaguera et al. 2012a). Difficulties were found due to the unavailability of MSG-ET remote sensing data coincident with the literature, together with the fact that water resources and irrigation are politically critical issues and generally practices are not regulated or in situ quality data are difficult to access. Moreover, statistical databases such as AQUASTAT (FAO, 2009) provide static and scattered data. Therefore, the validation of the improved method with in situ data remains an open challenge. Although further research is needed to fully understand the $\mathrm{ET}_{\mathrm{b}}$ values found, this chapter has shown to improve the classification scheme and the estimation of the bias curves between the sets of ET data from MSG and GLDAS. An example of application of this improved method to time series of data in the Horn of Africa and Southwest of China is presented in Romaguera et al. (2014b).

\subsection{Conclusions}

This chapter provided a more generic and robust methodology to estimate blue water evapotranspiration $\left(\mathrm{ET}_{\mathrm{b}}\right)$ from remote sensing and simulated 
$\mathrm{ET}_{\text {actual }}$ data, by enhancing the classification scheme employed in the literature. A new selection of input parameters was proposed and the analysis of different classifiers provided the best results for the k-means technique.

The main outcome was the improvement of the definition of the bias between the two $\mathrm{ET}_{\text {actual }}$ datasets, i.e. the ability to differentiate bias curves of different classes, reduction of the standard deviation of the data and achievement of the expected variability of the maximum bias.

This chapter proposed new tools to evaluate the variability of the biases between remote sensing and simulated $\mathrm{ET}_{\text {actual }}$ data. However, the comparison of $\mathrm{ET}_{\mathrm{b}}$ in Europe and Africa with existing literature showed the need of further research to fully understand the final $\mathrm{ET}_{\mathrm{b}}$ values found. 


\title{
Chapter 6
}

\section{Monthly Blue Water Evapotranspiration in Irrigated Agriculture. Study cases of Ethiopia and Sichuan Province of China ${ }^{5}$}

\begin{abstract}
In this chapter we show the potential of combining evapotranspiration (ET) series obtained from remote sensing and land surface modelling, to monitor community practice in irrigation at monthly scale. This study obtained evapotranspiration of blue water $\left(\mathrm{ET}_{\mathrm{b}}\right)$, i.e. due to irrigation, in two study areas affected by a drought event during the period of analysis, but with differences in terms of water control and storage infrastructure: the Horn of Africa (2010-2012) and the province of Sichuan (China) (2001-2010). The monthly $\mathrm{ET}_{\mathrm{b}}$ results were separated by water source - surface water, groundwater or conjunctive use - based on the Global Irrigated Area Map and were analyzed per country/province. The preliminary results showed that the temporal signature of the total $\mathrm{ET}_{\mathrm{b}}$ allowed distinguishing seasonal patterns within a year and inter annual $\mathrm{ET}_{\mathrm{b}}$ dynamics. Overall, in Ethiopia $\mathrm{ET}_{\mathrm{b}}$ decreased during the dry year, thus lower amounts of irrigation water use. Moreover in this period an increase of groundwater use was observed at the expense of surface water use. In Sichuan province, the values of $\mathrm{ET}_{\mathrm{b}}$ in the dry year were of similar magnitude to the previous years or increased, especially in the month of August, which points at a higher amount of irrigation water used. This could be explained by the existence of infrastructure for water storage and water availability, in particular surface water. Although further research is needed to fully understand the temporal patterns found, in face of an extreme event like a drought, the results obtained in the case studies of the present chapter indicated the possibility of identifying and explaining the episode in terms of irrigated water. The application presented in this chapter is innovative and has potential to assess the existence of irrigation, the source, the duration and variability in time, at pixel and country scales, and is especially useful to monitor irrigation practice during periods of drought.
\end{abstract}

${ }^{5}$ Based on Romaguera et al. (2014b) 


\subsection{Introduction}

The assessment of water use is crucial in a changing environment where water is an essential but scarce resource. From a water management perspective, an accurate evaluation of the irrigation water used in agriculture is of high importance. The latest data of water withdrawal for irrigation published at the AQUASTAT database (FAO, 2014a) showed a wide range of values, reporting for example percentages of $0.6,60$ and $85 \%$ of total national water withdrawals in The Netherlands, Spain and United Republic of Tanzania respectively.

Crop water use, or evapotranspiration (ET) has traditionally been separated into its 'blue' and 'green' components, depending on the source of water supply; that is irrigation and precipitation respectively. Early studies in the literature estimated blue and/or green water use at country, continental or global levels (Postel et al., 1996; Rockstrom et al., 1999; Seckler et al., 1998; Shiklomanov and Rodda, 2003). Later, global estimates of consumptive water use for a number of crops per country were retrieved (Chapagain and Hoekstra, 2004; Hoekstra and Chapagain, 2007, 2008; Hoekstra and Hung, 2002). At a global scale and higher spatial resolution, different studies have tackled this issue: Alcamo et al. (2007) estimated blue water withdrawal and Döll and Siebert (2002) the irrigation water requirements. More recently, a few studies have separated global water consumption for crop production into green and blue water at spatial resolutions of 30 and 5 arc minutes (Fader et al., 2011; Hanasaki et al., 2010; Liu and Yang, 2010; Liu et al., 2009; Mekonnen and Hoekstra, 2011; Pfister et al., 2011; Rost et al., 2008; Siebert and Döll, 2008, 2010).

The aforementioned approaches used hydrological models with the objective of estimating evapotranspiration from croplands per crop type, distinguishing between blue and green ET. However, the input used and the type of output produced, differed. The results were presented at spatial resolutions of country scale, 5 , and 30 arc minutes and covered different time periods. The inputs of the methods were national statistics, reports, climatic databases and crop-related maps. The spatial and temporal resolutions of the source data were coarse in some cases, especially where extracted from statistical databases, implying in some cases the use of disaggregation techniques. 
Bearing this in mind, remote sensing techniques may improve on the estimates of blue and green water use since they provide global coverage, varied temporal and spatial resolution and broad spectral information. This allows characterizing the physical processes and monitoring crops in appropriate space and time scales. In this context, Romaguera et al. (2012a, 2014a) included the use of remote sensing data and proposed a methodology to estimate blue water evapotranspiration $\left(\mathrm{ET}_{\mathrm{b}}\right)$ that could benefit from the remote sensing advantages. This method allows estimating $\mathrm{ET}_{\mathrm{b}}$ at different time scales, i.e. hourly, daily, monthly and yearly, which is supposed an improvement with respect to the existing static maps for monitoring irrigation practice. At regional scale, other works used remote sensing to evaluate irrigation performance (Bastiaanssen and Bos, 1999; D'Urso et al., 2012; Santos et al., 2010).

Moreover, in recent years, several studies have approached the problem of global irrigation mapping, using national statistical data as input (Siebert et al., 2005; Siebert et al., 2006) or making use of spectral and temporal remote sensing data to perform classifications and obtain irrigated areas (Ozdogan and Gutman, 2008; Thenkabail et al., 2009a). These methods provide information about areas equipped for irrigation, about crop dominance and irrigation source, and about existence or absence of irrigation, but none of the methods quantifies the actual amount of water received by the crops through irrigation, or blue water. In particular, the source of irrigation water was determined by Thenkabail et al. (2008, 2009a) in their Global Irrigated Area Map (GIAM), where irrigated areas were classified as a function of three sources of irrigation supply: surface water, groundwater and conjunctive use (due to usage of stored rain water).

The objective of this chapter is to apply the remote sensing method by Romaguera et al. (2012a, 2014a) and obtain $\mathrm{ET}_{\mathrm{b}}$ values at relevant time scales for water management purposes, that is at monthly and country/province scale, as well as to show preliminary results and the potential of exploiting these data when combined with the source of irrigation water, from the aforementioned GIAM map. The regions and period of study are the Horn of Africa (period 2010-2012) and the Chinese province of Sichuan (period 20012010), both affected by a drought event during the period of study, but with differences in terms of water control and storage infrastructure. 
Section 6.2 describes the method and datasets used in this chapter and Section 6.3 the selected study areas. Section 6.4 includes $\mathrm{ET}_{\mathrm{b}}$ time series per source of irrigation water in the study areas and a sensitivity analysis. Section 6.5 discusses relevant aspects of the application tackled in this research and finally the conclusions of this work are summarized.

\subsection{Method and Data}

The method to estimate $\mathrm{ET}_{\mathrm{b}}$ used in this chapter is described in Romaguera et al. (2012a, 2014a). It is based on the calculation of the differences in actual evapotranspiration (ET) given by the remotely sensed ET data (RS-ET in the following) and the GLDAS ET model simulations (GLDAS-ET in the following). The former included the effect of irrigation where relevant, whereas irrigation was not incorporated in GLDAS simulations. A bias between the two datasets is calculated in rain-fed croplands, where no irrigation is supplied, and then used to correct the whole dataset, obtaining $\mathrm{ET}_{\mathrm{b}}$ as:

$$
E T_{b}=\Delta E T-b i a s
$$

Where $\Delta \mathrm{ET}$ is the difference between RS-ET and GLDAS-ET and bias is this difference calculated only in rain-fed croplands. The idea behind this formulation relies on the fact that GLDAS-ET products do not account for extra water supply in form of irrigation in the land surface model (Ozdogan et al., 2010), whereas RS-ET are based on the energy balance and therefore are able to observe full ET from croplands, including all sources of water. Therefore, the difference between the two datasets provides information about the water used in the form of irrigation.

\subsubsection{Bias Estimation}

Since the two datasets present systematic discrepancies, rain-fed croplands were used to calculate a reference bias to correct for this effect and isolate the differences due to irrigation practices. The GlobCover land cover map (ver 2.3) (UCLouvain and ESA, 2011) was used to identify rain-fed croplands.

Previous literature showed temporal and spatial variations of this bias (LSASAF, 2010; Romaguera et al., 2012a). For example, in Europe the bias 
amplitude changed along the year roughly resembling a positive concave curve. The maximum amplitude value reached up to $3 \mathrm{~mm} /$ day and occurred in the months of spring and summer in northern latitudes (Romaguera et al., 2012a). In that paper, the spatial variability of the bias was taken into account by performing a classification of the study area and calculating the spatial mean bias per class and per month. Normalized Difference Vegetation Index (NDVI) and satellite observation angle were the input parameters for the classification. The validity of the bias curves obtained was carried out by analyzing their representativeness in bigger areas, providing satisfactory results in majority classes.

The classification scheme was improved in recent literature (Romaguera et al., 2014a) by testing different classification approaches and proposing a new set of input parameters. This allowed to obtain a better differentiation of the bias curves, reduced the standard deviation of the data and captured the expected variability of the maximum bias.

Therefore, following Romaguera et al. (2014a), in the present work a yearly classification of every study area was carried out with the k-means algorithm and using the following parameters as inputs: a yearly climatic indicator $(\mathrm{CI})$ based on net radiation and precipitation, the maximum value of monthly ET along the year $\left(\mathrm{ETm}_{\max }\right)$, the month where the $\mathrm{ET}_{\text {mmax }}$ occurs $\left(\mathrm{t}_{-} \mathrm{ET}_{\mathrm{mmax}}\right)$ and the maximum NDVI $\left(\mathrm{NDVI}_{\max }\right)$ in the year of interest. The optimal number of classes was calculated using a scattering distance (SD) quality index (Rezaee et al., 1998).

For every year and area, a classification was generated and biases per month were obtained by spatially averaging the bias obtained in rain-fed croplands per class. Finally, equation (6.1) was used in the study areas to calculate the total $\mathrm{ET}_{\mathrm{b}}$ per month and the GIAM map to assign the source of irrigation water per pixel.

\subsubsection{Data}

Table 1 describes the main characteristics of the datasets used in the present work which are detailed in the following paragraphs.

Remote sensing ET estimates were obtained from two sources, the Meteosat Second Generation products provided by the Land Surface Analysis - Satellite 
Applications Facility (LSA-SAF) (Ghilain et al., 2011) for the region of Africa (period 2010-2012) and the dataset produced by Chen et al. (2013, 2014) over China during the years 2001 till 2010. The periods of study and areas were (partially) determined by the availability of data at the moment of writing this chapter. The inclusion of the region of China allowed analyzing a longer time series of data, which was limited in the Meteosat products over Africa, and also allowed to estimate $\mathrm{ET}_{\mathrm{b}}$ in a region with more extensive irrigation practices and infrastructure, which is China.

The MSG ET model is a simplified Soil-Vegetation-Atmosphere Transfer (SVAT) scheme that uses as input a combination of remote sensed data and atmospheric model outputs. The inputs based on remote sensing are LSA-SAF products of albedo, and downwelling short and longwave radiation fluxes (Gellens-Meulenberghs et al., 2007; Ghilain et al., 2011).The dataset from Chen et al. (2014) is based on the Surface Energy Balance System (SEBS) (Su, 2002), which uses multi-sensor remote sensing based NDVI, albedo, surface emissivity and temperature.

Simulated ET data with the Noah model (Chen et al., 1996) were acquired from the Global Land Data Assimilation System (GLDAS) (Rodell et al., 2004). The Noah land surface model is a $1 \mathrm{D}$ column model that describes the physical processes of the soil, vegetation and snowpack. The inputs of this model are satellite and ground-based observational data. The calculation of the latent (LE) and sensible (H) heat flux start from potential LE (LEp), based on the soil moisture, atmosphere states, and vegetation characteristics. Constrains to LEp are applied resulting in the actual LE and ET.

The GlobCover land cover map (ver 2.3) (UCLouvain and ESA, 2011) was used to identify rain-fed croplands. This map is based on classification techniques which use the surface reflectances observed by the Medium Resolution Imaging Spectrometer (MERIS). 
Table 6.1. Specifications of the datasets used in the present work.

\begin{tabular}{|c|c|c|c|c|c|}
\hline Data & Source & $\begin{array}{l}\text { Spatial } \\
\text { Cover. }\end{array}$ & $\begin{array}{l}\text { Spatial } \\
\text { Resol. }\end{array}$ & $\begin{array}{l}\text { Temp. } \\
\text { Resol. }\end{array}$ & Details \\
\hline \multirow{3}{*}{ ET } & LSA-SAF & $\begin{array}{l}\text { MSG } \\
\text { disk* }^{*}\end{array}$ & $\begin{array}{l}3 \mathrm{~km} \text { at } \\
\text { nadir }\end{array}$ & daily & $\begin{array}{l}\text { Availability of data: } \\
\text { Europe: Jan. } 2007 \text {-present } \\
\text { The rest: Sept. 2009-present } \\
\text { Used for the study area in } \\
\text { Africa }\end{array}$ \\
\hline & $\begin{array}{l}\text { Chen et al. (2014) } \\
\text { (SEBS model) }\end{array}$ & China & $0.1^{\circ}$ & monthly & $\begin{array}{l}\text { Availability of data: } \\
\text { Years 2001-2010 } \\
\text { Used for the study area in } \\
\text { China }\end{array}$ \\
\hline & $\begin{array}{l}\text { GLDAS } \\
\text { (Noah model) }\end{array}$ & Global & $\begin{array}{l}0.25^{\circ} \\
(\sim 30 \mathrm{~km} \\
\text { at } \\
\text { equator })\end{array}$ & monthly & $\begin{array}{l}\text { Availability of data: } \\
\text { March 200o-present }\end{array}$ \\
\hline $\begin{array}{l}\text { Land } \\
\text { Cover }\end{array}$ & MERIS & Global & $300 \mathrm{~m}$ & Static & $\begin{array}{l}\text { GlobCover map calculated in } \\
\text { year } 2009\end{array}$ \\
\hline $\mathbf{R}_{\mathrm{n}}, \mathbf{P}$ & $\begin{array}{l}\text { GLDAS } \\
\text { (Noah model) }\end{array}$ & Global & $\begin{array}{l}0.25^{\circ} \\
(\sim 30 \mathrm{~km} \\
\text { at } \\
\text { equator })\end{array}$ & monthly & $\begin{array}{l}\text { Availability of data: } \\
\text { February 200o-present }\end{array}$ \\
\hline \multirow[t]{2}{*}{ NDVI } & AVHRR & Africa & $1 \mathrm{~km}$ & monthly & $\begin{array}{l}\text { Generated by IGBP } \\
\text { April 1992- March } 1993 \\
\text { Used for the study area in } \\
\text { Africa }\end{array}$ \\
\hline & SPOT-VEG & Global & $1 \mathrm{~km}$ & monthly & $\begin{array}{l}\text { Used for the study area in } \\
\text { China }\end{array}$ \\
\hline $\begin{array}{l}\text { Irrigation } \\
\text { source }\end{array}$ & GIAM & Global & $10 \mathrm{~km}$ & static & $\begin{array}{l}\text { Data: Type of irrigation } \\
\text { Primary data used: } \\
\text {-AVHRR from } 1997 \text { till } 1999 \\
\text {-TOA NDVI from } 1982 \text { till } \\
2000\end{array}$ \\
\hline
\end{tabular}

${ }^{*}$ Meteosat disk covers latitudes between $-60^{\circ}$ and $+60^{\circ}$ and longitudes between $-60^{\circ}$ to $+60^{\circ}$.

**List of acronyms: LSA-SAF (Land Surface Analysis -Satellite Applications Facility), MSG (Meteosat Second Generation), GLDAS (Global Land Data Assimilation System), SEBS (Surface Energy Balance System), MERIS (Medium Resolution Imaging Spectrometer), AVHRR (Advanced Very High Resolution Radiometer), IGBP (International Geosphere-Biosphere Programme Data), SPOT-VEG (Satellite Pour l'Observation de la Terre-Vegetation), GIAM (Global irrigated Area Map), TOA (Top Of Atmosphere). 
The inputs for the classification of the study areas were obtained from the following sources. Net radiation $\left(R_{n}\right)$ (as a sum of longwave and shortwave radiation) and precipitation (P) (as a sum of rainfall and snowfall rate) were also taken from the GLDAS dataset. These were used to calculate the climatic indicator as the ratio $\mathrm{LP} / \mathrm{R}_{\mathrm{n}}$, where $\mathrm{L}(\mathrm{J} / \mathrm{kg})$ is the latent heat of vaporization, $\mathrm{P}$ $(\mathrm{mm})$ is the annual precipitation and $\mathrm{R}_{\mathrm{n}}\left(\mathrm{W} / \mathrm{m}^{2}\right)$ is the annual net radiation. The monthly ET used for the classification were taken from GLDAS. Data on NDVI was obtained from the Advanced Very High Resolution Radiometer (AVHRR) delivered by the Deutsches Zentrum für Luft- und Raumfahrt (DLR) and from the Satellite Pour l'Observation de la Terre (SPOTVegetation). These NDVI sources were selected as inputs for the classification because they are the ones used for the RS-ET estimations, and their values may influence the differences/biases between RS-ET and model simulations.

The Global Irrigated Area Map by Thenkabail et al. (2008) was used to identify the source of irrigation, i.e. surface water, groundwater or conjunctive use. This map shows global irrigated areas and classifies them depending on the type of irrigation. The 'surface water' (SW) class includes major and medium irrigation from surface water based on large and medium dams. The 'groundwater' (GW) class describes minor irrigation from groundwater, small reservoirs and tanks. The 'conjunctive use' (CU) class comprises predominately minor irrigation from groundwater, small reservoirs and tanks, but with some mix of surface water irrigation from major reservoirs. This map was generated using classification techniques whose input data were remote sensing based reflectivity, NDVI, rainfall, tree cover and elevation, combined with ground data and Google Earth imagery.

From a technical point of view the inputs were resampled to a common grid and projection, and the resolution of remote sensing data was chosen to calculate the $\mathrm{ET}_{\mathrm{b}}$ results, that is 0.030 and o.1 degree for the Horn of Africa and the Chinese region respectively. The separation of SW, GW and CU was carried out at the resolution of the GIAM map, which is 1okm. The temporal resolution of a month was chosen in this analysis. In order to homogenize the data, daily ET values from MSG were monthly aggregated. 


\subsection{Study Areas}

Based on the availability of remote sensing data, two study areas affected by a drought event during the period of study, but with differences in terms of water control/storage infrastructure were selected. First, the Horn of Africa was affected by a drought in the year 2011 (Anderson et al., 2012; Viste et al., 2013). In particular, Ethiopia is considered a water scarce country. Despite the abundance of water in some parts of the country (central, western and southwestern parts), the distribution and availability of water is erratic both in space and time due to the lack of water control/storage infrastructures (Awulachew et al., 2007). Strategies have been implemented at national level to improve in this direction, like the Irrigation and Drainage Project (Onimus, 2014).

Secondly, China is a country with abundant water resources where dams and reservoirs are numerous, built for hydropower generation, flood control, irrigation and drought mitigation. In particular, in the province of Sichuan we can find the Dujiangyan irrigation project (Zhang et al., 2013), a more than 2000 years old system that was developed to prevent flood and nowadays is crucial in draining off flood water, irrigating farms and provide water resources for more than 50 cities in the province. This region suffered a severe drought in 2006 (Dai et al., 2008; Wang et al., 2012).

a)

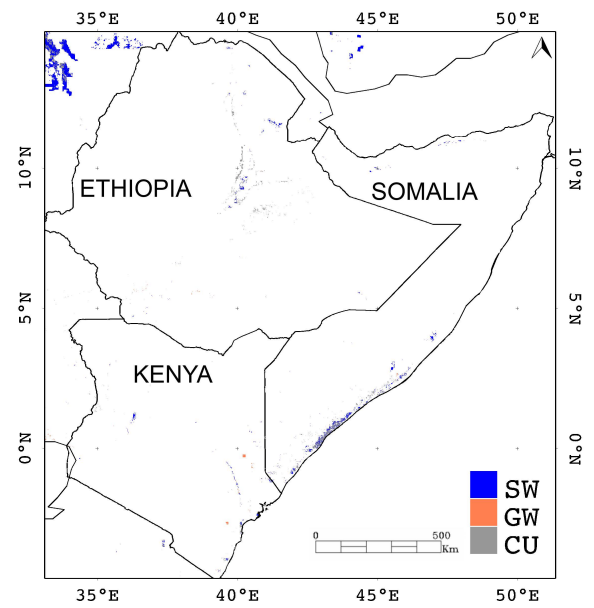

b)

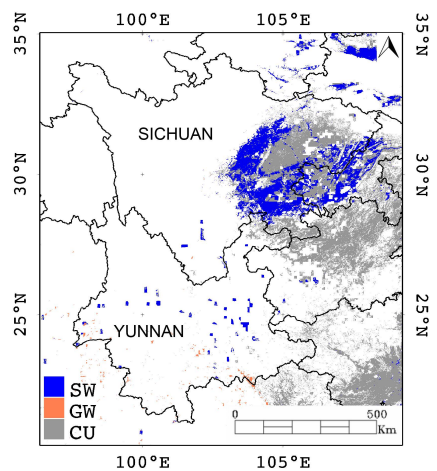

Figure 6.1. GIAM map in the regions of study (a) Horn of Africa and (b) southwest of China, where SW, GW and CU stand for surface water, groundwater and conjunctive use, respectively. 
Figure 6.1 shows the GIAM map, location and size of the study areas. For the sake of comparison, the neighboring countries/provinces were included in the study area, which computed a total of 1680000 and $875000 \mathrm{~km}^{2}$ in the regions of east Africa and southwest of China respectively. Based on this map, irrigated areas were scarce in the Horn of Africa, mainly concentrated in the center and middle-north of Ethiopia, middle-west and southeast of Kenya and in the coastal areas of south Somalia. In Sichuan province, irrigated areas were abundant in the eastern part and they were scattered in Yunnan province.

\subsection{Results}

\subsubsection{Bias Curves}

The spatial distribution of the bias was obtained monthly for every study area (not shown here). These computed a total of 36 images in the Horn of Africa, and 120 in the Chinese area, for the time periods analyzed ( 3 and 10 years respectively). After the classification of the study areas, the monthly bias value was obtained per class by averaging the monthly biases in rain-fed croplands.

Figure 6.2 shows the inter-annual variability of the resulting bias curves. The yearly classification of the study areas provided the following number of classes: 6 (for 2010 and 2011) and 8 (for 2012) in the Horn of Africa; 6 (for 2001, 2003, 2004, 2006), 7 (for 2002, 2005, 2007, 2008, 2009) and 8 (for 2010) in the Chinese area. In general, largest biases and similar patterns over the years were found in southwest of China, with amplitudes between -80 and 80 $\mathrm{mm} / \mathrm{month}$. The largest biases were found for the years 2005 and 2010, and the lowest biases for 2009 .

The bias curves found in the Horn of Africa show no clear pattern over the years for some classes, which may be explained by the relatively low number of rain-fed pixels used to obtain them. This is the case for classes 1 and 2 in 2010 and class 1 in 2011, where the number of pixels used is one or two orders of magnitude lower than the rest of the classes; for all classes biases are relatively modest compared to the ones found in the region of China. 
a)
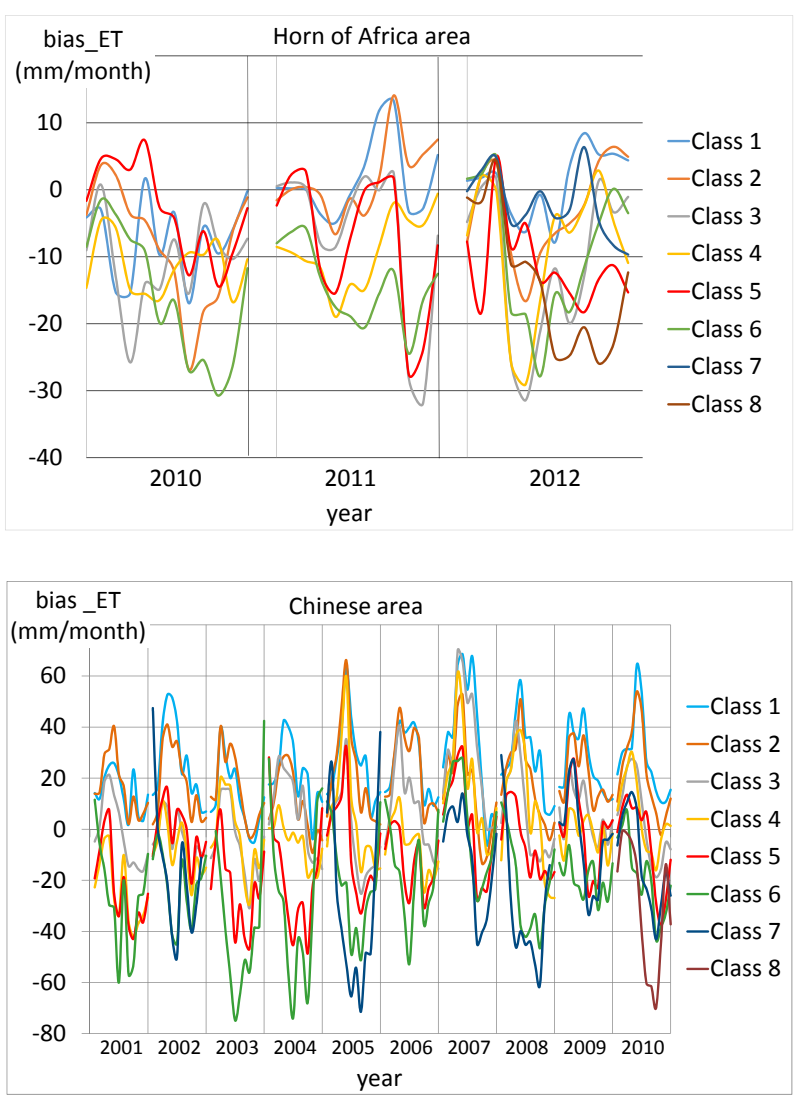

Figure 6.2. Spatial mean bias per class for (a) Horn of Africa and (b) southwest of China study areas, obtained in rain-fed croplands as the difference of RS-ET and GLDAS-ET. (Note that the discrete $\mathrm{ET}_{\mathrm{b}}$ monthly values are connected to ease visualization)

As a reference, we provide the average monthly ET in both regions for the year 2010 obtained from the GLDAS-ET data set. The value was computed over all land pixels shown in Figure 6.1. The average monthly ET ranged from 25 to $60 \mathrm{~mm} / \mathrm{month}$ and from 25 to $120 \mathrm{~mm} /$ month in the African and Chinese regions respectively. These differences can partly explain the magnitude of the amplitudes found in the bias curves.

\subsubsection{Monthly $E T_{b}$ and Source of Irrigation}

This section contains preliminary results of the application of the $\mathrm{ET}_{\mathrm{b}}$ method in the study areas. Monthly $\mathrm{ET}_{\mathrm{b}}$ was calculated for the Horn of Africa for the 
period 2010 till 2012 and for the southwest of China for the years 2001 to 2010. Monthly $\mathrm{ET}_{\mathrm{b}}$ values were extracted from the pixels labeled by GIAM as irrigated and assigned to the corresponding source of irrigation (SW, GW, $\mathrm{CU})$. Pixel values were converted to volumes $\left(\mathrm{Mm}^{3} / \mathrm{month}\right)$ by using the pixel area and then aggregated per country/province. Figure 6.3 shows the first results in the study areas where the monthly values of precipitation aggregated over the evaluated pixels are also included.

The temporal signature of $\mathrm{ET}_{\mathrm{b}}$ allows distinguishing seasonal patterns within a year and also inter annual $\mathrm{ET}_{\mathrm{b}}$ dynamics, especially in the long series of $\mathrm{ET}_{\mathrm{b}}$ obtained in the provinces of China. The $\mathrm{ET}_{\mathrm{b}}$ pattern in Yunnan province was found to be relatively regular, contrary to what was observed in Sichuan, with some $\mathrm{ET}_{\mathrm{b}}$ peaks in years 2006 and 2007 and lower general values in 2009 and 2010.

Precipitation showed a significant decrease in the year 2011 in Ethiopia and in the year 2006 in Sichuan province. This corresponds to drought periods as explained in Section 6.3.

In Ethiopia, a general decrease of $\mathrm{ET}_{\mathrm{b}}$ was observed in 2011, which points at a lower amount of irrigation water used. Moreover, in this period an increase of groundwater use at the expense of surface water use was observed, which is consistent with the report by Hendrix (2012). Despite of the existence of the drought, national crop production did not appear to be significantly affected as reported by the Food and Agriculture Organization of the United Nations (FAO, 2014b). This might be explained by the fact that the drought mainly affected the east and south of the country and the majority of croplands use rain-fed production systems and are located in the other part of the country (See et al., 2013).

A decrease of $\mathrm{ET}_{\mathrm{b}}$ in half of the year 2011 was also observed in Kenya. The precipitation values in this period were only slightly lower than for other years. The drought in Kenya affected the northeastern regions of the country and therefore there is no significant effect on the precipitation in irrigated areas. The study of longer time series of data would allow analyzing inter annual variability, trends and anomalies with a better statistical representation, and therefore have a better interpretation of these patterns. 


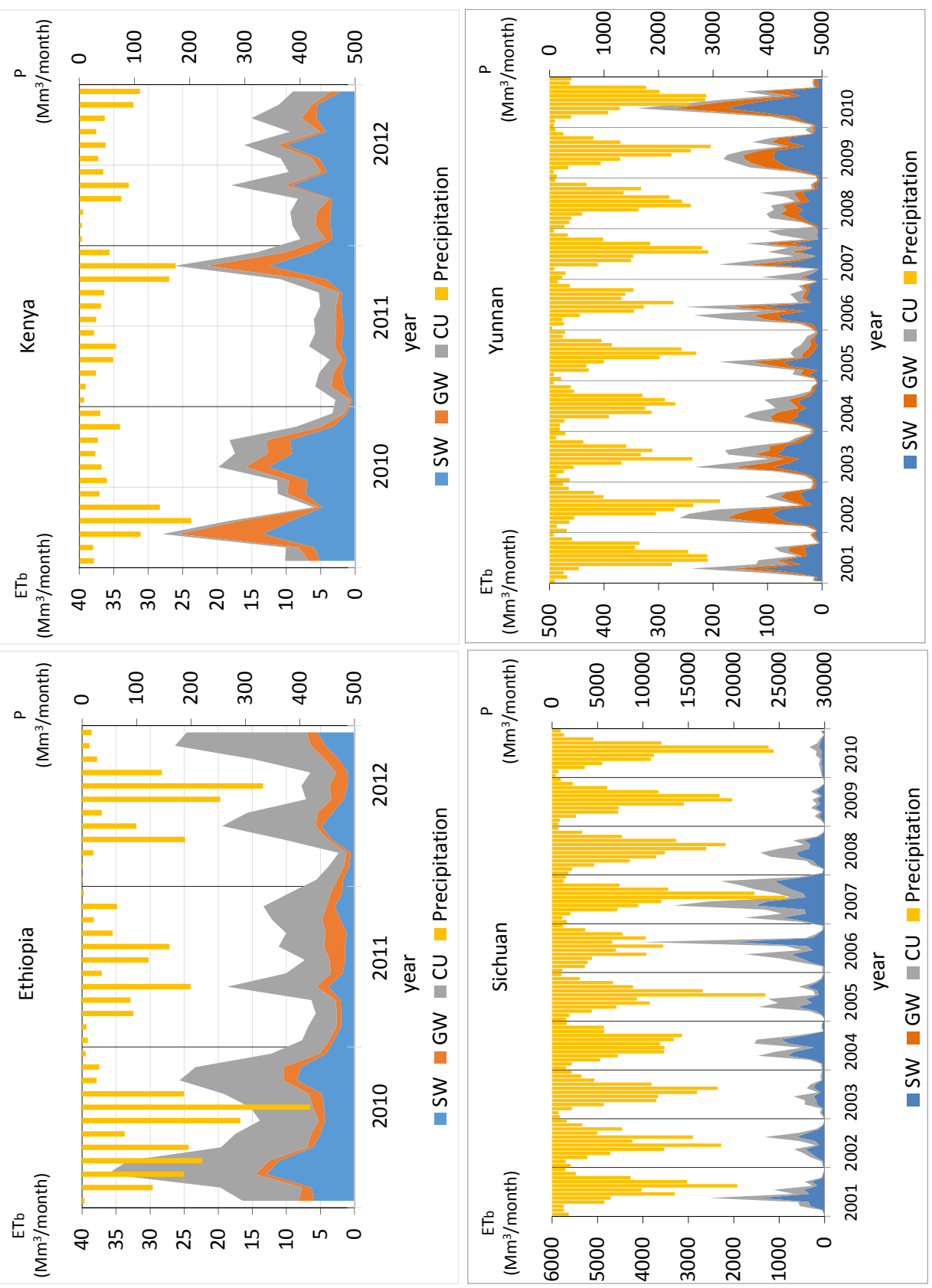

Figure 6.3. Monthly $\mathrm{ET}_{\mathrm{b}}$ per source of irrigation water (surface water, $\mathrm{SW}$; groundwater, GW; conjunctive use, CU) in irrigated areas of (a) Ethiopia and (b) Kenya (years 2010-2012) and the Chinese provinces of (c) Sichuan and (d) Yunnan (years 2001-2010). The figure also shows monthly precipitation. (Note that the discrete ET $_{\mathrm{b}}$ monthly values are connected to ease visualization) 
In Sichuan province, the values of $\mathrm{ET}_{\mathrm{b}}$ in the dry year were of similar magnitude to the previous years or increased, especially in the month of August, which points at a higher amount of irrigation water used. The National Bureau of Statistics of China (National Data Base, 2014) reported that total water resources in Sichuan decreased by $26 \%$ in 2006 with respect to the average of other reported years (2004-2012), but still with a high value of 187 billion $\mathrm{m}^{3}$. Moreover, the grain production in 2006 was only $10 \%$ lower than in year 2005. These two facts suggest that water was still available for irrigation and it was used when precipitation decreased.

In order to better interpret the results obtained, Figure 6.4 shows the input RS-ET and GLDAS-ET values in August 2006, where a peak of $\mathrm{ET}_{\mathrm{b}}$ is found in Sichuan. In this study area the range of RS-ET values was double the ones given by the land surface model in GLDAS-ET, with values up to 330 $\mathrm{mm} / \mathrm{month}$. In particular, a hot spot was found in Sichuan province near the border with Chongqing province with low values of GLDAS-ET. There is a high density of irrigated agriculture in this area (see Figure 6.1), so that the aggregated results per province are highly influenced by these values. Figure 6.4 also includes the temporal series of these two ET estimates in a pixel of the hot spot, where the significant decrease of GLDAS-ET outputs in the year 2006 can be observed. Due to the lack of precipitation, the ET model outputs given by the land surface model are lower.

In Yunnan province, in which there was no significant dry year during the period of analysis, the total $\mathrm{ET}_{\mathrm{b}}$ curves show relatively regular patterns and values ten times smaller than in Sichuan. The use of the three sources of irrigation water is observed in this province with a major use of surface water. In general, the preliminary results shown in Figure 6.3 revealed also features that could not be explained, like the $\mathrm{ET}_{\mathrm{b}}$ peaks in Sichuan in 2007 or low $\mathrm{ET}_{\mathrm{b}}$ values in 2009 and 2010. Although further research is needed to fully understand the patterns, this chapter exemplifies the potential exploitation of the temporal dimension of $\mathrm{ET}_{\mathrm{b}}$, combined with the source of irrigation water, which could be useful for water management purposes.

The analysis of data in longer periods of time showed an advantage when interpreting and better understanding the $\mathrm{ET}_{\mathrm{b}}$ patterns. Bearing this in mind, the following section about sensitivity was elaborated using the case study of Sichuan province (years 2001-2010). 


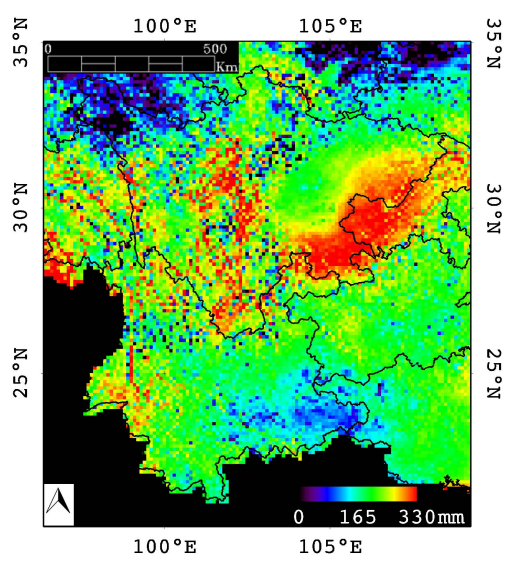

a) RS-ET

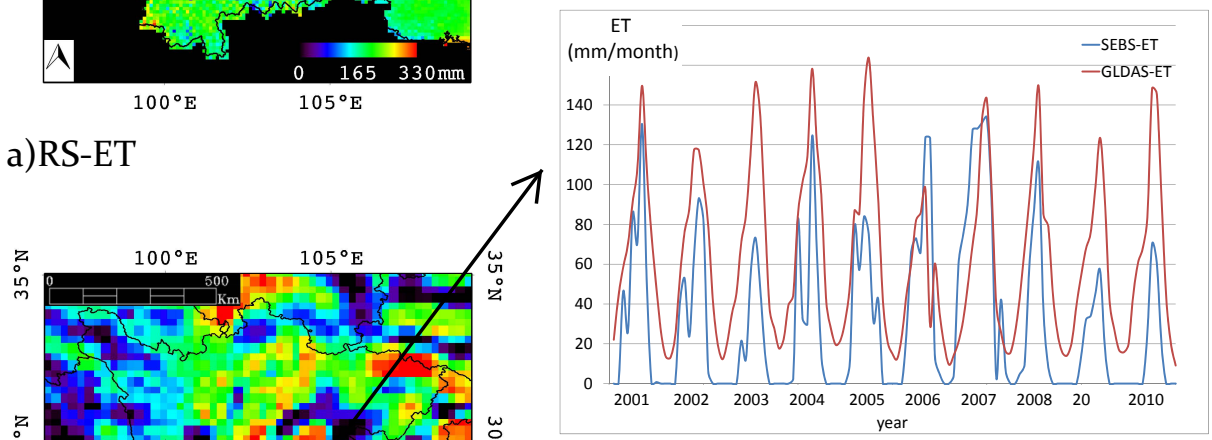

c)

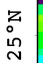

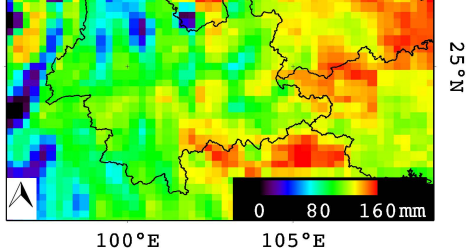

b)GLDAS-ET

Figure 6.4. Monthly evapotranspiration in the study area of southwest of China in August 2006 obtained from (a) the remote sensing estimates with the SEBS method and (b) GLDAS data, and (c) 10 years of monthly ET in the identified hot spot $\left(30^{\circ} 34^{\prime} \mathrm{N}, 105^{\circ} 19^{\prime} \mathrm{E}\right)$ (Note that the discrete monthly values are connected to ease visualization).

\subsubsection{Sensitivity to Bias Curve Assignment}

Since the principal aspect of the $\mathrm{ET}_{\mathrm{b}}$ method used is the definition of the bias curves, this section analyzes whether the $\mathrm{ET}_{\mathrm{b}}$ estimates are sensitive to the bias assignment. Figure 6.5 shows the monthly $\mathrm{ET}_{\mathrm{b}}$ results obtained in the 
province of Sichuan in the irrigated pixels as indicated in Figure 6.1. Four cases were considered depending on the bias assigned per month: i) maximum of all classes, ii) minimum of all classes, iii) bias assigned based on the classification and iv) mean bias calculated in all rain-fed croplands when no classes are considered.

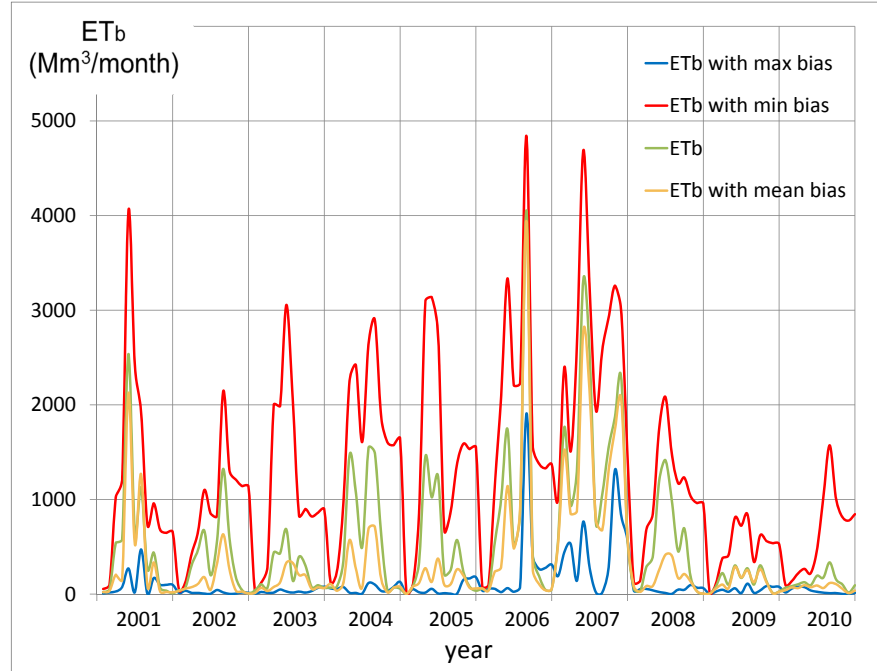

Figure 6.5. $\mathrm{ET}_{\mathrm{b}}$ obtained in the province of Sichuan using the maximum, minimum, assigned-per-class and mean bias.

All four cases show maximum values of $\mathrm{ET}_{\mathrm{b}}$ in the years 2006 and 2007 . However, inter annual variability was found to be sensitive to the selection of the bias. $\mathrm{ET}_{\mathrm{b}}$ presented low monthly values in most of the study period when using the maximum bias, whereas higher values and relatively regular patterns were obtained with the minimum bias. The curves obtained with the mean and assigned-per-class bias showed intermediate values, with $\mathrm{ET}_{\mathrm{b}}$ in general lower in the former case. In this context, Romaguera et al. (2014a) showed that the bias estimation was improved when using different classes instead of a single mean bias obtained for all rain-fed pixels. Therefore, despite the possible $\mathrm{ET}_{\mathrm{b}}$ similarities between these two cases, the classification approach is preferred to evaluate $\mathrm{ET}_{\mathrm{b}}$.

\subsection{Discussion}

This chapter illustrates preliminary results of the potential of using a remote sensing based method for obtaining time series of blue water evapotranspiration and combining it with the source of irrigation to monitor 
irrigation practices. The details and drawbacks of the models and data used were discussed in Romaguera et al. (2012a, 2014a) and Thenkabail et al. (2008, 2009a).

The outputs produced in this chapter need to be understood as preliminary examples of application. A better understanding of the ET inputs used would be required in order to obtain concluding outcomes. Regarding the bias, Section 6.4.3 showed how the $\mathrm{ET}_{\mathrm{b}}$ estimates were sensitive to the bias assignment.

The uncertainties in ET estimation from remote sensing and the land surface modelling played an important role in the total $\mathrm{ET}_{\mathrm{b}}$ uncertainty. Kalma et al. (2008) showed that remote sensing data provided typically relative errors of $15-30 \%$ in ET estimation. In the case of the GLDAS products, the ET accuracy was not sufficiently evaluated in the literature, although some estimates exist. Fang et al. (2009) reported the uncertainty in GLDAS-ET estimates by continent as equivalent heights of water based on 1979-2007 outputs from the four models included in the system. The climatology values of ET were 55 $\mathrm{cm} /$ year in Africa and $43 \mathrm{~cm} /$ year in Asia, with an uncertainty of $\pm 6 \mathrm{~cm} /$ year in both cases. Besides, the definition of the bias curves has a standard deviation associated to the spatial averaging of the values per class. Despite the lack of detailed information about the GLDAS-ET accuracies, the aforementioned quantities were used (not shown here) to obtain the contributions of these three aspects to the total uncertainty by using the first order Taylor series expansion, where the covariance terms were neglected (inputs are independent) and linearity was assumed. A typical daily evapotranspiration rate of $5 \mathrm{~mm}$, a $30 \%$ in error of RS-ET, an average uncertainty of $5 \mathrm{~mm} / \mathrm{month}$ in GLDAS-ET, and a bias curve in the Sichuan province were assumed. It was found that the error in RS-ET was the major contributor ( 50 to $95 \%$ ), modulated by the error of the bias which oscillated in time from around $5 \%$ to $50 \%$. The contribution of the GLDAS-ET inaccuracy was negligible. Increasing daily ET rates resulted in higher relative contribution of RS-ET, as expected, while decreasing the role of the bias, and being insignificant the GLDAS-ET impact. Decreasing daily ET rates resulted in higher relative contribution of GLDAS-ET, with a maximum of $20 \%$ when a low value of daily ET was considered ( $0.1 \mathrm{~mm} /$ day). 
These values served as an indication of the relative importance of RS-ET, GLDAS-ET and the bias, to the total uncertainty of $\mathrm{ET}_{\mathrm{b}}$. In the case of irrigated areas, ET values are expected to be high, and therefore the role of the bias accuracy is less significant. However a better estimate of the GLDASET uncertainty is required to properly quantify the different contributions.

Moreover, the accuracy of the static GlobCover and GIAM maps may decrease in time. These are used in the method to define rain-fed areas and to assign the type of irrigation respectively. Therefore, they are also a source of uncertainty.

The results in this chapter were aggregated per country/province, which may be appropriate for regional planning purposes. However, specific spatial features may be lost in big areas due to the aggregation process, such as multiple cropping practices. Therefore, analysis at different spatial scales is recommended when examining particular features. Besides, the spatial resolution of the input data may be a limitation in heterogeneous areas, and therefore scaling techniques (Anderson et al., 2007c; Jia et al., 2011) are advised for understanding the sub-pixel variability.

In order to obtain concluding results about the application shown in this chapter, long time series of data are desired to be able to properly analyze trends, and possible anomalies in the climatology. From the point of view of the land surface models, global data can be obtained for long time periods, since the year 1970 until present for the Noah model in GLDAS. However, remote sensing ET outputs are more limited in time and space and depend a lot on the geometry of observation, technical characteristics and lifetime of the sensors on board the satellites. In this context, Mu et al. (2011) provided global ET products every 8 days at $1 \mathrm{~km}$ resolution between the years 20012010. Their algorithm is based on the Penman-Monteith equation using daily meteorological reanalysis data and 8-day remotely sensed vegetation property dynamics from the Moderate-Resolution Imaging Spectroradiometer (MODIS) as inputs.

In general terms, the interpretation of the results regarding irrigation practices bears an uncertainty related to the multiple situations that can be found in reality. Water availability and decisions taken by the farmers to irrigate or not and how much, are factors that influence the results. However, 
in face of an extreme event like a drought, the results obtained in the case studies of the present chapter indicated the possibility of identifying and explaining the episode in terms of irrigated water.

Finally, compared with the existing literature about $\mathrm{ET}_{\mathrm{b}}$ given by Liu and Yang (2010) and Mekonnen and Hoekstra (2011), the method applied in this chapter is innovative in two aspects: first it uses physically based remote sensing data instead of statistical data, and second it provides a better temporal resolution, more suitable for water management applications. Moreover, from an implementation point of view the method has a reasonably straightforward application procedure.

\subsection{Conclusions}

This chapter illustrates the potential of using time series of blue evapotranspiration $\left(\mathrm{ET}_{\mathrm{b}}\right)$ combined with an existing 'type of irrigation' map to monitor irrigation practice. Monthly $\mathrm{ET}_{\mathrm{b}}$ values were obtained with a remote sensing based method in two study areas: the Horn of Africa (period 20102012) and the Chinese province of Sichuan (period 2001-2010), both affected by a drought event during the periods of analysis, but with differences in terms of water control and storage infrastructure. Further, monthly $\mathrm{ET}_{\mathrm{b}}$ were subdivided in surface water, groundwater and conjunctive use per country/province.

The preliminary results indicate that in face of an extreme event like a drought, it is possible to identify and explain the episode in terms of irrigated water. However, further research is needed to fully understand the whole of the temporal patterns found.

The research also discusses issues related with the application of the $\mathrm{ET}_{\mathrm{b}}$ method, such as the assignation of the bias curves and the need for understanding the input ET patterns. In addition, the use of longer time series of data for better interpretation of the results is recommended.

This chapter constitutes a starting point for global temporal $\mathrm{ET}_{\mathrm{b}}$ analysis using an innovative remote sensing based approach and further research will contribute to the achievement of more concluding and operative results. In 
the field of water management, the approach has potential to assess the existence of irrigation, the source, the duration and variability in time, at pixel and country scales, and could be especially useful to monitor irrigation practice during periods of drought. 


\section{Chapter 7}

\section{Conclusions and Future Outlook}

The main objective of this thesis was to explore the use of remote sensing techniques and data to retrieve global water use in agriculture, focusing on the blue component of the evapotranspiration $\left(\mathrm{ET}_{\mathrm{b}}\right)$, i.e. due to irrigation water. The state of the art was analyzed and different methods were developed, improved and applied.

Chapter 2 served as a motivation of this thesis to illustrate the potential of using remote sensing data and methods in the field of water management, in particular for global water footprint studies. Precipitation, evapotranspiration, water storage, surface runoff and land use were identified as key aspects where remote sensing could improve the current estimates. These may be obtained from available global products or alternatively may be derived with existing methods. These data range from local to global scales, with temporal resolutions of 15 minutes up to weeks and from scales of meters to thousands of meters of spatial resolution.

A mass balance was proposed as a starting point to estimate irrigation and consecutively separate ET in its blue and green components. The source of the inputs involved was described and the approach was applied to a simplified case study. This served to discuss the general limitations encountered when using remote sensing data in this field; the combination of multi resolution data implies the use of specific fusion algorithms, and the availability of global data for hydrological applications is not always ensured.

In terms of spatial resolution, the applicability of some hydrological parameters is limited due to the coarse resolution at which remote sensing data are currently available, which is the case of the water storage term obtained from GRACE. The estimates may be improved by using techniques of data assimilation and downscaling. However, there is a tradeoff between defining the spatial resolution needed for observing the processes, while at the same time preserving feasibility for application with global coverage. 
The development of remote sensing methods for the separation of ET into the blue and green components, and the derivation of irrigation was extensively tackled throughout Chapters 2, 3 and 4, in which the effects of different hydrological parameters were explored. A mass balance was proposed in Chapter 2 to estimate irrigation and applied to a simplified case, following a similar separation of green and blue as is done in water balance models. A mass balance combined with the identification of soil moisture anomalies and the ET decay time was described in Chapter 3 and applied to Europe. Because of the inaccuracies of inputs, and the imposed assumptions, the applicability of these two proposed methods was found to be limited to regions with specific hydrometeorological conditions (semi-arid areas). Chapter 4 presented a method to identify irrigated areas and estimate $\mathrm{ET}_{\mathrm{b}}$. This approach constituted the core of this thesis and was based on the synergistic use of remote sensing evapotranspiration products and simulated ET data from a land surface model, and the production of a spatially dependent bias. The comparison of the irrigated areas and $\mathrm{ET}_{\mathrm{b}}$ outputs with the existing literature and in situ data was limited by the lack of data in coincident time spans and the absence of detailed accuracy assessments of the products used. The discrepancies were influenced by the subpixel heterogeneity and the spatial resolution of the data, as well as by the inaccuracies of the inputs, imposed assumptions and the used methodology.

The proposed method provided an operational framework for quantifying and monitoring of irrigation at large scale and high temporal frequency, which is an improvement with respect to existing approaches. It is innovative, relatively simple to implement and can be easily generalized. However, major limitations are related to the availability of historical global remote sensing ET data, the relative simple spatial classification scheme used and the spatial resolution of the outputs which may not be sufficient for specific applications.

The objective of Chapter 5 was to produce a generic and robust hydrometeorological classification of the study area (Europe). This improved the method proposed in Chapter 4 in terms of the spatial representation of the bias in rain-fed croplands, which resulted in better estimates of $\mathrm{ET}_{\mathrm{b}}$. Different classifiers were compared and evaluated based on the generated bias curves per class and their variability. The simple k-means classifier showed to be sufficient and to improve the existing classification in the 
analyzed study case. The comparison of the $\mathrm{ET}_{\mathrm{b}}$ outputs with the literature provided differences below $50 \mathrm{~mm} /$ year in most of Europe. The $\mathrm{ET}_{\mathrm{b}}$ comparison in Africa was found to be highly influenced by the assigned land cover type and the heterogeneity of the pixel and suggested the combination of approaches to achieve a better estimate.

Chapter 6 illustrated the potential of using time series of remote sensing data to monitor irrigation practice and calculated monthly blue evapotranspiration in two study areas: the Horn of Africa and Sichuan province of China, both affected by a drought event during the periods of analysis, but with differences in terms of irrigation infrastructure to deal with those droughts.

Monthly $\mathrm{ET}_{\mathrm{b}}$ were subdivided in surface water, groundwater and conjunctive use per country/province using the Global Irrigated Area Map. The preliminary results indicated that in face of an extreme event like a drought, it was possible to identify and explain the episode in terms of irrigated water. However, further research is needed to fully understand the whole of the temporal patterns found. In the field of water management, the approach has potential to assess the existence of irrigation, the source, the duration and variability in time, at pixel and country scales, and could be especially useful to monitor irrigation practice during periods of drought.

All in all, this thesis provided a framework to quantify irrigation water at large scale and high temporal frequency, which constitutes an improvement with respect to existing methods.

\section{Future Outlook}

The recommendations for future research elaborated as a result of the present thesis look towards the eventual operability of the proposed method and/or elaboration of new methods, and can be summarized in five points: a) evaluation and improvement of the accuracy of the hydroclimatic remote sensing and modelled inputs, b) incorporation of ground water and crop growth model, c) multiscale analysis of the processes and $\mathrm{ET}_{\mathrm{b}}$ outcomes, d) application to longer time series of data and analysis of anomalies, and e) acquisition of in situ irrigation data for validation. 
The evaluation and improvement of the accuracy of the remote sensing and modelled hydroclimatic parameters is a task where different disciplines are involved, from the design of the remote sensing sensors, the enhancing of the modelling of the physical processes and the selection of proper validation strategies. At the moment, there is potential to investigate on the assessment of the accuracies of large scale products, and opportunities for improvement in the methods, as it is shown in product comparison studies (Garrigues et al., 2008; Rudiger et al., 2009; Gao and Long, 2008).

The effect of groundwater on evapotranspiration was not treated in this thesis. The Land Surface Model (LSM) used in this thesis does not account for the possible groundwater root uptake during dry periods. In that case, ET from LSM is underestimated and the final $\mathrm{ET}_{\mathrm{b}}$ may be misinterpreted as irrigation. This issue can be talked by coupling the LSM with groundwater models, as exemplified by Tian et al. (2012). Moreover, crop growth models (Bassu et al., 2014) could be incorporated in order to account for the variability in water use and need for irrigation of different crops, as well as their phenology, growth and yield.

Multi-scale analysis is of major importance to define the spatial resolution needed for observing the processes and to interpret the resulting $\mathrm{ET}_{\mathrm{b}}$. Subpixel heterogeneity influences the retrieval of the input parameters and the classification in the presented method. In this context, Velpuri et al. (2009) reported about the effects of resolution in irrigation area mapping. Bearing in mind the coarse resolution of the inputs used in the method proposed in this thesis, a multi resolution analysis is recommended in order to analyze specific patterns and understand the impacts on the results.

From the point of view of irrigation monitoring, $\mathrm{ET}_{\mathrm{b}}$ should be ideally estimated in a monthly scale during long periods of time (tens of years), so that trends could be analyzed and anomalies in climatology could be identified. The major drawback for these calculations is the lack of long term operative remote sensing global products. Bearing this in mind, the European Space Agency (ESA) launched the Water Cycle Multi-mission Observation Strategy (WACMOS) (Su et al., 2014) aiming at enhancing, developing and validating a novel set of multi-mission based methods and algorithms to retrieve a number of key variables relevant to the water cycle at global scale. Moreover, the scheduled launch of the Sentinel-2, SMAP and GRACE-FO 
missions is expected to offer useful tools for hydrometeorological applications. These, amongst other initiatives, will provide the scientific community with new opportunities for the temporal analysis of $\mathrm{ET}_{\mathrm{b}}$ and monitoring global irrigation practice.

Finally, the validation of the $\mathrm{ET}_{\mathrm{b}}$ estimates produced in this thesis is hampered by the scarcity of good quality spatial data on irrigation at regional scale. The availability of irrigation water management information on a detailed scale like farmer fields or for entire river basins is not common. Even statistical databases such as AQUASTAT (FAO, 2014a) provide static and scattered data. Therefore, although an attempt was made in Chapter 4 to validate the methodology in a corn field in a cropland area in Spain, there is an evident need of collecting multitemporal irrigation data for validation purposes. 


\section{Bibliography}

Agbu, P. A., and James, M. E.: The NOAA/NASA Pathfinder AVHRR Land Data Set User's Manual, Goddard Distributed Active Archive Center, NASA, Goddard Space Flight Center, Greenbelt, USA, 1994.

Alcamo, J., Florke, M., and Marker, M.: Future long-term changes in global water resources driven by socio-economic and climatic changes, Hydrol. Sci. J., 52, 247-275, 2007.

Allan, J. A.: Virtual water: A strategic resource. Global solutions to regional deficits, Ground Water, 36, 545-546, 1998.

Allen, R., Pereira, L. S., Raes, D., and Smith, M.: FAO Irrigation and Drainage Paper n.56: Crop Evapotranspiration, Food and Agriculture Organization, Rome, 1998.

Allen, R.G., Tasumi, M., and Trezza, R.: Satellite-based energy balance for mapping evapotranspiration with internalized calibration (METRIC) model. J. Irrig. Drainage Eng-ASCE, 133, 380-394, 2007.

Anderson, M. C., Norman, J. M., Mecikalski, J. R., Otkin, J. A., and Kustas, W. P.: A climatological study of evapotranspiration and moisture stress across the continental United States based on thermal remote sensing: 1. Model formulation, J. Geophys. Res.-Atmos., 112, Dio117, doi:10.1029/2006JDoo7506, 2007a.

Anderson, M. C., Norman, J. M., Mecikalski, J. R., Otkin, J. A., and Kustas, W. P.: A climatological study of evapotranspiration and moisture stress across the continental United States based on thermal remote sensing: 2. Surface moisture climatology, J. Geophys. Res.-Atmos., 112, D11112, doi:10.1029/2006JDoo7507, 2007b.

Anderson, M.C., Kustas, W.P., and Norman, J.M.: Upscaling flux observations from local to continental scales using thermal remote sensing, Amer Soc Agronomy: pp 240-254, 2007c.

Anderson, W. B., Zaitchik, B. F., Hain, C. R., Anderson, M. C., Yilmaz, M. T., Mecikalski, J., and Schultz, L.: Towards an integrated soil moisture 
drought monitor for East Africa, Hydrology and Earth System Sciences, 16, 2893-2913, 2012.

Arino, O., Gross, D., Ranera, F., Leroy, M., Bicheron, P., Brockman, C., Defourny, P., Vancutsem, C., Achard, F., Durieux, L., Bourg, L., Latham, J., Di Gregorio, A., Witt, R., Herold, M., Sambale, J., and Plummer, S.: GlobCover: ESA service for Global Land Cover from MERIS, IGARSS 2007. Geoscience and Remote Sensing Symposium, Barcelona, Spain, 23-28 July, 2007.

Awulachew, S. B., Yilma, A. D., Loulseged, M., Loiskandl, W., Ayana, M., and Alamirew, T.: Water resources and irrigation development in Ethiopia. IWMI working paper 123, International Water Management Institute (IWMI), Colombo, Sri Lanka, 2007.

Baret, F., Hagolle, O., Geiger, B., Bicheron, P., Miras, B., Huc, M., Berthelot, B., Nino, F., Weiss, M., Samain, O., Roujean, J. L., and Leroy, M.: LAI, fAPAR and fCover CYCLOPES global products derived from VEGETATION - Part 1: Principles of the algorithm, Remote Sensing of Environment, 110, 275-286, 2007.

Barthel, R., Sonneveld, B., Gotzinger, J., Keyzer, M. A., Pande, S., Printz, A., and Gaiser, T.: Integrated assessment of groundwater resources in the Oueme basin, Benin, West Africa, Physics and Chemistry of the Earth, 34, 236-250, 2009.

Bartholome, E., and Belward, A. S.: GLC20oo: a new approach to global land cover mapping from Earth observation data, International Journal of Remote Sensing, 26, 1959-1977, 2005.

Bassu, S., Brisson, N., Durand, J.L., Boote, K., Lizaso, J., Jones, J.W., Rosenzweig, C., Ruane, A.C., Adam, M., Baron, C., Basso, B., Biernath, C., Boogaard, H., Conijn, S., Corbeels, M., Deryng, D., De Sanctis, G., Gayler, S., Grassini, P., Hatfield, J., Hoek, S., Izaurralde, C., Jongschaap, R., Kemanian, A.R., Kersebaum, K.C., Kim, S.H., Kumar, N.S., Makowski, D., Muller, C., Nendel, C., Priesack, E., Pravia, M.V., Sau, F., Shcherbak, I., Tao, F., Teixeira, E., Timlin, D., and Waha, K.: How do various maize crop models vary in their responses to climate change factors? Global Change Biology, 20, 2301-2320, 2014. 
Bastiaanssen, W. G. M., Menenti, M., Feddes, R. A., and Holtslag, A. A. M.: A remote sensing surface energy balance algorithm for land (SEBAL) - 1. Formulation, J. Hydrol., 213, 198-212, 1998a.

Bastiaanssen, W. G. M., Pelgrum, H., Wang, J., Ma, Y., Moreno, J. F., Roerink, G. J., and van der Wal, T.: A remote sensing surface energy balance algorithm for land (SEBAL) - 2. Validation, J. Hydrol., 213, 213-229, 1998b.

Bastiaanssen, W.G.M., and Bos, M.G. Irrigation performance indicators based on remotely sensed data: a review of literature. Irrigation and Drainage Systems, 13, 192-311, 1999.

Batjes, N. H.: ISRIC-WISE derived soil properties on a 5 by 5 arc-minutes global grid, International Soil Reference \& Information Centre, Wageningen, The Netherlands, 2006.

Belward, A. S., Estes, J. E., and Kline, K. D.: The IGBP/DIS Global 1-Km LandCover Data Set DISCover. A project Overview, Photogramm. Eng. Remote Sens., 65(9), 1013-1020, 1999.

Berger, M., Moreno, J., Johannessen, J. A., Levelt, P. F., and Hanssen, R. F.: ESA's sentinel missions in support of Earth system science, Remote Sensing of Environment, 120, 84-90, 2012.

Blaes, X., Vanhalle, L., and Defourny, P.: Efficiency of crop identification based on optical and SAR image time series, Remote Sensing of Environment, 96, 352-365, 2005.

Calera, A., Jochum, A. M., Cuesta, A., Montoro, A., and Lopez, P.: Irrigation management from space: Towards user-friendly products, Irrigation and Drainage Systems, 19, 337-353, 2005.

Chapagain, A. K., and Hoekstra, A. Y.: Water footprints of nations, UNESCOIHE, Delft, The Netherlands, 2004.

Chapagain, A. K., and Hoekstra, A. Y.: The global component of freshwater demand and supply: an assessment of virtual water flows between nations as a result of trade in agricultural and industrial products, Water Int., 33, $19-32,2008$.

Chatterjee, R., and Purohit, R. R.: Estimation of replenishable groundwater resources of India and their status of utilization, Curr. Sci., 96, 1581-1591, 2009. 
Chen, F., Mitchell, K., Schaake, J., Xue, Y. K., Pan, H. L., Koren, V., Duan, Q. Y., Ek, M., and Betts, A.: Modeling of land surface evaporation by four schemes and comparison with FIFE observations, J. Geophys. Res.-Atmos., 101, 7251-7268, 1996.

Chen, X.: The plateau scale land - air interaction and its connections to troposphere and lower stratosphere, Enschede, University of Twente. Faculty of Geo-Information and Earth Observation (ITC). ITC Dissertation 237, ISBN: 978-90-6164-365-4, 2013.

Chen, X., Su, Z., Ma, Y., Yang, K., and Wang, B.: Estimation of surface energy fluxes under complex terrain of Mt. Qomolangma over the Tibetan plateau. Hydrology and Earth System Sciences, 17, 1607-1618, 2013.

Chen, X., Su, Z., Ma, Y., Liu, S. and Xu, Z.: Development of a 10 year (20012010) $0.1^{\circ}$ dataset of land-surface energy balance for mainland China. Atmos. Chem. Phys. Discuss. 14, 14471-14518, 2014.

Congalton, R. G., and Green, K.: Assessing the accuracy of remotely sensed data- Principles and practices. , edited by: Boca Raton, F., CRC Press, Taylor \& Francis Group, 183p., 2009.

Dai, Z. J., Du, J. Z., Li, J. F., Li, W. H., and Chen, J. Y.: Runoff characteristics of the Changjiang River during 2006: Effect of extreme drought and the impounding of the Three Gorges Dam, Geophys. Res. Lett., 35, Lo7406, doi:10.1029/2008GL033456, 2008.

Dempster, A. P., Laird, N. M., and Rubin, D. B.: Maximum Likelihood from Incomplete Data via the EM Algorithm, Journal of the Royal Statistical Society, B, vol. 39, no. 1, pp. 1-38, 1977.

Döll, P., and Siebert, S.: Global modeling of irrigation water requirements, Water Resour. Res., 38(4), doi:10.1029/2001WRoo0355, 2002.

Dong, J., Zhuang, D. F., Huang, Y. H., and Fu, J. Y.: Advances in Multi-Sensor Data Fusion: Algorithms and Applications, Sensors, 9, 7771-7784, 2009.

D'Urso, G., Vuolo, F., and De Michele, C.: Remote Sensing Techniques to improve on farm irrigation efficiency, Irrigation Australia, Melbourne, 2008.

D'Urso, G., De Michele, C., and Vuolo, F. Operational irrigation services from remote sensing: The irrigation advisory plan for the Campania region, 
Italy. In Remote sensing and hydrology, Neale, C.M.U., Cosh, M.H., Eds. Int Assoc Hydrological Sciences, Wallingford, UK, Vol. 352, pp 419-422, 2012.

Ebert, E. E., Janowiak, J. E., and Kidd, C.: Comparison of near-real-time precipitation estimates from satellite observations and numerical models, Bull. Amer. Meteorol. Soc., 88, 47-64, 2007.

ECMWF: ERA-40: ECMWF 45-year reanalysis of the global atmosphere and surface conditions 1957-2002. In: ECMWF Newsletter 101, 2004.

ECMWF: Towards a climate data assimilation system: Status update of ERAInterim. In: ECMWF Newsletter 115, 2008.

Entekhabi, D., Njoku, E. G., O'Neill, P. E., Kellogg, K. H., Crow, W. T., Edelstein, W. N., Entin, J. K., Goodman, S. D., Jackson, T. J., Johnson, J., Kimball, J., Piepmeier, J. R., Koster, R. D., Martin, N., McDonald, K. C., Moghaddam, M., Moran, S., Reichle, R., Shi, J. C., Spencer, M. W., Thurman, S. W., Tsang, L., and Van Zyl, J.: The Soil Moisture Active Passive (SMAP) Mission, Proc. IEEE, 98, 704-716, 2010.

ESA: GLOBCOVER Products Description Manual v2, European Space Agency, 2008.

Exelis Visual Information Solutions, ENVI Tutorial: Classification Methods. Boulder, Colorado: Exelis Visual Information Solutions, 2006.

Fader, M., Gerten, D., Thammer, M., Heinke, J., Lotze-Campen, H., Lucht, W., and Cramer, W.: Internal and external green-blue agricultural water footprints of nations, and related water and land savings through trade, Hydrology and Earth System Sciences, 15, 1641-166o, 2011.

Fang, H., Beaudoing, H. K., Rodell, M., Teng, W. L., and Vollmer, B. E.: Global Land Data Assimilation System (GLDAS) products, services and applications from NASA Hydrology Data and Information Services Center (HDISC), Baltimore, Maryland, 2009.

Farah, H. O.: Estimation of regional evaporation under different weather conditions from satellite and meteorological data: a case study in the Naivasha basin, Kenya. Doctoral Thesis Wageningen University and ITC (Enschede), The Netherlands, 170 pp., ISBN 90-5808-331-4, 2001. 
FAO: FAOSTAT on-line database. Food and Agriculture Organization, Rome, Italy. http://faostat3.fao.org/, 2005a.

FAO: CLIMWAT 2.o Database. Food and Agriculture Organization: Rome, Italy.www.fao.org/nr/water/infores_databases_climwat.html, 2005b.

FAO: Global map of monthly reference evapotranspiration - 10 arc minutes. GeoNetwork: grid database, Food and Agriculture Organization, Rome, Italy. www.fao.org/geonetwork/srv/en/, accessed on: 15/10/2008, 2008 a.

FAO: AQUASTAT database - Food and Agriculture Organization of the United Nations. Rome, Italy. http://faostat.fao.org/site/544/default.aspx, accessed on 1/06/2014, 2014a.

FAO: FAOSTAT database. Food and Agriculture Organization, Rome, Italy. http://faostat3.fao.org/faostat-gateway/go/to/download/Q/QC/E, accessed on 27/04/2014, 2014b.

French, A. N., Jacob, F., Anderson, M. C., Kustas, W. P., Timmermans, W., Gieske, A., Su, Z., Su, H., McCabe, M. F., Li, F., Prueger, J., and Brunsell, N.: Surface energy fluxes with the Advanced Spaceborne Thermal Emission and Reflection radiometer (ASTER) at the Iowa 2002 SMACEX site (USA), Remote Sensing of Environment, 99, 55-65, 2005.

Friedl, M. A., Mclver, D. K., Hodges, J. C. F., Zhang, X. Y., Muchoney, D., Strahler, A. H., Woodcock, C. E., Gopal, S., Schneider, A., Cooper, A., Baccini, A., Gao, F., and Schaaf, C.: Global land cover mapping from MODIS: algorithms and early results, Remote Sensing of Environment, 83, 287-302, 2002.

Funk, C.: New satellite observations and rainfall forecasts help provide earlier warning of African drought, Earth Observ., 21,23-27, 2009.

Funk, C.: We thought trouble was coming, Nature, 476, 7,doi:10.1038/476007a, 2011.

Gao, Y. C., and Long, D.: Intercomparison of remote sensing-based models for estimation of evapotranspiration and accuracy assessment based on SWAT, Hydrol. Process., 22, 4850-4869, 2008.

Garrigues, S., Lacaze, R., Baret, F., Morisette, J. T., Weiss, M., Nickeson, J. E., Fernandes, R., Plummer, S., Shabanov, N. V., Myneni, R. B., Knyazikhin, Y., and Yang, W.: Validation and intercomparison of global Leaf Area 
Index products derived from remote sensing data, J. Geophys. Res.Biogeosci., 113, Go2028, doi:10.1029/2007JGooo635, 2008.

Gellens-Meulenberghs, F., Arboleda, A., and Ghilain, N.: Towards a continuous monitoring of evapotranspiration based on MSG data, IAHS Symposium on Remote Sensing for Environmental Monitoring and Change Detection, IAHS Publication, Wallingford, UK, 228-236, 2007.

Ghilain, N., Arboleda, A., and Gellens-Meulenberghs, F.: Evapotranspiration modelling at large scale using near-real time MSG SEVIRI derived data, Hydrology and Earth System Sciences, 15, 771-786, 2011.

Glenn, E. P., Huete, A. R., Nagler, P. L., Hirschboeck, K. K., and Brown, P.: Integrating remote sensing and ground methods to estimate evapotranspiration, Crit. Rev. Plant Sci., 26, 139-168, 2007.

Gowda, P. H., Chavez, J. L., Colaizzi, P. D., Evett, S. R., Howell, T. A., and Tolk, J. A.: ET mapping for agricultural water management: present status and challenges, Irrigation Science, 26, 223-237, 2008.

Guanter, L., Estelles, V., and Moreno, J.: Spectral calibration and atmospheric correction of ultra-fine spectral and spatial resolution remote sensing data. Application to CASI-150o data, Remote Sensing of Environment, 109, 54-65, 2007.

Guanter, L., Gomez-Chova, L., and Moreno, J.: Coupled retrieval of aerosol optical thickness, columnar water vapor and surface reflectance maps from ENVISAT/MERIS data over land, Remote Sensing of Environment, 112, 2898-2913, 2008.

Hall, M., Frank, E., Holmes, G., Pfahringer, B., Reutemann, P., and Witten, I.H.: The WEKA Data Mining Software: An Update; SIGKDD Explorations, Volume 11, Issue 1, 2009.

Hanasaki, N., Inuzuka, T., Kanae, S., and Oki, T.: An estimation of global virtual water flow and sources of water withdrawal for major crops and livestock products using a global hydrological model, J. Hydrol., 384, 232244, 2010.

Heinemann, T., Latanzio, A., and Roveda, F.: The Eumetsat multi-sensor precipitation estimate (MPE), Second International Precipitation Working group (IPWG) meeting, Madrid, Spain, 2002. 
Hendrix, M.: Water in Ethiopia: Drought, Disease and Death, Global Majority E-Journal, 3(2), 110-120, 2012.

Hoekstra, A. Y.: Virtual water trade. Proceedings of the international expert meeting on virtual water trade, Value of water research report series No.12, IHE Delft, 2003.

Hoekstra, A. Y., and Chapagain, A. K.: Water footprints of nations: Water use by people as a function of their consumption pattern, Water Resour. Manag., 21, 35-48, 2007.

Hoekstra, A. Y., and Chapagain, A. K.: Globalization of water. Sharing the Planet's Freshwater Resources, Blackwell Publishing, Oxford, UK, 1-208 pp., 2008.

Hoekstra, A. Y., and Hung, P. Q.: A quantification of virtual water flows between nations in relation to international crop trade, UNESCO-IHE, Delft, The Netherlands, 2002.

Hoekstra, A. Y., and Hung, P. Q.: Globalisation of water resources: international virtual water flows in relation to crop trade, Glob. Environ. Change-Human Policy Dimens., 15, 45-56, 2005.

Hoekstra, A. Y., Chapagain, A. K., Aldaya, M. M., and Mekonnen, M. M.: Water footprint manual. State of the art 2009, Water footprint Network, 2009 .

Hsu, K. L., Gao, X. G., Sorooshian, S., and Gupta, H. V.: Precipitation estimation from remotely sensed information using artificial neural networks, J. Appl. Meteorol., 36, 1176-1190, 1997.

Hsu, K.-l., Gupta, H. V., Gao, X., and Sorooshian, S.: Estimation of Physical Variables from Multichannel Remotely Sensed Imagery Using a Neural Network: Application to Rainfall Estimation, Water Resour. Res., 35(5), 1605-1618, doi:10.1029/1999WR9ooo32, 1999.

Jia, L., Su, Z. B., van den Hurk, B., Menenti, M., Moene, A., De Bruin, H. A. R., Yrisarry, J. J. B., Ibanez, M., and Cuesta, A.: Estimation of sensible heat flux using the Surface Energy Balance System (SEBS) and ATSR measurements, Physics and Chemistry of the Earth, 28, 75-88, 2003. 
Jia, S., Zhu, W., Lü, A., Yan, and T.: A statistical spatial downscaling algorithm of TRMM precipitation based on NDVI and DEM in the Qaidam basin of China. Remote Sensing of Environment, 115, 3069-3079, 2011.

Joyce, R. J., Janowiak, J. E., Arkin, P. A., and Xie, P. P.: CMORPH: A method that produces global precipitation estimates from passive microwave and infrared data at high spatial and temporal resolution, J. Hydrometeorol., 5, 487-503, 2004.

Kalma, J. D., McVicar, T. R., and McCabe, M. F.: Estimating land surface evaporation: A review of methods using remotely sensed surface temperature data, Surv. Geophys., 29, 421-469, 2008.

Koren, V., Schaake, J., Mitchell, K., Duan, Q. Y., Chen, F., and Baker, J. M.: A parameterization of snowpack and frozen ground intended for NCEP weather and climate models, J. Geophys. Res.-Atmos., 104, 19569-19585, 1999 .

Ledwith, T.: Crisis in the Horn of Africa: Rethinking the Humanitarian Response, 5 October 2011, http://www.unicef.org/infobycountry/kenya_59997.html, last access: 19 July 2014 .

Liu, J. G., and Yang, H.: Spatially explicit assessment of global consumptive water uses in cropland: Green and blue water, J. Hydrol., 384, 187-197, 2010.

Liu, J. G., Zehnder, A. J. B., and Yang, H.: Global consumptive water use for crop production: The importance of green water and virtual water, Water Resour. Res., 45, Wo5428, doi:10.1029/2007WRoo6051, 2009.

Liu, J., Wiberg, D., Zehnder, A. J. B., and Yang, H.: Modeling the role of irrigation in winter wheat yield, crop water productivity, and production in China, Irrigation Science, 26, 21-33, 2007.

Liu, X., Ditmar, P., Siemes, C., Slobbe, D. C., Revtova, E. A., Klees, R., Riva, R., and Zhao, Q.: DEOS Mass Transport model (DMT-1) based on GRACE satellite data: methodology and validation, Geophysical Journal International. 181 (2), 769-788, 2010.

LSA-SAF: LSA-SAF Product User Manual. Evapotranspiration (ET), The EUMETSAT Network of Satellite Application Facilities: Darmstadt, Germany. Doc. num. SAF/LAND/RMI/PUM_MET/2.3, 2010a. 
LSA-SAF: LSA-SAF Validation Report. Products LSA-16 (MET), LSA-17 (DMET), The EUMETSAT Network of Satellite Application Facilities. Doc. Num. SAF/LAND/RMI/VR/o.6, 2o10b.

Lu, D., and Weng, Q.: A survey of image classification methods and techniques for improving classification performance, International Journal of Remote Sensing, 28, 823-870, 2007.

Masson, V., Champeaux, J. L., Chauvin, F., Meriguet, C., and Lacaze, R.: A global database of land surface parameters at $1-\mathrm{km}$ resolution in meteorological and climate models, J. Clim., 16 (9), 1261-1282, 2003.

Mekonnen, M. M., and Hoekstra, A. Y.: A global and high-resolution assessment of the green, blue and grey water footprint of wheat. Value of Water Research Report No.42, UNESCO-IHE, Delft, The Netherlands, 2010.

Mekonnen, M. M., and Hoekstra, A. Y.: The green, blue and grey water footprint of crops and derived crop products, Hydrology and Earth System Sciences, 15, 1577-1600, 2011.

Melesse, A. M., and Shih, S. F.: Spatially distributed storm runoff depth estimation using Landsat images and GIS, Comput. Electron. Agric., 37, 173-183, 2002.

Mitchell, T. D., and Jones, P. D.: An improved method of constructing a database of monthly climate observations and associated high-resolution grids, Int. J. Climatol., 25, 693-712, 2005.

Monfreda, C., Ramankutty, N., and Foley, J. A.: Farming the planet: 2. Geographic distribution of crop areas, yields, physiological types, and net primary production in the year 2000, Glob. Biogeochem. Cycle, 22, GB1022, doi:10.1029/2007GBoo2947, 2008.

Monserud, R. A., and Leemans, R.: Comparing GLobal Vegetation Maps with the Kappa-Statistic, Ecol. Model., 62, 275-293, 1992.

Montoro, A., Lopez-Fuster, P., and Fereres, E.: Improving on-farm water management through an irrigation scheduling service, Irrigation Science, 29, 311-319, 2011. 
Mu, Q., Heinsch, F. A., Zhao, M., and Running, S. W.: Development of a global evapotranspiration algorithm based on MODIS and global meteorology data, Remote Sensing of Environment, 111, 519-536, 2007.

Mu, Q. Z., Zhao, M. S., and Running, S. W.: Improvements to a MODIS global terrestrial evapotranspiration algorithm, Remote Sensing of Environment, 115, 1781-180o, 2011.

Mucher, C. A., Champeaux, J. L., Steinnocher, K. T., Griguolo, S., Wester, K., Heunks, C., Winiwater, W., Kressler, F. P., Goutorbe, J. P., ten Brink, B., van Katwijk, V. F., Furgerg, O., Perdigao, V., and Nieuwenhuis, G. J. A.: Development of a consistent methodology to derive land cover information on an European scale from remote sensing for environmental modeling., Center for Geo-Information (CGI), Alterra, Wageningen, the Netherlands, 16o, 2001.

Myneni, R. B., Hoffman, S., Knyazikhin, Y., Privette, J. L., Glassy, J., Tian, Y., Wang, Y., Song, X., Zhang, Y., Smith, G. R., Lotsch, A., Friedl, M., Morisette, J. T., Votava, P., Nemani, R. R., and Running, S. W.: Global products of vegetation leaf area and fraction absorbed PAR from year one of MODIS data, Remote Sensing of Environment, 83, 214 - 231, 2002.

National Database. National Bureau of Statistics of China. http://data.stats.gov.cn/index, accessed on 17/04/2014, 2014.

Nijssen, B., Schnur, R., and Lettenmaier, D. P.: Global retrospective estimation of soil moisture using the variable infiltration capacity land surface model, 1980-93, J. Clim., 14, 1790-1808, 2001.

Norman, J. M., Kustas, W. P., and Humes, K. S.: Source approach for estimating soil and vegetation energy fluxes in observations of directional radiometric surface temperature, Agric. For. Meteorol., 77, 263-293, 1995.

NWC-SAF: Algorithm Theoretical Basis Document for SAFNWC/PPS "Cloud Mask" (CMPGEo1 v3.o-patch1), The EUMETSAT Network of Satellite Application Facilities. Doc. Num. SAF/NWC/CDOP/SMHIPPS/SCI/ATBD/1, 2010.

Onimus, F.: Ethiopia - Irrigation and Drainage Project: Po92353 Implementation Status Results Report: Sequence 15, Washington, DC: World Bank, 2014. 
Owe, M., de Jeu, R., and Holmes, T.: Multisensor historical climatology of satellite-derived global land surface moisture. Journal of Geophysical Research-Earth Surface, 113, Fo10o2, doi:10.1029/2007jfooo769, 2008.

Ozdogan, M., and Gutman, G.: A new methodology to map irrigated areas using multi-temporal MODIS and ancillary data: An application example in the continental US, Remote Sensing of Environment, 112, 3520-3537, 2008.

Ozdogan, M., Rodell, M., Beaudoing, H. K., and Toll, D. L.: Simulating the effects of irrigation over the United States in a land surface model based on satellite-derived agricultural data, J. Hydrometeorol., 11, 171-184, 2010.

Pfister, S., Bayer, P., Koehler, A., and Hellweg, S.: Environmental impacts of water use in global crop production: hotspots and trade-offs with land use, Environ. Sci. Technol., 45, 5761-5768, 2011.

Portmann, F., Siebert, S., Bauer, C., and Döll, P.: Global data set of monthly growing areas of 26 irrigated crops, Institute of Physical Geography, University of Frankfurt (Main), Germany, 2008.

Portmann, F. T., Siebert, S., and Döll, P.: MIRCA2ooo-Global Monthly Irrigated and Rainfed Crop Areas around the year 2000: A new highresolution data set for agricultural and hydrological modeling, Glob. Biogeochem. Cycle, doi:10.1029/2008GBoo3435, 2010.

Postel, S. L., Daily, G. C., and Ehrlich, P. R.: Human appropriation of renewable fresh water, Science, 271, 785-788, 1996.

Price, K. P., Guo, X. L., and Stiles, J. M.: Optimal Landsat TM band combinations and vegetation indices for discrimination of six grassland types in eastern Kansas, International Journal of Remote Sensing, 23, 50315042, 2002.

Ramankutty, N., Evan, A. T., Monfreda, C., and Foley, J. A.: Farming the planet: 1. Geographic distribution of global agricultural lands in the year 2000, Glob. Biogeochem. Cycle, 22, GB1003, doi:1010.1029/2007GBoo2952, 2008.

Rao, N. R.: Development of a crop-specific spectral library and discrimination of various agricultural crop varieties using hyperspectral imagery, International Journal of Remote Sensing, 29, 131-144, 2008. 
Rezaee, M. R., Lelieveldt, B. P. F., and Reiber, J. H. C.: A new cluster validity index for the fuzzy c-mean, Pattern Recognition Letters, 19, 237-246, 1998.

Richards, J. A., and Jia, X.: Remote sensing digital image analysis: an introduction, Springer-Verlag, Berlin, Germany, 240 pp., 1999.

Rockstrom, J., Gordon, L., Falkenmark, M., Folke, C., and Engvall, M.: Linkages among water vapor flows, food production, and terrestrial ecosystem services, Conservation Ecology 3(2): 5, 1999.

Rodell, M., Houser, P. R., Jambor, U., Gottschalck, J., Mitchell, K., Meng, C. J., Arsenault, K., Cosgrove, B., Radakovich, J., Bosilovich, M., Entin, J. K., Walker, J. P., Lohmann, D., and Toll, D.: The Global Land Data Assimilation System, Bull. Amer. Meteorol. Soc., 85, 381-394, 2004.

Rodell, M., Velicogna, I., and Famiglietti, J. S.: Satellite-based estimates of groundwater depletion in India, Nature, 46o, 999-1002, 2009.

Roerink, G. J., Su, Z., and Menenti, M.: S-SEBI: A simple remote sensing algorithm to estimate the surface energy balance, Phys. Chem. Earth Pt BHydrol. Oceans Atmos., 25, 147-157, 2000.

Roerink, G. J., Menenti, M., Soepboer, W., and Su, Z.: Assessment of climate impact on vegetation dynamics by using remote sensing, Physics and Chemistry of the Earth, 28, 103-109, 2003.

Romaguera, M., Hoekstra, A. Y., Su, Z., Krol, M. S., and Salama, M. S.: Potential of using remote sensing techniques for global assessment of water footprint of crops, Remote Sensing, 2(4), 1177-1196, 2010.

Romaguera, M., Krol, M. S., Salama, M. S., Hoekstra, A. Y., and Su, Z.: Determining irrigated areas and quantifying blue water use in Europe using remote sensing Meteosat Second Generation (MSG) products and Global Land Data Assimilation System (GLDAS) data, Photogramm. Eng. Remote Sens., 78, 861-873, 2012 a.

Romaguera, M., Salama, M. S., Krol, M. S., Su, Z., and Hoekstra, A. Y.: Remote sensing method for estimating green and blue water footprint, in: Remote Sensing and Hydrology, edited by: Neale, C. M. U., and Cosh, M. H., IAHS Publication, Int Assoc Hydrological Sciences, Wallingford, UK, 288-291, 2012b. 
Romaguera, M., Salama, S., Krol, M. S., Hoekstra, A. Y., and Su, Z.: Synergy Between Remote Sensing ET Products and Simulated Data to Retrieve Irrigated Areas and Blue ET in Europe and Africa. Poster. In Abstracts of the 5th International Workshop on Catchment Hydrological Modeling and Data Assimilation CAHMDA-V: Catchments in a Changing Climate; Enschede, The Netherlands, 9-13 July, 2012c.

Romaguera, M., Salama, S., Krol, M. S., Hoekstra, A. Y., and Su, Z.: Towards the improvement of blue evapotranspiration estimates by combining remote sensing and model simulation, Remote Sensing, 6(8), 7026-7049, 2014a.

Romaguera, M., Krol, M. S., Salama, S., Su, Z., and Hoekstra, A. Y.: Application of a remote sensing method for estimating monthly blue water evapotranspiration in irrigated agriculture, Remote Sensing, 6(10), 10033-10050, 2014b.

Rost, S., Gerten, D., Bondeau, A., Lucht, W., Rohwer, J., and Schaphoff, S.: Agricultural green and blue water consumption and its influence on the global water system, Water Resour. Res., 44, Wo9405, doi:10.1029/2007WRoo6331, 2008.

Rudiger, C., Calvet, J. C., Gruhier, C., Holmes, T. R. H., de Jeu, R. A. M., and Wagner, W.: An Intercomparison of ERS-Scat and AMSR-E Soil Moisture Observations with Model Simulations over France, J. Hydrometeorol., 10, 431-447, 2009.

Santos, C., Lorite, I.J., Tasumi, M., Allen, R.G., and Fereres, E.: Performance assessment of an irrigation scheme using indicators determined with remote sensing techniques. Irrigation Science, 28, 461-477 2010.

Sapiano, M. R. P., and Arkin, P. A.: An intercomparison and validation of high-resolution satellite precipitation estimates with 3-hourly gauge data, J. Hydrometeorol., 10, 149-166, 2009.

Seckler, D., Amarasinghe, U., Molden, D. J., de Silva, R., and Barker, R.: World water demand and supply, 1990-2025: Scenarios and issues, IWMI, Colombo, Sri Lanka, 1998.

See, L., McCallum, I., Fritz, S., Perger, C., Kraxner, F., Obersteiner, M., Baruah, U. D., Mili, N., and Kalita, N. R.: Mapping Cropland in Ethiopia Using Crowdsourcing, International Journal of Geosciences, 4, 6-13, 2013. 
Serra, P., and Pons, X.: Monitoring farmers' decisions on Mediterranean irrigated crops using satellite image time series, International Journal of Remote Sensing, 29, 2293-2316, 2008.

Sheffield, J., Ferguson, C. R., Troy, T. J., Wood, E. F., and McCabe, M. F.: Closing the terrestrial water budget from satellite remote sensing, Geophys. Res. Lett., 36, Lo7403, doi:10.1029/2009GL037338, 2009.

Shiklomanov, I. A., and Rodda, J. C.: World water resources at the beginning of the twenty-first century, Cambridge University Press, Cambridge, UK., 2003.

Siebert, S., and Döll, P.: The Global Crop Water Model (GCWM): Documentation and first results for irrigated crops, Institute of Physical Geography, University of Frankfurt (Main), Germany, 2008.

Siebert, S., and Döll, P.: Quantifying blue and green virtual water contents in global crop production as well as potential production losses without irrigation, J. Hydrol., 384, 198-217, 2010.

Siebert, S., Döll, P., Hoogeveen, J., Faures, J. M., Frenken, K., and Feick, S.: Development and validation of the global map of irrigation areas, Hydrology and Earth System Sciences, 9, 535-547, 2005.

Siebert, S., Hoogeveen, J., and Frenken, K.: Irrigation in Africa, Europe and Latin America. Update of the digital global map of irrigation areas to version 4, Institute of Physical Geography, University of Frankfurt (Main), Germany, 2006.

Siebert, S., P. Döll, S. Feick, J. Hoogeveen, and K. Frenken: Global Map of Irrigation Areas, version 4.o.1. Johann Wolfgang Goethe University, Frankfurt am Main, Germany / Food and Agriculture Organization of the United Nations, Rome, Italy, 2007.

Smith, M.: CROPWAT: Manual and Guidelines, Rome, Italy, 1991.

Sobrino, J. A., and Raissouni, N.: Toward remote sensing methods for land cover dynamic monitoring: application to Morocco, International Journal of Remote Sensing, 21, 353-366, 2000.

Sobrino, J. A., and Romaguera, M.: Land surface temperature retrieval from MSG1-SEVIRI data, Remote Sensing of Environment, 92, 247-254, 2004. 
Sobrino, J. A., Gomez, M., Jimenez-Munoz, C., and Olioso, A.: Application of a simple algorithm to estimate daily evapotranspiration from NOAAAVHRR images for the Iberian Peninsula, Remote Sensing of Environment, 110, 139-148, 2007.

Sobrino, J. A., Jimenez-Munoz, J. C., Soria, G., Gomez, M., Ortiz, A. B., Romaguera, M., Zaragoza, M., Julien, Y., Cuenca, J., Atitar, M., Hidalgo, V., Franch, B., Mattar, C., Ruescas, A., Morales, L., Gillespie, A., Balick, L., Su, Z., Nerry, F., Peres, L., and Libonati, R.: Thermal remote sensing in the framework of the SEN2FLEX project: field measurements, airborne data and applications, International Journal of Remote Sensing, 29, 4961-4991, 2008a.

Sobrino, J. A., Jimenez-Munoz, J. C., Soria, G., Romaguera, M., Guanter, L., Moreno, J., Plaza, A., and Martinez, P.: Land surface emissivity retrieval from different VNIR and TIR sensors, IEEE Transactions on Geoscience and Remote Sensing, 46(2), 316-327, 2008b.

Su, Z.: The Surface Energy Balance System (SEBS) for estimation of turbulent heat fluxes, Hydrology and Earth System Sciences, 6, 85-99, 2002.

Su, Z., Timmermans, W., Gieske, A., Jia, L., Elbers, J. A., Olioso, A., Timmermans, J., Van Der Velde, R., Jin, X., Van Der Kwast, H., Nerry, F., Sabol, D., Sobrino, J. A., Moreno, J., and Bianchi, R.: Quantification of land-atmosphere exchanges of water, energy and carbon dioxide in space and time over the heterogeneous Barrax site, International Journal of Remote Sensing, 29, 5215-5235, 2008.

Su, Z., Fernández-Prieto, D., Timmermans, J., Chen, X., Hungershoefer, K., Roebeling, R., Schröder, M., Schulz, J., Stammes, P., Wang, P., and Wolters, E.: First results of the earth observation Water Cycle Multimission Observation Strategy (WACMOS), Int. J. Appl. Earth Obs. Geoinf., 26, 270-285, 2014.

Swenson, S., and Wahr, J.: Monitoring the water balance of Lake Victoria, East Africa, from space, J. Hydrol., 370, 163-176, 2009.

Teuling, A.J., Seneviratne, S.I., Williams, C., and Troch, P.A. (2006). Observed timescales of evapotranspiration response to soil moisture. Geophysical Research Letters, 33, 5 L23403, doi:10.1029/2006glo28178, 2006. 
Thenkabail, P. S., Gangadhara Rao, P., Biggs, T., Krishna, M., and Turral, H.: Spectral matching techniques to determine historical land use/land cover (LULC) and irrigated areas using time series AVHRR Pathfinder datasets in the Krishna River basin, India, Photogramm. Eng. Remote Sens., 73(9), 1029-1040, 2007.

Thenkabail, P. S., Biradar, C. M., Noojipady, P., Dheeravath, V., Li, Y. J., Velpuri, M., Reddy, G. P. O., Cai, X. L., Gumma, M., Turral, H., Vithanage, J., Schull, M., and Dutta, R.: A global irrigated area map (GIAM) using remote sensing at the end of the last millenium, International Water Management Institute ed., 63 pp., 2008.

Thenkabail, P. S., Biradar, C. M., Noojipady, P., Dheeravath, V., Li, Y. J., Velpuri, M., Gumma, M., Gangalakunta, O. R. P., Turral, H., Cai, X. L., Vithanage, J., Schull, M. A., and Dutta, R.: Global Irrigated Area Map (GIAM), derived from remote sensing, for the end of the last millennium, International Journal of Remote Sensing, 30, 3679-3733, 2009 a.

Thenkabail, P., Lyon, G. J., Turral, H., and Biradar, C. M.: Remote sensing of global croplands for food security. CRC Press- Taylor and Francis group, Boca Raton edited by: CRC Press- Taylor and Francis group, B. R., London, New York. 556 pp., 2009b.

Tian, Y., Peters-Lidard, C. D., Choudhury, B. J., and Garcia, M.: Multitemporal analysis of TRMM-based satellite precipitation products for land data assimilation applications, J. Hydrometeorol., 8, 1165-1183, 2007.

Tian, W., Li, X., Cheng, G.D., Wang, X.S., and Hu, B.X.: Coupling a groundwater model with a land surface model to improve water and energy cycle simulation. Hydrology and Earth System Sciences, 16, 47074723, 2012.

Tou, J. T., and Gonzalez, R. C.: Pattern recognition principles, AddisonWesley Publishing Company. Reading, Massachusetts, 1974.

UCLouvain, and ESA: GlobCover 2009. Products description and Validation Report. European Space Agency: Paris, France, 2011.

van der Kwast, J., Timmermans, W., Gieske, A., Su, Z., Olioso, A., Jia, L., Elbers, J., Karssenberg, D., and de Jong, S.: Evaluation of the Surface Energy Balance System (SEBS) applied to ASTER imagery with flux- 
measurements at the SPARC 2004 site (Barrax, Spain), Hydrology and Earth System Sciences, 13, 1337-1347, 2009.

Velpuri, N. M., Thenkabail, P. S., Gumma, M. K., Biradar, C., Dheeravath, V., Noojipady, P., and Yuanjie, L.: Influence of Resolution in Irrigated Area Mapping and Area Estimation, Photogramm. Eng. Remote Sens., 75(12), 1383-1395, 2009.

Virsta, A., Giurma, I., Oancea, S., Sofronie, R., and Craciun, I.: Efecte ale insulelor de caldura in climatologie, medicina si inginerie. ISBN: 978-6o68082-78-3. 186 pp., edited by: Noua, E., 2010.

Viste, E., Korecha, D., and Sorteberg, A.: Recent drought and precipitation tendencies in Ethiopia, Theor. Appl. Climatol., 112, 535-551, 2013.

Wagner, W., and Scipal, K.: Large-scale soil moisture mapping in western Africa using the ERS scatterometer, IEEE Transactions on Geoscience and Remote Sensing, 38, 1777-1782, 2000.

Wang, Y. Q., Shi, J. C., Liu, Z. H., Liu and W. J.: Application of Microwave Vegetation Index (MVI) to Monitoring Drought in Sichuan Province of China, 2012 First International Conference on Agro-Geoinformatics, IEEE, New York, 458-463 pp., 2012.

Yilmaz, M.T., Anderson, M.C., Zaitchik, B., Hain, C.R., Crow, W.T., Ozdogan, M., Chun, J.A., and Evans, J.: Comparison of prognostic and diagnostic surface flux modeling approaches over the Nile river basin. Water Resour. Res., 50, 386-408, 2014.

Zaitchik, B. F., Rodell, M., and Olivera, F.: Evaluation of the Global Land Data Assimilation System using global river discharge data and a source to sink routing scheme, Water Resources Research, doi:10.1029/2009WRoo7811, 2010.

Zhang, M. W., Zhou, Q. B., Chen, Z. X., Liu, J., Zhou, Y., and Cai, C. F.: Crop discrimination in Northern China with double cropping systems using Fourier analysis of time-series MODIS data, Int. J. Appl. Earth Obs. Geoinf., 10, 476-485, 2008.

Zhang, S. H., Yi, Y. J., Liu, Y., and Wang, X. K.: Hydraulic Principles of the 2,268-Year-Old Dujiangyan Project in China, J. Hydraul. Eng.-ASCE, 139, 538-546, 2013 


\section{Summary}

The assessment of water use is crucial in a changing environment in which water is an essential but scarce resource. From a water management perspective, an accurate evaluation of the irrigation water used in agriculture is of high importance. In this context, the concept of actual evapotranspiration (ET) accounts for the plant transpiration (crop water use) and evaporation. This ET has generally been separated into a 'green' $\left(\mathrm{ET}_{\mathrm{g}}\right)$ and 'blue' $\left(\mathrm{ET}_{\mathrm{b}}\right)$ component, referring to the origin of the used water: precipitation or irrigation water, respectively.

Remote sensing techniques and Earth observation data are used nowadays in multiple applications in the fields of hydrology, agriculture or meteorology amongst others, with different spatial coverages and diverse spatial and temporal resolutions. This thesis has the objective of exploring the use of remote sensing techniques and data to retrieve and monitor global water use in agriculture, focusing on the blue component of the evapotranspiration.

Chapter 2 analyses the concept of Water Footprint (WF) and the key parameters needed for its estimation. This chapter discusses the potential of using remote sensing based data in this field, by reviewing the existing methods and data and identifying the limitations and opportunities for improvement. Specific attention is paid to the estimation of irrigation. A mass balance approach is proposed and detailed information about the involved hydrological parameters obtained via remote sensing techniques is provided. In this context, crop evapotranspiration due to precipitation and irrigation respectively, are separated using a simple approach. The content of this chapter serves as a motivation of the whole thesis, since it describes the state of the art for WF estimation, identifies new research lines and provides preliminary tools and data sources.

Chapter 3 tackles the separation of ET in its green and blue components by using an approach based on anomalies of soil moisture (SM). This new approach combines the remote sensing Advanced Microwave Scanning Radiometer-EOS (AMSR-E) soil moisture products with other hydrological parameters that are simulated by a land surface model. Daily irrigation events 
are identified when positive SM anomalies are found and precipitation values are below a certain threshold. Monthly $\mathrm{ET}_{\mathrm{b}}$ is obtained by using the calculated daily irrigation values and the ET depletion time. This chapter presents a first approach for $\mathrm{ET}_{\mathrm{b}}$ estimation using remote sensing data.

The core of this thesis starts in Chapter 4 where an innovative method for determining irrigated areas and $\mathrm{ET}_{\mathrm{b}}$ retrieval is proposed, developed and tested. $\mathrm{ET}_{\mathrm{b}}$ is obtained by calculating - at a resolution of around $5 \mathrm{~km}-$ the difference between the actual ET estimates from remote sensing and the simulated actual ET from a land surface model. This difference is interpreted as the so-called irrigation term and is corrected with a reference bias, reflecting structural differences in the estimation methods and primary data used. The remote sensing based ET values are the ones provided by the Land Surface Analysis Satellite Applications Facility (LSA-SAF) which are estimated from the Meteosat Second Generation satellite. The simulated data are obtained from the Global Land Data Assimilation System (GLDAS), estimated with the Noah model. A classification map of the study area (Europe) is generated using as a proxy the Normalized Difference Vegetation Index (NDVI) and the viewing angle of the remote sensing sensor, and a bias is obtained per class.

Chapter 5 investigates the improvement of the method proposed in Chapter 4. This is done by enhancing the classification scheme in two aspects. First, a new set of parameters is selected for the classification, which better accounts for the different hydrometeorological conditions. These are evapotranspiration, NDVI and a climate index based on precipitation and net radiation. Second, the performance of three classifiers is explored and evaluated in terms of the classification output and the bias curves generated. This results in a more robust approach avoiding relatively arbitrary thresholds used in the original classification method. The improved methodology for $\mathrm{ET}_{\mathrm{b}}$ is applied over the European and African continents and results are discussed in comparison with existing literature.

Chapter 6 includes the application of the new method to time series of data. It shows the possibility to exploit the method and data for monitoring irrigation practices in time. Monthly $\mathrm{ET}_{\mathrm{b}}$ values are obtained in two case studies: the Horn of Africa (period 2010-2012) and Sichuan province of China (period 2001-2010). Moreover, $\mathrm{ET}_{\mathrm{b}}$ is divided into the sources of irrigation 
water by using the Global Irrigated Area Map (GIAM), i.e. surface water, groundwater and conjunctive use. The analysis of the temporal evolution of the total $\mathrm{ET}_{\mathrm{b}}$ and the relative contribution of its components showed the potential of the method and the data for monitoring irrigation practices, especially useful in periods of drought. 


\section{Samenvatting}

De bepaling van water gebruik is cruciaal in een veranderend milieu waarin water een essentieel maar schaars goed is. Vanuit water management oogpunt bezien is een nauwkeurige bepaling van het water gebruik voor irrigatie van groot belang. Binnen deze context omvat het begrip actuele evapotranspiratie (ET) zowel de transpiratie door de plant (gewasverdamping) als de evaporatie. Deze ET wordt normaalgesproken onderverdeeld in een 'groene' $\left(\mathrm{ET}_{\mathrm{g}}\right)$ en een 'blauwe' $\left(\mathrm{ET}_{\mathrm{b}}\right)$ component, daarbij verwijzend naar de herkomst van het gebruikte water: respectievelijk neerslag of irrigatie water.

Teledetectie technieken en aard observatie gegevens worden vandaag de dag gebruikt in verschillende applicaties in onder andere de domeinen hydrologie, landbouw of meteorologie, met verschillende ruimtelijke dekking en verschillende ruimtelijke en temporele resoluties. Deze dissertatie heeft als doel het verkennen van teledetectie-technieken en -gegevens ten behoeve van het afleiden en monitoren van wereldwijd water verbruik in de landbouw, met een focus op de blauwe evapotranspiratie component.

Hoofdstuk 2 beschrijft het Water Footprint (WF) concept alsmede de belangrijkste parameters die nodig zijn voor de bepaling hiervan. Dit hoofdstuk bediscussieert het potentieel van het gebruik van teledetectie gegevens in dit concept, door het geven van een overzicht van bestaande methodieken en gegevens en het aangeven van de beperkingen hiervan alsook de mogelijkheden voor verbetering. Bijzondere aandacht wordt hierbij geschonken aan de schatting van irrigatiewater. Hiertoe wordt een massabalans benadering voorgesteld en gedetailleerde informatie wordt gegeven over de betrokken hydrologische parameters die verkregen zijn door middel van teledetectie technieken. Binnen deze context wordt actuele ET, als gevolg van respectievelijk neerslag en als gevolg van irrigatie, gescheiden met behulp van een eenvoudige benadering. De inhoud van dit hoofdstuk dient als een uitgangspunt voor deze dissertatie, aangezien het de huidige stand van zaken weergeeft voor wat betreft de bepaling van de WF, het 
nieuwe onderzoekslijnen identificeert en voorlopige instrumenten en gegevensbronnen aanlevert.

Hoofdstuk 3 behelst de scheiding van actuele evapotranspiratie in de groene en blauwe component door het gebruik van een benadering gebaseerd op anomalieën in bodemvocht. Deze nieuwe benadering combineert de met behulp van teledetectie verkregen Advanced Microwave Scanning Radiometer-EOS (AMSR-E) bodemvocht producten met andere hydrologische parameters die gesimuleerd zijn door een landoppervlakte model. Dagelijkse irrigatie wordt geïdentificeerd indien er positieve bodemvocht anomalieën gevonden worden en neerslagwaarden zich beneden een zekere grenswaarde bevinden. Maandelijkse $\mathrm{ET}_{\mathrm{b}}$ wordt verkregen door gebruik te maken van de berekende dagelijkse irrigatie hoeveelheden en de verdampingsafnametijd. Dit hoofdstuk beschrijft een eerste benadering voor de bepaling van de blauwe actuele verdamping met gebruikmaking van teledetectie gegevens.

De kern van deze dissertatie begint in hoofdstuk 4 waar een innovatieve methode voor de bepaling van geïrrigeerde gebieden en de blauwe verdampingscomponent wordt voorgesteld, ontwikkeld en getest. Deze blauwe verdampingscomponent wordt verkregen door - op een resolutie van zo'n $5 \mathrm{~km}$ - het verschil tussen de actuele verdampingsschatting uit teledetectie en uit de simulaties van het landoppervlakte model te berekenen. Dit verschil wordt geïnterpreteerd als de zogenoemde irrigatie term en wordt gecorrigeerd met een referentie bias, welke structurele verschillen in de schattingsmethoden en de daarin gebruikte gegevens weergeeft. De op teledetectie gebaseerde verdampingswaarden zijn diegene die verstrekt worden door de Land Surface Analysis Satellite Applications Facility (LSA$\mathrm{SAF}$ ) en welke geschat worden met behulp van de Meteosat Second Generation satelliet. De gesimuleerde gegevens worden verkregen uit het Global Land Data Assimilation System (GLDAS), geschat met behulp van het Noah model. Een geclassificeerde kaart van het studiegebied (Europa) is gegenereerd waarbij de Normalized Difference Vegetation Index (NDVI) en de kijkhoek van de teledetectie sensor gebruikt zijn als een proxy, en een bias per klasse wordt verkregen.

Hoofdstuk 5 beschrijft onderzoek naar de verbetering van de benadering die is voorgesteld in hoofdstuk 4 . Dit is gedaan door het classificatie systeem in 
twee opzichten te verbeteren. Ten eerste is er een nieuwe set van parameters geselecteerd voor de classificatie welke de verschillende hydrologische condities beter in acht neemt. Deze set omvat evapotranspiratie, NDVI en een klimaat index gebaseerd op neerslag en netto straling. Ten tweede is de werking van drie classificatietechnieken onderzocht en geëvalueerd in termen van de classificatie resultaten en de gegenereerde bias-curves. Deze benadering resulteert in een meer robuuste benadering welke het gebruik van relatief arbitraire grenswaarden, zoals in de originele classificatie methode, vermijdt. De verbeterde methode voor de bepaling van ETb is vervolgens toegepast voor het Europese en Afrikaanse continent en de resultaten worden besproken in vergelijking met bestaande literatuur.

Hoofdstuk 6 omvat de toepassing van de nieuwe methode op een tijdreeks. Dit demonstreert de mogelijkheid de methode te gebruiken voor het monitoren van irrigatie beoefening. Maandelijkse waarden voor ETb zijn bepaald voor twee voorbeeld studies: de Hoorn van Afrika (periode 2010 2012) en de Sichuan provincie in China (periode 2001 - 2010). Aanvullend hierop is de blauwe component onderverdeeld naar herkomst van het irrigatiewater door gebruikmaking van de Global Irrigated Area Map (GIAM), te weten, oppervlaktewater, grondwater en conjunctief gebruik. De analyse van de temporele ontwikkeling van de totale ETb en de relatieve bijdrage van haar componenten illustreert het potentieel van deze methode en gegevens voor het monitoren van irrigatie beoefening, wat vooral van belang is in tijden van droogte. 


\section{About the Author}

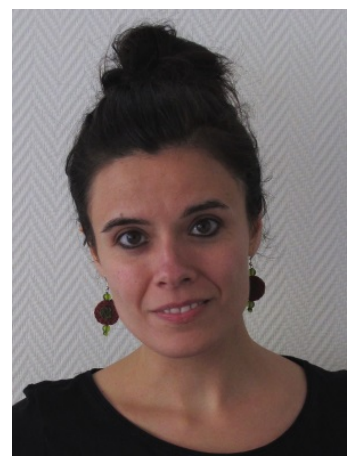

Mireia Romaguera Albentosa was born in Valencia, on 26th April 1979. She got her MSc in Physics at the University of Valencia (Spain) and a BSc at the University of Leeds (United Kingdom). She obtained a $\mathrm{PhD}$ degree in 2006 while working at the Global Change Unit of the University of Valencia. The research consisted in the development of methods for retrieving land and sea surface temperature from remote sensed data, in particular from Meteosat Second Generation. By that time she also obtained a degree as a sound technician and was awarded with the regional prize in 'Sounds and Image' studies. In 2007 she started working for Iberalp (Madrid, Spain), an official distributor of professional audio equipment. Meanwhile she continued collaborating scientifically with the Global Change Unit, where she returned in 2008 as a full time researcher. In 2009, she continued her professional career at the University of Twente with a second $\mathrm{PhD}$ on the topic 'remote sensing and water resources'. This was a shared project between the CTW and ITC faculties, which she completed with the present dissertation. Since June 2014 she has a Postdoc position at ITC on the topic 'remote sensing and geothermal exploration'.

She is also involved in different artistic projects that vary from interpretation to promotion activities and at the moment she is starting with an audiovisual project named “Op Roll”. 


\section{Publications}

Romaguera, M., Hoekstra, A. Y., Su, Z., Krol, M. S., and Salama, M. S.: Potential of using remote sensing techniques for global assessment of water footprint of crops, Remote Sensing, 2(4), 1177-1196, 2010.

Romaguera, M., Krol, M. S., Salama, M. S., Hoekstra, A. Y., and Su, Z.: Determining irrigated areas and quantifying blue water use in Europe using remote sensing Meteosat Second Generation (MSG) products and Global Land Data Assimilation System (GLDAS) data, Photogramm. Eng. Remote Sens., 78, 861-873, 2012 a.

Romaguera, M., Salama, M. S., Krol, M. S., Su, Z., and Hoekstra, A. Y.: Remote sensing method for estimating green and blue water footprint, in: Remote Sensing and Hydrology, edited by: Neale, C. M. U., and Cosh, M. H., IAHS Publication, Int. Assoc. Hydrological Sciences, Wallingford, 288291, 2012b.

Romaguera, M., Salama, S., Krol, M. S., Hoekstra, A. Y., and Su, Z.: Towards the improvement of blue evapotranspiration estimates by combining remote sensing and model simulation, Remote Sensing, 6, 7026-7049, $2014 a$.

Romaguera, M., Krol, M. S., Salama, S., Su, Z., and Hoekstra, A. Y.: Application of a remote sensing method for estimating monthly blue water evapotranspiration in irrigated agriculture, Remote Sensing, 6, 10033-10050, 2014b.

\section{Additional publications}

Sobrino, J.A., and Romaguera, M.: Land surface temperature retrieval from MSG1-SEVIRI data. Remote Sensing of Environment, 92, 247-254, 2004.

Romaguera, M., Sobrino, J.A., Soria, G., Zaragoza, M.M., Cuenca, J., Gomez, M., Jimenez-Munoz, J.C., and Galdon-Ruiz, A.: Land surface temperature derived from the MSG-SEVIRI data. In H. Lacoste (Ed.), Proceedings of the Second MSG RAO Workshop (pp. 107-111), 2004. 
Romaguera, M., Sobrino, J.A., and Olesen, F.S.: Estimation of sea surface temperature from SEVIRI data: algorithm testing and comparison with AVHRR products. International Journal of Remote Sensing, 27, 5081-5086, 2006.

Sobrino, J.A., and Romaguera, M.: Water-vapour retrieval from Meteosat 8/SEVIRI observations. International Journal of Remote Sensing, 29, 741754, 2008.

Sobrino, J.A., Jimenez-Munoz, J.C., Soria, G., Romaguera, M., Guanter, L., Moreno, J., Plaza, A., and Martinez, P.: Land surface emissivity retrieval from different VNIR and TIR sensors. IEEE Transactions on Geoscience and Remote Sensing, 46(2), 316-327, 2008.

Sobrino, J.A., Jimenez-Munoz, J.C., Soria, G., Gomez, M., Ortiz, A.B., Romaguera, M., Zaragoza, M., Julien, Y., Cuenca, J., Atitar, M., Hidalgo, V., Franch, B., Mattar, C., Ruescas, A., Morales, L., Gillespie, A., Balick, L., Su, Z., Nerry, F., Peres, L., and Libonati, R.: Thermal remote sensing in the framework of the SEN2FLEX project: field measurements, airborne data and applications. International Journal of Remote Sensing, 29, 4961-4991, 2008 .

Sobrino, J.A., Jimenez-Munoz, J.C., Zarco-Tejada, P.J., Sepulcre-Canto, G., de Miguel, E., Soria, G., Romaguera, M., Julien, Y., Cuenca, J., Hidalgo, V., Franch, B., Mattar, C., Morales, L., Gillespie, A., Sabol, D., Balick, L., Su, Z., Jia, L., Gieske, A., Timmermans, W., Olioso, A., Nerry, F., Guanter, L., Moreno, J., and Shen, Q.: Thermal remote sensing from Airborne Hyperspectral Scanner data in the framework of the SPARC and SEN2FLEX projects: an overview. Hydrology and Earth System Sciences, 13, 2031-2037, 2009.

Sobrino, J.A., Oltra-Carrio, R., Soria, G., Jimenez-Munoz, J.C., Franch, B., Hidalgo, V., Mattar, C., Julien, Y., Cuenca, J., Romaguera, M., Gomez, J.A., De Miguel, E., Bianchi, R., and Paganini, M.: Evaluation of the surface urban heat island effect in the city of Madrid by thermal remote sensing. International Journal of Remote Sensing, 34, 3177-3192, 2013. 


\section{ITC Dissertation List}

http://www.itc.nl/research/phd/phd graduates.aspx 